UNIVERSIDADE DE SÃO PAULO

CENTRO DE ENERGIA NUCLEAR NA AGRICULTURA

MARCOS AUGUSTO DA SILVA SCARANELLO

Dinâmica da comunidade arbórea de Floresta Ombrófila Densa de Terras Baixas e de Restinga no Parque Estadual da Serra do Mar, SP

PIRACICABA 


\title{
Dinâmica da comunidade arbórea de Floresta Ombrófila Densa de Terras Baixas e de Restinga no Parque Estadual da Serra do Mar, SP
}

\author{
Dissertação apresentada ao Centro de \\ Energia Nuclear na Agricultura da \\ Universidade de São Paulo para obtenção \\ do título de Mestre em Ciências \\ Área de Concentração: Química na \\ Agricultura e no Ambiente \\ Orientador: Prof. Dr. Plínio Barbosa de \\ Camargo
}

PIRACICABA 
AUTORIZO A DIVULGAÇÃO TOTAL OU PARCIAL DESTE TRABALHO, POR QUALQUER MEIO CONVENCIONAL OU ELETRÔNICO, PARA FINS DE ESTUDO E PESQUISA, DESDE QUE CITADA A FONTE.

Dados Internacionais de Catalogação na Publicação (CIP)

Seção Técnica de Biblioteca - CENA/USP

Scaranello, Marcos Augusto da Silva

Dinâmica da comunidade arbórea de floresta ombrófila densa de terras baixas e de restinga no Parque Estadual da Serra do Mar, SP / Marcos Augusto da Silva Scaranello; orientador Plínio Barbosa de Camargo. - Piracicaba, 2010.

$113 \mathrm{f}$. : il.

Dissertação (Mestrado - Programa de Pós-Graduação em Ciências. Área de Concentração: Química na Agricultura e no Ambiente) - Centro de Energia Nuclear na Agricultura da Universidade de São Paulo.

1. Biomassa 2. Ecologia de comunidades 3. Ecossistemas florestais 4. Florestas tropicais - Mata Atlântica I. Título

CDU $630 * 5: 551.583$ 


\section{DEDICO}

“À minha mãe Aparecida de Fátima da Silva Scaranello, e ao meu pai Milton Diogenes Scaranello, com muito carinho e amor, pelos incentivos incessantes ao longo de toda a minha carreira acadêmica, desde o primeiro momento em que pisei em uma universidade. Ainda, aos meus irmãos Marcelo e Milton pela união e amizade em todos esses anos." 


\section{Agradecimentos}

Ao meu orientador Dr. Plínio Barbosa de Camargo pela orientação, amizade de todos esses anos, confiança, apoio, e principalmente por ter me introduzido a ciência. Agradeço muito todas as possibilidades proporcionadas.

À Dra. Luciana Ferreira Alves e Dra. Simone Aparecida Vieira pelas orientações, apoio, conselhos, amizade e acolhimento desde a minha iniciação científica. Sou eternamente grato por tudo isso e também pelo incentivo em todas as minhas decisões. Além dos valiosos ensinamentos e apoio, as campanhas de campo eram muito mais agradáveis com vocês!

Ao Dr. Luiz Antonio Martinelli pela orientação, apoio, amizade e oportunidades concedidas desde o inicio da minha carreira científica no Laboratório de Ecologia Isotópica (CENA/USP).

Ao Dr. Jean Pierre H. B. Ometto e Dra. Daniela M. L. da Silva pelas oportunidades concedidas, orientações e amizade em todos esses anos de convívio no laboratório.

À Dra. Janaina B. do Carmo pela orientação no inicio da minha carreira acadêmica, amizade e confiança.

Esse time de fabulosos cientistas contribuiu diretamente na minha formação científica, alguns em maior ou menor intensidade. Tive o privilégio e a sorte de tê-los como "mestres" durante todo esse período e sou eternamente grato por isso.

Ao Dr. Jadson Dezincourt Dias pela confiança depositada durante parte da minha iniciação científica, amizade e convívio em todos esses anos, além de me mostrar muitas vezes o verdadeiro sentido da vida e da ciência natural.

À todos os integrantes do Laboratório de Ecologia Isotópica do CENA/USP pelo convívio de todos esses longos anos de trabalho e diversão. São eles: Fabiana Fracassi, Geraldo (Gera), Maria Antônia (Tonica), Marcelo Moreira, Eráclito Neto, Maíra Bezerra, Carlos Beduschi (Carlão), Vania Neu, José Mauro, Adelaine Michela, Luciana Coletta, Tatiana Morgan, Fenando Godoy, Alexandre Pereira, Uwe Herpin, Susian Martins, Thiago Pexe, Edmar Mazzi, Nei Leite, Giovana, Elizabethe Ravagnani, Eduardo Duzão, Sandra Navarro, Sandra Furlan, Simoni Grilo e Fernanda.

À República Siriguela e seus integrantes: Paulo Cesar (Sambaqui), Marcelo Germani (Ancião), Carolina Mathias (Lombra), e muitos outros que habitaram essa maravilhosa casa. O convívio com vocês em todos esses anos de ESALQ me tornou uma pessoa muito mais feliz!

À República Brejão e todos os seus integrantes: Lava-pé (Gordo), Anta (Totonho), Zebu (Bubu), Quiá, Parteiro (Bizu) e muitos outros que habitaram essa consagrada mansão. 
À República Área 51 por ter me acolhido durante o período de mestrado, em especial a Bruno Simionato (Fidéu) pela colaboração nas campanhas de campo e amizade.

À toda a turma de Engenheiros Florestais do ano de 2007 por todos os anos de convívio e diversão. Não tenho dúvida que o mundo agradecerá muito por recebêlos.

À toda a equipe do Núcleo Picinguaba do Parque Estadual da Serra do Mar, em especial a Eliana Simões (Gestora).

À todas as pessoas que colaboraram com as campanhas de inventário: Luciana Ferreira Alves, Simone Aparecida Vieira, Luis Antonio Martinelli, Manuel (Casa da Farinha), Larissa Veiga (Larissinha), Bruno Simionato, Oldac (CENA), Maira (UNICAMP), Bruno (Cocada) e muitos outros.

Ao Fundo de Amparo à Pesquisa do Estado de São Paulo (processo no. 07/06821-5) pela bolsa de mestrado concedida.

Ao projeto Gradiente Funcional - BIOTA (FAPESP) pela maravilhosa oportunidade de interação, em especial aos coordenadores Carlos A. Joly e Luis Antonio Martinelli.

À Bibliotecária Chefe Marilia R. G. Henyei por todo o auxilio na fase final da dissertação. Agradeço muito a paciência e a boa vontade, sempre disponível!

À Gestora Ambiental Paula Bernasconi pelo companheirismo durante o período de graduação, e por todo o amor que se iniciou no final da graduação e se estendeu por todo o período de pós-graduação trazendo muita inspiração e serenidade. Agradeço cada segundo da sua companhia na redação de cada palavra desse texto e todos os estímulos indispensáveis em todas as etapas. Obrigado por ser essa pessoa maravilhosa e me proporcionar tamanha felicidade. 
"I went to the woods because I wished to live deliberately, to front only the essential facts of life, and see if I could not learn what it had to teach, and not, when I came to die, discover that I had not lived..." Henry David Thoreau (American Essayist, Poet and Philosopher, 1817-1862) 


\section{RESUMO}

\section{SCARANELLO, M. A. S. Dinâmica da comunidade arbórea de Floresta Ombrófila}

Densa de Terras Baixas e de Restinga no Parque Estadual da Serra do Mar, SP. 2010. 113 f. Dissertação (Mestrado) - Centro de Energia Nuclear na Agricultura, Universidade de São Paulo, Piracicaba, 2010.

As florestas tropicais exibem elevada biodiversidade e desempenham um importante papel no ciclo global do carbono. Porém, essas florestas têm sido impactadas aceleradamente nos últimos anos. No Brasil, a floresta tropical Atlântica está restrita a aproximadamente $7 \%$ de sua extensão original e seus remanescentes ainda sofrem ameaças. Com isso, informações sobre a dinâmica da vegetação desse bioma são importantes para entender 0 funcionamento desse ecossistema e servem de subsídio para auxiliar em sua conservação e restauração. No presente estudo, os principais processos que regem a dinâmica de uma floresta (mortalidade, recrutamento e crescimento) foram estimados em duas fisionomias distintas da floresta tropical Atlântica. Além disso, a variação líquida da biomassa acima do solo (BAS) também foi estimada. Para o presente estudo foram utilizadas cinco (5) parcelas permanentes de um (1) hectare inseridas no projeto temático "Gradiente Funcional", sendo: quatro (4) na floresta de Terras Baixas e uma (1) na floresta de Restinga. Os inventários foram realizados no momento da implantação das parcelas permanentes (2006) e após dois (2) anos. Os resultados obtidos demonstraram que a Restinga (1635 ind.ha ${ }^{-1}$ ) possui maior densidade total de indivíduos vivos com o DAP $\geq 4,8 \mathrm{~cm}$ que a Terras Baixas (1221 ind.ha ${ }^{-1}$ ). $O$ estoque de biomassa acima do solo (BAS) foi maior na Terras Baixas (212,3 Mg.ha ${ }^{-1}$ ) que na Restinga (166,3 Mg.ha-1) (DAP $\geq 4,8 \mathrm{~cm}$ ). A distribuição dos indivíduos nas classes de diâmetro influenciou essas diferenças estruturais: a Restinga possui maior densidade total de indivíduos na menor classe de diâmetro e a floresta de Terras Baixas possui maior densidade de indivíduos na maior classe. Tal fato também impactou a distribuição do estoque de BAS nas classes de diâmetro: a floresta de Restinga estoca mais biomassa na classe de 10-30 cm e a floresta de Terras Baixas na maior classe de DAP, $\geq 50 \mathrm{~cm}$. A mediana da taxa de incremento diamétrico da comunidade arbórea não diferiu entre os dois tipos de floresta, sendo igual a $1,0 \mathrm{~mm}$.ano ${ }^{-1}$ na Restinga e $0,8 \mathrm{~mm}$.ano- ${ }^{-1}$ na Terras Baixas (DAP $\geq 4,8 \mathrm{~cm}$ ). Diferenças na taxa de incremento diamétrico com relação às formas de vida (árvores e palmeiras) foram observadas. A taxa de incremento diamétrico das árvores apresentou relação positiva com o aumento das classes de DAP e o índice de iluminação de copa. O mesmo padrão não foi observado para as palmeiras. A taxa de mortalidade da comunidade arbórea foi semelhante entre os dois tipos de floresta, sendo igual a $2,46 \%$ na Restinga e $2,00 \%$ na Terras Baixas (DAP $\geq 4,8 \mathrm{~cm}$ ). A taxa de recrutamento também foi semelhante entre as florestas, sendo igual a 1,42 \% na Restinga e 1,36 \% na floresta de Terras Baixas. A variação líquida da BAS foi maior nas Terras baixas $\left(0,64 \mathrm{Mg} \mathrm{ha}^{-1}\right.$. $\left.\mathrm{ano}^{-1}\right)$ que na Restinga $\left(0,32 \mathrm{Mg} \cdot \mathrm{ha}^{-1}\right.$.ano-1 $)$. Por fim, a floresta tropical Atlântica apresenta maior densidade de indivíduos vivos, menor estoque de BAS, menor taxa de incremento e reposição quando comparada com outras florestas tropicais, possivelmente devido à distribuição da precipitação ao longo do ano.

Palavras-chave: Dinâmica florestal, floresta tropical Atlântica, variação líquida da biomassa viva acima do solo. 


\begin{abstract}
SCARANELLO, M. A. S. Forest dynamics in lowland and coastal seasonally flooded Atlantic forest at Serra do Mar State Park, Brazil. 2010. $113 \mathrm{f}$. Dissertação (Mestrado) - Centro de Energia Nuclear na Agricultura, Universidade de São Paulo, Piracicaba, 2010.
\end{abstract}

Tropical forests display a biodiversity unmatched by any other vegetation type and play an important role in the global terrestrial carbon cycle. However, tropical forests have been severely impacted in the last years. In Brazil, the tropical Atlantic forest is restricted to approximately $7 \%$ of its original extension and its fragments still remain threatened. Hence, information regarding the vegetation dynamic of this important biome is important to understand the functioning of this ecosystem and support conservation and restoration actions. Here, the principal processes that drive forest dynamics (mortality, recruitment and growth) were estimated for two tropical Atlantic forest types. Additionally, the net aboveground biomass change (AGB) also was estimated. In this study, five one-hectare permanent plots established by the "Gradiente Funcional" project were adopted: four (4) plots in lowland and one (1) in seasonally flooded Atlantic forest. The forestry inventories were performed in the same time of permanent plot establishment (2006) and after two (2) years (2008). The results showed that the seasonally flooded Atlantic forest has greater total stem density $(\mathrm{DBH} \geq 4.8 \mathrm{~cm})$ than lowland Atlantic forest, equal to 1635 ind.ha $^{-1}$ in seasonally flooded and 1221 ind. ha $^{-1}$ in lowland forest. The aboveground biomass (AGB) was greater in lowland than in seasonally flooded forest, equal to $166.3 \mathrm{Mg}^{-h^{-1}}$ in seasonally flooded and $212.3 \mathrm{Mg} \cdot \mathrm{ha}^{-1}$ in lowland forest $(4,8 \mathrm{~cm} \mathrm{DBH})$. The distribution of trees among DBH classes influenced these structural differences: the seasonally flooded forest has high stem density at smaller DBH size class while the lowland forest has high stem density at larger $\mathrm{DBH}$ size class. In addition, that variation in size structure also impacted the AGB distribution among DBH classes: the seasonally flooded Atlantic forest has more AGB in the $10-30 \mathrm{~cm}$ DBH class and the lowland Atlantic forest has more AGB in the large size class $(\geq$ $50 \mathrm{~cm}$ ). The median growth rate of tree community did not differ between the two forest types, equal to $1.0 \mathrm{~mm} . \mathrm{yr}^{-1}$ in seasonally flooded and $0.8 \mathrm{~mm} . \mathrm{yr}^{-1}$ in lowland forest $(\geq 4.8 \mathrm{~cm}$ $\mathrm{DBH})$. Differences in growth rates regarding the life forms (tree and palm) were observed. Tree growth rates showed positive relationship with crown illumination index and DBH classes. The same tendency was not observed for palm life form. The mortality rate of tree community did not differ between the two forest types, equal to $2.46 \%$ in seasonally flooded and $2.00 \%$ in lowland forest $(\geq 4.8 \mathrm{~cm} \mathrm{DBH})$. The recruitment rate also did not differ between the two forest types, equal to $1.42 \%$ in seasonally flooded and $1.36 \%$ in lowland forest $(4.8 \mathrm{~cm} \mathrm{DBH})$. The lowland Atlantic forest AGB net change $\left(0.64 \mathrm{Mg}^{-\mathrm{ha}^{-1}}\right.$. $\left.\mathrm{yr}^{-1}\right)$ was higher than seasonally flooded Atlantic forest $\left(0.64 \mathrm{Mg} \cdot \mathrm{ha}^{-1} \cdot \mathrm{yr}^{-1}\right)$. Finally, the tropical Atlantic forest has higher stem density, lower AGB, lower growth and turnover rates than other tropical forests probably due to rainfall distribution among year.

Keywords: Forest dynamic, tropical Atlantic forest, aboveground biomass net change 


\section{LISTA DE FIGURAS}

Figura 1 - Localização das parcelas permanentes na floresta tropical Atlântica, Ubatuba, $\mathrm{SP}$

Figura 2 - Precipitação e temperatura de 1993 a 2008 no município de Ubatuba, SP

Figura 3 - Distribuição média dos indivíduos (árvores e palmeiras) por classe de DAP no primeiro inventário de estudo, na floresta de restinga e de terras baixas. As barras indicam o desvio padrão da média

Figura 4 - Distribuição da média do estoque de BAS por classe de DAP no primeiro inventário e em ambas as áreas de estudo. As barras indicam o desvio padrão da média. Chave et al. (2005): 2-var.

Figura 5 - Distribuição da média do estoque de BAS por classe de DAP no primeiro inventário e em ambas as áreas de estudo. As barras indicam o desvio padrão da média. Chave et al. (2005): 3-var

Figura 6 - "Boxplot" da distribuição do DAP $(\mathrm{cm})$ de cada classe de IC na parcela A (a) e C (b). T3, T4 e T5: árvores da classe IC3, IC4 e IC5. P3, P4 e P5: palmeiras da classe IC3, IC4 e IC5. Em cada caixa, a linha central horizontal indica a mediana e as extremidades os quartis

Figura 7 - Taxa de incremento diamétrico média $\left(\mathrm{mm} \mathrm{ano}^{-1}\right)$ das árvores na floresta de restinga (linha contínua) e de terras baixas (linha pontilhada). As barras indicam erro padrão médio .

Figura 8 - Taxa de incremento diamétrico média $\left(\mathrm{mm} \mathrm{ano}^{-1}\right)$ das palmeiras na floresta de restinga (linha contínua) e de terras baixas (linha pontilhada). As barras indicam erro padrão médio

Figura 9 - Taxa de incremento diamétrico média ( $\mathrm{mm}$ ano-1) por classe de IC das árvores na floresta de Restinga (linha contínua) e na Terras baixas (linha pontilhada). As barras indicam o erro padrão médio

Figura 10 - Taxa de incremento diamétrico média $\left(\mathrm{mm} \mathrm{ano}^{-1}\right)$ por classe de IC das palmeiras na floresta de Restinga (linha contínua) e na Terras baixas (linha pontilhada). As barras indicam o erro padrão médio

Figura 11 - Taxa de mortalidade ( $\lambda$ ), limite inferior (LI) e superior (LS) na floresta de restinga e de terras baixas, por classe de DAP (árvores e palmeiras)

Figura 12 - Taxa de mortalidade ( $\lambda$ ), limite inferior (LI) e superior (LS) na floresta de restinga e de terras baixas das árvores por classe de DAP.

Figura 13 - Taxa de mortalidade $(\lambda)$, limite inferior (LI) e superior (LS) na floresta de restinga e de terras baixas, das palmeiras por classe de DAP.

Figura 14 - Taxa de mortalidade ( $\lambda$ ), limite inferior (LI) e superior (LS) das árvores e palmeiras na floresta de restinga e de terras baixas por classe de IC.

Figura 15 - Taxa de mortalidade $(\lambda)$, limite inferior (LI) e superior (LS) das árvores na floresta de restinga e de terras baixas por classe de IC

Figura 16 - Taxa de mortalidade $(\lambda)$, limite inferior (LI) e superior (LS) das palmeiras na floresta de restinga e de terras baixas por classe de IC

Figura 17 - Distribuição espacial dos indivíduos mortos na parcela $A$, nas diferentes classes de mortalidade. Os símbolos se apresentam em 3 tamanhos: menor 
representa a classe de DAP $<10 \mathrm{~cm}$, o intermediário $10-30 \mathrm{~cm}$ e o maior de $30-50 \mathrm{~cm}$. Os círculos representam um possível "efeito dominó".

Figura 18 - Distribuição espacial dos indivíduos mortos na parcela $\mathrm{B}$, nas diferentes classes de mortalidade. Os símbolos se apresentam em 4 tamanhos: menor representa a classe de DAP $<10 \mathrm{~cm}$, os intermediários $10-30 \mathrm{~cm}$ e $30-50$ $\mathrm{cm}$ e o maior representa a classe $\geq 50 \mathrm{~cm}(\mathrm{n}=2)$. Os círculos representam um possível "efeito dominó".

Figura 19 - Taxas de mortalidade e recrutamento das árvores com DAP $\geq 4,8 \mathrm{~cm}$ nas parcelas A, B, C, D e E. As barras indicam o limite inferior e superior

Figura 20 - Incremento em BAS (sobreviventes) por classe de DAP, em cada parcela permanente deste estudo (Chave et al. (2005): 3-var). MTB: média da floresta de terras baixas (barras indicam desvio padrão)

Figura 21 - Perdas de BAS (mortalidade) por classe de DAP, em cada parcela permanente deste estudo (Chave et al. (2005): 3-var). MTB: média da floresta de terras baixas (barras indicam desvio padrão)

Figura 22 - Relação entre a taxa de mortalidade e recrutamento em cada parcela permanente deste estudo e da floresta de terras baixas (geral) das árvores com DAP $\geq 4,8$ (a) e DAP $\geq 10 \mathrm{~cm}$ (b)

Figura 23 - Taxa de "turnover" (\%) de cada parcela permanente deste estudo das árvores com DAP $\geq 4,8$ (a) e DAP $\geq 10 \mathrm{~cm}$ (b) 73

Figura 24 - Relação entre a taxa de "turnover" (\%) e a variação líquida da BAS (Mg ha ${ }^{-1}$ $a^{-1}{ }^{-1}$ ) de cada parcela permanente deste estudo e da floresta de terras baixas (geral) (DAP $\geq 4,8 \mathrm{~cm}$ ). Regressão linear: Variaçao líquida BAS $(\mathrm{Mg}$ ha $^{-1}$ ano $\left.^{-1}\right)=7,29-4,24^{*}$ Taxa de turnover (\%). R2 $=0,82$ 


\section{LISTA DE TABELAS}

Tabela 1 - Propriedades físico-químicas da camada superficial $(0$ a $5 \mathrm{~cm})$ do solo das parcelas permanentes $\mathrm{A}, \mathrm{B}$ e $\mathrm{E}$

Tabela 2 - Data do início dos inventários e intervalo de amostragem das parcelas permanentes na floresta de restinga e de terras baixas

Tabela 3 - Densidade total (árvores e palmeiras) dos indivíduos com DAP $\geq 4,8 \mathrm{~cm}$ e 10 $\mathrm{cm}$ em ambos os inventários deste estudo (2006 e 2008), na floresta de restinga e terras baixas.

Tabela 4 - Resumo do DAP $(\mathrm{cm})$ e da altura total $(\mathrm{m})$ na floresta de restinga e de terras baixas

Tabela 5 - Área basal total $\left(\mathrm{m}^{2} \mathrm{ha}^{-1}\right)$ dos indivíduos com DAP $\geq 4,8$ e $10 \mathrm{~cm}$ nos dois inventários, na floresta de restinga e de terras baixas

Tabela 6 - Mediana, valor mínimo e máximo do estoque de BAS para indivíduos com $\mathrm{DAP} \geq 4,8$ e $10 \mathrm{~cm}$, na floresta de restinga e de terras baixas. $O$ valor referente à parcela de 1-ha de restinga representa 0 valor referente ao estoque de somente uma unidade amostral (1 ha). 2-var: estimativa de BAS através da equação 4. 3-var: estimativa de BAS através da equação 5

Tabela 7 - Densidade média de árvores e palmeiras e desvio padrão dos indivíduos com DAP $\geq 4,8$ e $10 \mathrm{~cm}$, em ambos os inventários e áreas de estudo

Tabela 8 - Densidade média e desvio padrão dos indivíduos (árvores e palmeiras) por classe de DAP, em ambos os inventários e áreas de estudo

Tabela 9 - Mediana, valor mínimo, valor máximo e \% de contribuição em relação ao total do estoque de BAS por classe de DAP. 2-var: estimativa de BVAS através da equação 4. 3-var: estimativa de BVAS através da equação 5.

Tabela 10 - Resumo da taxa de incremento diamétrico $\left(\mathrm{mm}^{2} \mathrm{ano}^{-1}\right)$ das árvores com o DAP $\geq 4,8$ e $10 \mathrm{~cm}$ em ambas as áreas de estudo.

Tabela 11 - Resumo da taxa de incremento diamétrico $\left(\mathrm{mm}^{\mathrm{ano}}{ }^{-1}\right)$ das palmeiras com o DAP $\geq 4,8$ e $10 \mathrm{~cm}$ em ambas as áreas de estudo

Tabela 12 - Resumo da taxa de incremento diamétrico $\left(\mathrm{mm} \mathrm{ano}^{-1}\right)$ das árvores por classe de DAP em ambas as áreas de estudo.

Tabela 13 - Resumo da taxa de incremento diamétrico das palmeiras por classe de DAP em ambas as áreas de estudo

Tabela 14 - Resumo da taxa de incremento diamétrico (mm ano-1) das árvores por classe de IC em ambas as áreas de estudo.

Tabela 15 - Resumo da taxa de incremento diamétrico ( $\mathrm{mm}$ ano-1) das palmeiras por classe de IC em ambas as áreas de estudo 
Tabela 16 - Taxa de mortalidade ( $\lambda$ ), limite inferior (LI) e superior (LS), população inicial (N0), número de mortos (M) e meia vida $(t(1 / 2))$ em anos na floresta de restinga e de terras baixas, para os indivíduos com DAP $\geq 4,8$ e $\geq 10 \mathrm{~cm}$.....

Tabela 17 - Taxa de recrutamento (i), limite inferior (LI) e superior (LS) e número de recrutas $(R)$ na floresta de restinga e de terras baixas, para os indivíduos com $\mathrm{DAP} \geq 4,8 \mathrm{e} \geq 10 \mathrm{~cm}$.

Tabela 18 - Taxa de mortalidade $(\lambda)$, limite inferior (LI) e superior (LS), população inicial (N0), número de mortos (M) e meia vida ( $t(1 / 2))$ em anos na floresta de restinga e de terras baixas, para árvores e palmeiras com $\mathrm{DAP} \geq 4,8$ e $\geq 10$ $\mathrm{cm}$

Tabela 19 - Taxa de recrutamento (i), limite inferior (LI) e superior (LS) e número de recrutas $(R)$ na floresta de restinga e de terras baixas, para árvores e palmeiras com DAP $\geq 4,8 \mathrm{e} \geq 10 \mathrm{~cm}$

Tabela 20 - Incremento em BASi (sobreviventes), ganho de BASr devido ao recrutamento, perdas de BASm devido a mortalidade e mudanças líquidas na BAS dos indivíduos com o DAP $\geq 4,8 \mathrm{~cm}$ de cada parcela permanente deste estudo. A "média" representa a média da floresta de terras baixas (Chave et al. (2005): 3-var)

Tabela 21 - Densidade (indivíduos ha $\left.{ }^{-1}\right)$, área basal $\left(\mathrm{m}^{2} \mathrm{ha}^{-1}\right)$ e biomassa acima do solo (BAS, $\mathrm{Mg} \mathrm{ha}^{-1}$ ) das áreas utilizadas neste estudo e de diversas florestas tropicais no Brasil e no mundo (DAP de inclusão igual a $10 \mathrm{~cm}$ )

Tabela 22 - Taxa de incremento diamétrico médio $\left(\mathrm{mm} \mathrm{ano}^{-1}\right)$ das áreas utilizadas neste estudo e de diversas florestas tropicais no Brasil e no mundo. A coluna precipitação contém informação de pluviosidade quando disponível ou o tipo de classificação da floresta quanto a essa característica (quando a informação de pluviosidade não foi disponível) (DAP de inclusão igual a 10 $\mathrm{cm})$

Tabela 23 - Perdas devido a mortalidade, incremento devido ao recrutamento e crescimento dos indivíduos vivos e mudanças líquidas da BAS ( $\mathrm{Mg} \mathrm{ha}^{-1}$ ano $\left.{ }^{1}\right)$ das áreas utilizadas neste estudo e de diversas florestas tropicais no Brasil e no mundo (DAP de inclusão igual a $10 \mathrm{~cm}$ )

Tabela 24 - Taxas de mortalidade, recrutamento e "turnover" (\%) das áreas utilizadas neste estudo e de diversas florestas tropicais no Brasil e no mundo (DAP de inclusão igual a $10 \mathrm{~cm}$ ) 


\section{SUMÁRIO}

1. INTRODUÇÃO

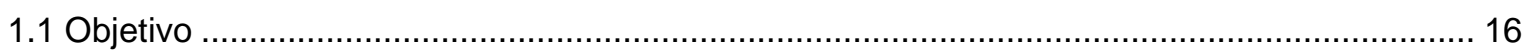

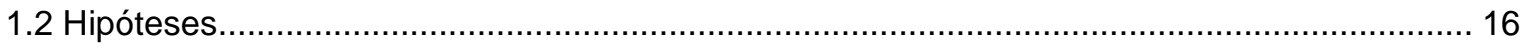

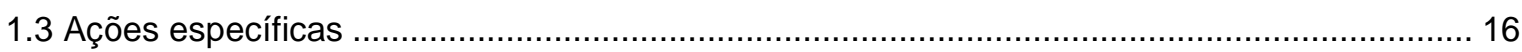

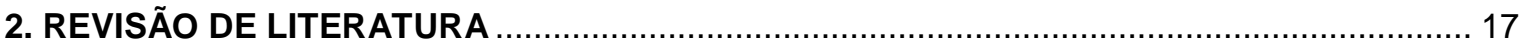

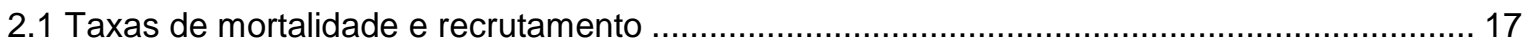

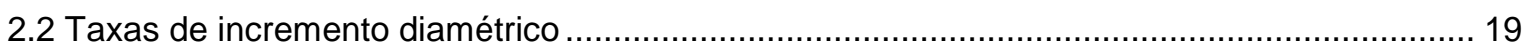

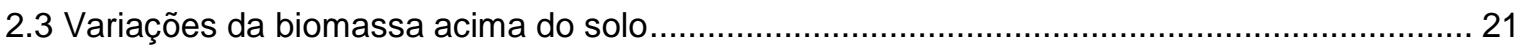

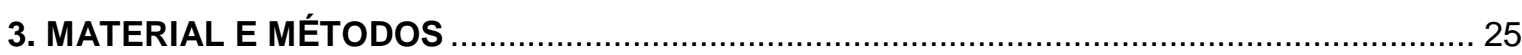

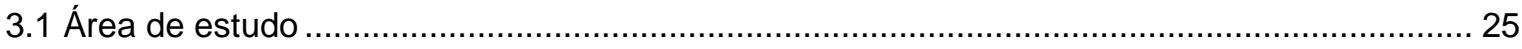

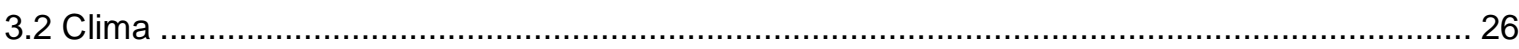

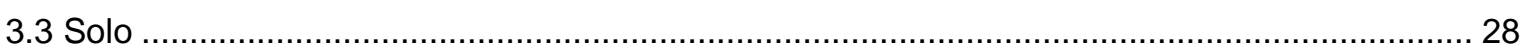

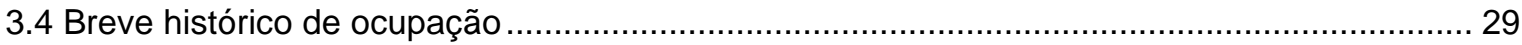

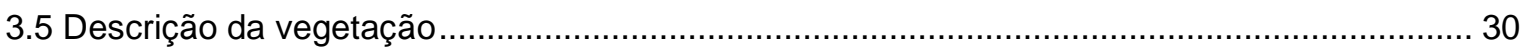

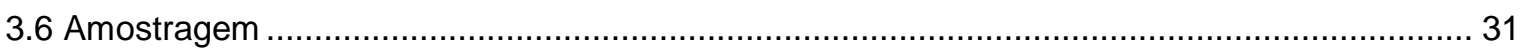

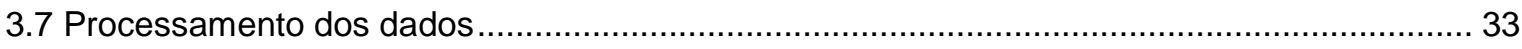

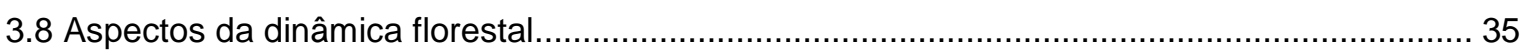

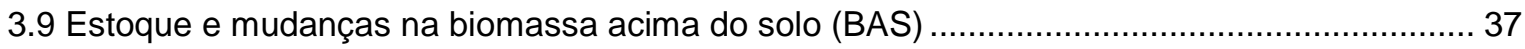

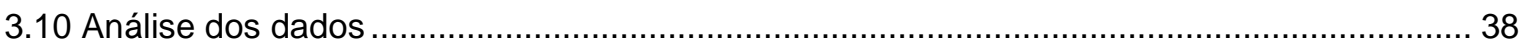

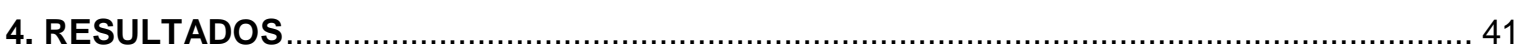

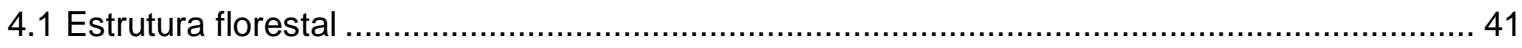

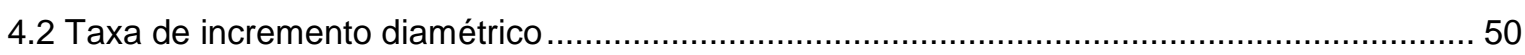

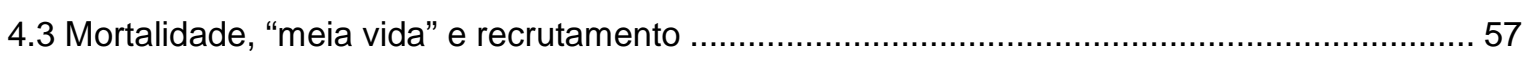

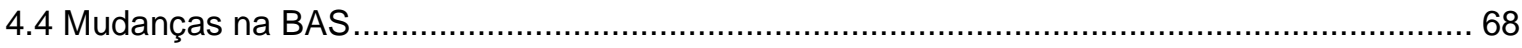

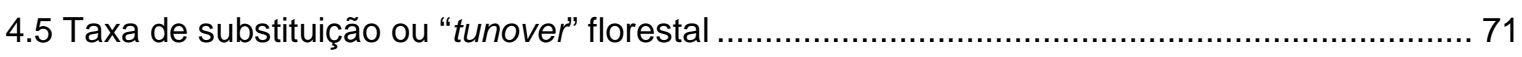

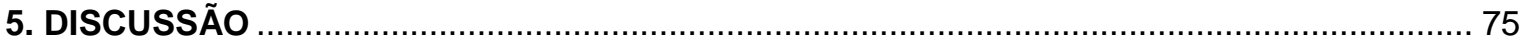

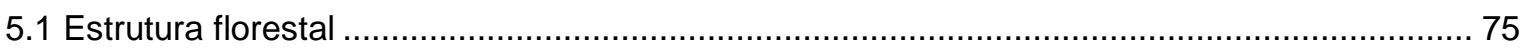

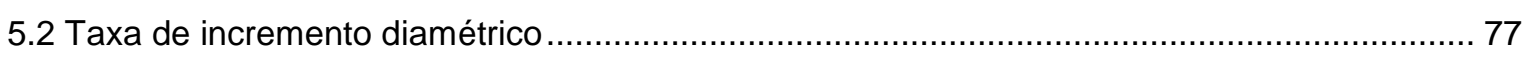

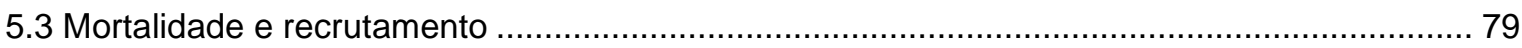

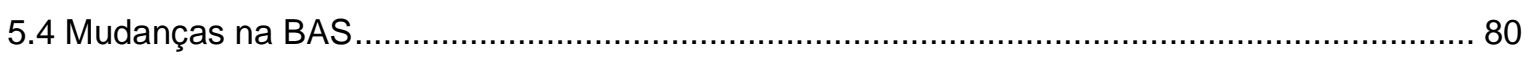

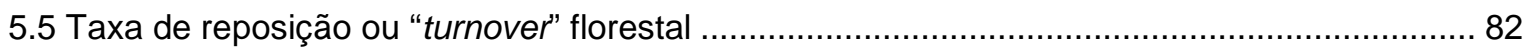

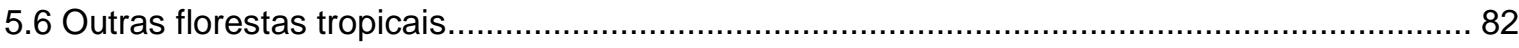

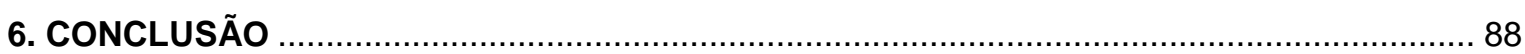

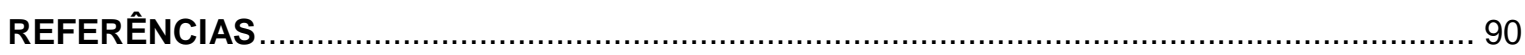

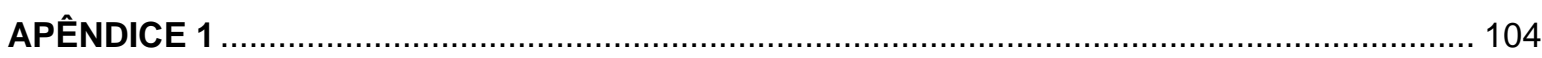

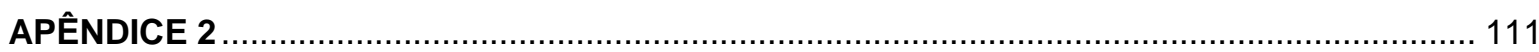

APÊNDICE 3 


\section{INTRODUÇÃO}

As florestas tropicais exibem uma biodiversidade única, maior do que qualquer outro tipo de vegetação (WILLIS; MCELWAIN, 2002). Além da elevada riqueza, as florestas tropicais desempenham um importante papel no ciclo global do carbono, estocando e processando grandes quantidades desse elemento (MALHI; GRACE, 2000). Estima-se que aproximadamente $40 \%$ do carbono estocado na biomassa terrestre esteja presente nas florestas tropicais (DIXON et al., 1994).

Por outro lado, essas florestas têm sido impactadas aceleradamente nos últimos anos. Entre 1990 e 1997, cerca de seis (6) milhões de hectares de florestas tropicais foram desflorestadas anualmente e substituídas por outro uso ou cobertura do solo em todo mundo (ACHARD et al., 2002). Esse processo de mudança do uso e cobertura da terra resulta em considerável diminuição de biodiversidade e em grandes emissões de gases de efeito estufa para a atmosfera, principalmente o $\mathrm{CO}_{2}$ (MALHI; GRACE, 2000).

No Brasil, a floresta tropical Atlântica (conhecida genericamente como Mata Atlântica) cobria anteriormente quase todas as zonas da costa Brasileira e parte do interior do país com uma área de aproximadamente $1.300 .000 \mathrm{Km}^{2}$ (COLLINS, 1990). Atualmente, está restrita a aproximadamente $7 \%$ de sua extensão original (SOS MATA ATLÂNTICA; INPE, 2002). É considerada um "hotspot" para a conservação da biodiversidade, devido a elevada riqueza de espécies e o alto nível de endemismo (MYERS et al., 2000).

Como resultado dessa intensa mudança do uso e cobertura da terra, os remanescentes de floresta tropical Atlântica estão concentrados principalmente em áreas de topo, encosta e sopé de cadeias montanhosas como, por exemplo, a Serra do Mar. Essas áreas de difícil acesso e sem aptidão agrícola são importantes maciços de remanescentes de floresta tropical Atlântica, pois abrigam grande parte do que restou desse importante bioma.

Dentro desse contexto, o Parque Estadual da Serra do Mar (PESM) desempenha um importante papel para a conservação dessas áreas, possuindo um dos maiores remanescentes de Floresta Ombrófila Densa Atlântica no Brasil (JOLY et al., 2008). 
Adicionalmente, o PESM apresenta áreas que vão desde a floresta de Restinga, no cordão do litoral norte de São Paulo, até áreas de Floresta Ombrófila Densa Montana, passando pelas Florestas Ombrófila Densa de Terras Baixas e Submontana no sopé e encosta da serra (ASSIS, 1999; VELOSO; RANGEL; LIMA, 1991).

As florestas de restingas e as florestas de terras baixas, como serão tratadas ao longo do texto, são importantes porque além de elevada diversidade de espécies e estoque de carbono, possuem características peculiares que as distinguem das demais fisionomias Atlânticas (ASSIS, 1999; JOLY et al., 2008). Adicionalmente, ambas ainda sofrem ameaças devido à pressão de ocupação humana e especulação imobiliária (TALORA; MAGRO; SCHILLING, 2007). Com isso, Informações sobre a dinâmica da vegetação dessas fisionomias são importantes para entender o funcionamento desses ecossistemas e servem de subsídio para auxiliar a conservação.

Os processos que regem a dinâmica de uma floresta podem ser resumidos em mortalidade, recrutamento e crescimento das árvores (SWAINE; LIEBERMAN; PUTZ, 1987). O entendimento das taxas e processos na qual as florestas mudam em todas as escalas (ecossistema e regional) contribui para o conhecimento dos sistemas naturais e da demografia da comunidade arbórea (CAREY et al., 1994). Ainda, esse tipo de conhecimento em áreas presumidamente não perturbadas por ações humanas pode auxiliar na detecção de alterações na floresta causadas por poluentes ambientais, gases de efeito estufa e outros distúrbios humanos (FRANKLIN; SHUGART; HARMON, 1987).

Estudos em florestas tropicais são também importantes pelo fato do desmatamento e a degradação contribuem para as mudanças climáticas globais, que por sua vez, causam impactos severos nos padrões de crescimento, mortalidade e recrutamento dos sistemas florestais (PHILLIPS et al., 1998). No final de 2005, devido à escassez de informações sobre a estrutura e funcionamento da floresta Ombrófila Densa Atlântica ao longo de um gradiente altitudinal, o projeto temático da FAPESP "Gradiente Funcional", inserido dentro do programa "BIOTA-FAPESP", teve como objetivo principal investigar de forma multidisciplinar este importante ecossistema. 
No presente estudo, variações a curto prazo da comunidade florestal de duas áreas da floresta Ombrófila Densa Atlântica, no início do gradiente altitudinal da Serra do Mar, foram avaliadas no âmbito desse importante projeto temático. Aqui, inicia-se uma seqüência de investigações sobre a dinâmica da floresta tropical Atlântica de adequada escala amostral, que se estenderá posteriormente ao longo do gradiente e por alguns anos.

\subsection{Objetivo}

O principal objetivo deste estudo foi estimar a taxa de mortalidade, recrutamento e incremento diamétrico da comunidade arbórea de duas formações florestais da floresta tropical Atlântica: terras baixas e restinga.

\subsection{Hipóteses}

- Devido às prévias diferenças reportadas na literatura entre as fisionomias, foram formuladas as seguintes hipóteses:

1. A floresta de terras baixas apresenta maior taxa de incremento diamétrico que a floresta de restinga.

2. Devido ao regime hídrico sazonal de inundação, a floresta de restinga apresenta maior taxa de mortalidade que a floresta de terras baixas.

3. Como conseqüência da maior taxa de mortalidade, a floresta de restinga também apresenta maior taxa de recrutamento.

\subsection{Ações específicas}

- Determinar as taxas de incremento diamétrico, mortalidade e recrutamento dos indivíduos arbóreos nas florestas de terras baixas e de restinga.

- Comparar as taxas de incremento diamétrico, mortalidade e recrutamento entre as diferentes formas de vida (palmeiras e árvores).

- Descrever as relações das taxas de mortalidade, recrutamento e crescimento com a disponibilidade de luz vertical e classes de tamanho.

- Identificar padrões espaciais de mortalidade.

- Estimar a variação no estoque de biomassa, comparando as contribuições do crescimento, mortalidade e recrutamento para essas variações. 


\section{REVISÃO DE LITERATURA}

\subsection{Taxas de mortalidade e recrutamento}

A marcação, contagem, medida de indivíduos e a re-contagem periódica desses indivíduos para inferir sobre mudanças na comunidade é uma prática comum em estudos ecológicos (BEGON; HARPER; TOWNSEND, 1996; KREBS, 1998). Em estudos envolvendo florestas tropicais, essas medidas são tomadas baseadas em inventários de parcelas permanentes, realizando o delineamento amostral da área, e marcando permanentemente cada fuste de árvore que excede um dado tamanho mínimo, freqüentemente maior ou igual a $10 \mathrm{~cm}$ de diâmetro à altura do peito (DAP). A parcela é visitada periodicamente para tomar nota dos indivíduos mortos e dos indivíduos que alcançaram o tamanho mínimo limite, e esses dados são então utilizados para calcular taxas de mortalidade e recrutamento (SHEIL; BURSLEM; ALDER, 1995). Quase todo o conhecimento sobre dinâmica de florestas tropicais deriva desse tipo de método (CAREY et al., 1994; CONDIT et al., 1999; LEWIS et al., 2004; PHILLIPS et al., 2004; PHILLIPS; GENTRY, 1994; SHEIL; JENNINGS; SAVILL, 2000; SWAINE; HALL; ALEXANDER, 1987; VÁSQUEZ; PHILLIPS 2000).

Após a coleta desses dados demográficos, a taxa de mortalidade então é freqüentemente calculada através de um modelo exponencial de declínio da população ou comunidade (SHEIL; BURSLEM; ALDER, 1995), definido como a inclinação do logaritmo natural da sobrevivência vs. tempo (LIEBERMAN et al., 1985; SWAINE; HALL, 1983). Esse método é uma aproximação da taxa instantânea de mortalidade, e quando o tempo é relativamente pequeno essa aproximação se torna ainda mais adequada (CONDIT; HUBBELL; FOSTER, 1993).

Em florestas naturais, a mortalidade de árvores está fortemente relacionada a fatores exógenos ou endógenos que afetam essas comunidades (BORMANN; LIKENS, 1979). O efeito do vento, chuva, patógenos, ataque de insetos e secas pronunciadas, podem conduzir o regime de queda natural de árvores (BROKAW; WALKER, 1991; VAN-DER-MEER; BONGERS, 1996).

A forma na qual as árvores morrem e a condição que finalmente alcançam o solo, podem depender de características biológicas ou físicas que atuam sobre elas mesmas (ARRIAGA, 2000). Árvores podem morrer em pé, quebradas ou arrancadas pela raiz (ARRIAGA, 2000). As propriedades arquitetônicas ou anatômicas das 
árvores junto com as características de solo determinam se uma árvore cai com a raiz ou quebra (BROKAW; WALKER 1991). A morte de uma árvore em pé pode ser resultado de senescência, mas também pode ocorrer como resultado de ataques de insetos e patógenos, ou devido a quebra da copa pela ação de algum fator físico (ARRIAGA, 2000). Nessa forma de mortalidade, a desagregação ocorre gradualmente.

Essa variação de como ocorre a mortalidade das árvores é importante, porque afeta a reposição seqüencial de espécies de plantas (PUTZ et al., 1983). Adicionalmente, a causa e o resultado da morte de uma árvore é que determina o papel ecológico da mortalidade. Árvores mortas em pé são importantes habitats para a fauna (DEWALT; MALIAKAL; DENSLOW, 2003). Árvores mortas caídas contribuem diretamente para aumentar o estoque de nutrientes e carbono do solo (HARMON et al., 1986).

A densidade da madeira, em particular, pode indicar risco de mortalidade e influenciar tal aspecto (KING et al., 2006; NASCIMENTO et al., 2005; VAN-GELDER; POORTER; STERCK, 2006). Vários atributos individuais também podem influenciar a probabilidade de uma árvore morrer: o vigor (VAN-MANTGEM et al., 2003) e o tamanho (CONDIT; HUBBELL; FOSTER, 1995; YAO; TITUS; MACDONALD, 2001). Árvores de crescimento lento apresentam maior probabilidade de insalubridade, de exibirem estresse fisiológico e serem propensas à senescência (BIGLER et al., 2004; VAN-MANTGEM et al., 2003). Além disso, a taxa de mortalidade pode ser maior em espécies de sub-bosque, seguido por espécies de dossel e emergentes (KORNING; BALSLEV, 1994).

A taxa de mortalidade em florestas tropicais primárias freqüentemente varia de 1 a 2\% para os indivíduos com o DAP $\geq 10 \mathrm{~cm}$ (CONDIT; HUBBELL; FOSTER, 1995; SWAINE; LIEBERMAN; PUTZ, 1987). Na floresta tropical Atlântica, estudos demonstraram que a taxa de mortalidade pode variar de 2,6 a 2,9\% (DAP $\geq 5 \mathrm{~cm}$ ) em áreas sob intenso processo de fragmentação (GUILHERME et al., 2004; OLIVEIRA-FILHO; MELLO; SCOLFORO, 1997) e em área livre de efeito de fragmentação pode chegar a 1,7\% em anos típicos ou até 5,0\% (DAP $\geq 10 \mathrm{~cm}$ ) em anos de seca pronunciada sob efeito de "El Niño" (ROLIM et al., 2005). 
Na maioria das florestas estudadas, a taxa de recrutamento de árvores a um DAP mínimo de inclusão está intimamente associada com a taxa de mortalidade, mantendo a densidade de árvores com DAP $>10 \mathrm{~cm}$ mais ou menos constante (SWAINE; LIEBERMAN; PUTZ, 1987). Em florestas tropicais, o padrão espacial de recrutamento é composto de dois componentes independentes, formando um componente aleatório e um complexo padrão de agrupamento (WEIGAND; MARTÍNEZ; HUTH, 2009). Adicionalmente, esse padrão pode ser atribuído a interações entre muitos mecanismos tais como: a dispersão animal (criando deposições de sementes agrupadas e/ou dispersas); clima local de luminosidade; "hotspots" de regeneração e limitações de dispersão (WEIGAND; MARTíNEZ; HUTH, 2009).

Análises em larga escala têm sugerido que mudanças significativas ocorreram na estrutura e funcionamento das florestas tropicais nas últimas décadas (PHILLIPS et al., 2004). Phillips e Gentry (1994) mostraram que a taxa de reposição ("turnover"), uma média da taxa de recrutamento e mortalidade, de florestas tropicais pouco perturbadas aumentaram ao longo dos anos de 1980 e início de 1990. Na Amazônia, a estrutura e a composição de florestas não-fragmentadas estão mudando em função do aumento da biomassa das árvores (BAKER et al., 2004a) e abundância relativa de lianas lenhosas (PHILLIPS et al., 2002). Esses padrões sugerem que as mudanças globais estão causando transformações previsíveis nas florestas tropicais (LEWIS; MALHI; PHILLIPS, 2004).

\subsection{Taxas de incremento diamétrico}

O crescimento das árvores é um dos principais temas de interesse de engenheiros florestais e ecólogos, devido às aplicações na avaliação e predição da produção de florestas (VANCLAY, 1994), bem como as implicações no entendimento de estudos demográficos e dinâmica de florestas (SWAINE; LIEBERMAN; PUTZ, 1987). Infelizmente, poucas espécies de árvores tropicais formam anéis anuais de crescimento no xilema, impossibilitando análises dendrocronológicas (BULLOCK, 1997; CLARK; CLARK, 1994). Por isso, estimativas de crescimento arbóreo são determinadas através de medidas sucessivas obtidas em parcelas permanentes, a partir do incremento em diâmetro (SHEIL, 2003). 
O incremento em diâmetro, por sua vez, é extremamente variável tanto entre espécies arbóreas como dentro da mesma espécie (FERRI, 1979), além de não apresentar padrões claros ao longo do tempo e da ontogenia (CLARK; CLARK 1994). Além disso, o incremento em diâmetro pode estar relacionado positivamente com a disponibilidade de água (precipitação) a curto prazo (SILVA et al., 2002; VIEIRA et al., 2004), porém a longo prazo a relação não se torna clara (CLARK; CLARK, 1994).

O incremento em diâmetro também é dependente do tamanho, onde árvores pequenas em geral crescem mais lentamente que árvores grandes (BRIENEN; ZUIDEMA; DURING, 2006). Além da dependência de tamanho, o incremento em diâmetro pode estar primariamente relacionado com a disponibilidade de luz (BAKER; SWAINE; BURSLEM, 2003). Porém, essa relação é diferenciada para espécies pertencentes a diferentes grupos funcionais (BAKER; SWAINE; BURSLEM, 2003). Por exemplo, espécies que demandam alta disponibilidade de luz para a germinação e/ou estabelecimento (freqüentemente denominadas de pioneiras) são diferenciadas de espécies que são habilitadas a germinarem e se estabelecerem sob a sombra do dossel (não-pioneiras) (WHITMORE, 1989). Portanto, sob condições de alta disponibilidade de luz, espécies pioneiras possuem taxas de incremento diamétrico maiores que espécies não-pioneiras (BAKER; SWAINE; BURSLEM, 2003).

Em condições de baixa disponibilidade de luz, por outro lado, se as espécies pioneiras apresentarão maiores taxas de incremento diamétrico, quando comparada com as não-pioneiras, dependerá de como a comparação é realizada (BAKER; SWAINE; BURSLEM, 2003). Quando baixas quantidades de luz são incluídas em experimentos (AGYEMAN; SWAINE; THOMPSON, 1999), espécies pioneiras crescem mais lentamente que espécies tolerantes a sombra e tipicamente revelam incremento negativo com aproximadamente $2 \%$ de irradiância (AGYEMAN; SWAINE; THOMPSON, 1999).

O suprimento de nutrientes também pode se apresentar como fator limitante para 0 incremento diamétrico de árvores em florestas tropicais (BAKER; SWAINE; BURSLEM, 2003). A fertilização de nitrogênio $(N)$ e fósforo $(P)$ em áreas de floresta tropical Montana demonstrou que o crescimento arbóreo é limitado por esses nutrientes (CAVELIER; TANNER; SANTAMARIA, 2000; VITOUSEK et al., 1993). Por 
outro lado, alguns estudos comparando padrões de disponibilidade natural de nutrientes no solo com o crescimento de árvores em florestas tropicais não revelaram relações claras, principalmente em relação a disponibilidade de $P$ (CLARK; CLARK; READ, 1998) ou outros nutrientes (ASHTON; HALL1992).

Estudos recentes reportaram que as taxas de crescimento de florestas tropicais têm se acelerado ao longo de várias décadas (LAURANCE et al., 2004a; LEWIS et al., 2004), consistente com a hipótese do aumento na produtividade, causado pelo aumento da concentração de $\mathrm{CO}_{2}$ na atmosfera e fertilização de carbono (MELILLO et al. 1993; LAURANCE et al., 2004a; LEWIS, 2006). Por outro lado, em contraste, Clark et al. (2003) encontraram que taxas de crescimento anuais decaíram continuamente ao longo do tempo, em seis espécies de dossel em La Selva, Costa Rica. Adicionalmente, Feeley et al. (2007) descreveram relações significativas entre as taxas de crescimento e as mudanças climáticas regionais, e contestaram a hipótese do aumento das taxas de crescimento associadas à fertilização de $\mathrm{CO}_{2}$.

\subsection{Variações da biomassa acima do solo}

$\mathrm{O}$ aumento de $\mathrm{CO}_{2}$ na atmosfera, resultado das atividades humanas, causará profundos efeitos no clima global (IPCC, 2007) e nos ecossistemas terrestres (CROWLEY, 2000). Nesse contexto, as florestas tropicais desempenham um papel importante no ciclo global do carbono (MALHI; GRACE, 2000). Além de apresentarem elevado estoque, ex. Amazônia de 39 a 93 PgC (HOUGHTON et al., 2001), são altamente produtivas. Estima-se uma contribuição de 32\% (FIELD et al., 1998) a 36\% (MELILLO et al., 1993) do potencial de produtividade primária líquida terrestre global.

Estudos realizados na Amazônia revelam que árvores maiores que $10 \mathrm{~cm}$ de DAP, tipicamente incluem mais de $80 \%$ do total de estoque da biomassa acima do solo (BAS) (MALHI et al., 2009; NASCIMENTO; LAURENCE, 2002). Ainda, após os componentes do dossel (folha, flor, fruto e ramo), a BAS é o segundo maior componente da produtividade primária líquida das florestas tropicais na Amazônia (MALHI et al., 2009).

Dados de torres de fluxos na Amazônia inicialmente sugeriram que as florestas tropicais pouco perturbadas poderiam ser significativos sumidouros de carbono 
(MALHI et al., 1998). Mais recentemente, experimentos utilizando metodologias padrões em campo também têm demonstrado que algumas áreas da Amazônia, principalmente sob solos de alta fertilidade, acumulam quantidades significativas de carbono (MAHLI et al., 2009). Phillips et al. (1998), através de medidas repetidas de árvores em parcelas permanentes ao redor do mundo, estimaram as variações anuais na BAS. Enquanto as análises indicaram mudanças não significativas na BAS nas florestas tropicais na Ásia e África, evidências de aumento significativo foram encontradas na BAS das florestas Neotropicais, particularmente em florestas de terras baixas. Malhi et al. (2009) estimaram a produtividade primária líquida da BAS na Amazônia variando de 2 a 2,9 MgC ha ${ }^{-1}$ ano $^{-1}$.

Por outro lado, esse padrão de significativo sumidouro de carbono pode ser afetado por eventos que afetam a dinâmica local. Eventos de seca pronunciada em anos de "El Niño" (ROLIM et al., 2005; SALESKA et al., 2003), por exemplo, podem contribuir para o aumento da taxa de mortalidade das árvores. Como resultado da alta mortalidade, significativas perdas de carbono podem ocorrer devido a respiração de grandes estoques de madeira morta que excedem os ganhos pela biomassa viva (SALESKA et al., 2003). Saleska et al. (2003) encontraram que uma floresta próximo a Santarém, PA, respondendo a um episódio de seca pronunciada em ano de "El Niño" perdeu em média 1,3 MgC ha- $\mathrm{ano}^{-1}$.

O incremento da BAS em parcelas permanentes é estimado a partir de duas estimativas de biomassas sucessivas. O estoque de biomassa é estimado por equações alométricas e medidas de diâmetro, altura e densidade da madeira dos indivíduos que estão acima de um tamanho mínimo (CLARK et al., 2001). Essas são as variáveis independentes das equações alométricas que estimam o peso de uma árvore. Pesquisadores usualmente utilizam equações alométricas existentes na literatura científica, desenvolvidas a partir de medidas destrutivas de alguns indivíduos de uma determinada região ou floresta (BROWN, 1997; NOGUEIRA et al., 2008a). Porém, essa prática comum pode introduzir erros nas estimativas dos estoques e incremento da BAS (GOWER; KUCHARIK; NORMAN, 1999).

O desenvolvimento de equações alométricas específicas para determinados locais possui algumas restrições. Além de ser uma operação de baixo rendimento e alto custo (CLARK et al., 2001), o método destrutivo empregado para o ajuste desses 
modelos esbarra em aspectos legais como, por exemplo, as áreas de proteção integral (VIERA et al., 2008). No caso da floresta Tropical Atlântica, Vieira et al. (2008) discutiram a importância da escolha do modelo alométrico adequado nas áreas de floresta Atlântica do Parque Estadual da Serra do Mar, SP. Ainda, reforça a introdução da densidade da madeira e altura total (BAKER et al. 2004b; NOGUEIRA et al. 2008b), e propõe a utilização do modelo pantropical proposto por Chave et al. (2005), que tem sido bem aceito na comunidade científica (GIBBS et al., 2007).

Existem duas abordagens para estimar o incremento em BAS, a partir de medidas de campo e relações alométricas (CLARK et al., 2001). Basicamente, a diferença entre as duas formas de estimar o incremento está na contabilização das árvores mortas e dos indivíduos recrutados.

Na primeira abordagem, o incremento de cada árvore é calculado como a diferença entre a biomassa estimada no início e final do intervalo. Se uma árvore morre durante o período considerado e esse intervalo é curto, o incremento desse indivíduo durante o período que esteve vivo pode ser desconsiderado. Assim, o incremento é resultado da soma de todas as árvores sobreviventes no intervalo. Esse total é então ajustado para o incremento dos recrutas, onde o incremento de cada árvore nova é calculado como a diferença entre a biomassa estimada no final do intervalo e a biomassa de uma árvore com o diâmetro mínimo de inclusão do estudo. A soma do incremento resultado dos recrutas é então somada ao incremento dos sobreviventes (CLARK et al., 2001).

Na segunda abordagem, a estimativa total da BAS no início do intervalo é subtraída da estimativa total da BAS no final do intervalo. A referência de incremento individual não é feita. Essa diferença da biomassa final e inicial então precisa ser ajustada com a mortalidade e incremento dos recrutas. A correção da mortalidade é realizada a partir das estimativas de biomassa de todas as árvores que morreram durante 0 período, utilizando o diâmetro inicial de cada uma, e adicionada a mudança líquida da biomassa. Muita atenção deverá ser tomada quando o intervalo entre os inventários for maior que dois anos, especialmente quando árvores grandes morreram durante esse período. Nesse caso, para evitar sub-estimativa do incremento da floresta, o crescimento das árvores que morreram deverá ser estimado e computado durante o período. Para a correção de incremento dos 
recrutas, o número de árvores recrutadas é multiplicado pela biomassa estimada a partir do diâmetro mínimo de inclusão e esse produto então é subtraído do incremento já corrigido pela mortalidade (CLARK et al., 2001).

Além das correções das diferentes abordagens, outras fontes de erros potenciais podem comprometer as estimativas de variações em BAS. A super ou subestimativa da biomassa das árvores grandes, que inclui cerca de 25 a $50 \%$ da biomassa total acima do solo (BROWN et al., 1995), pode comprometer as estimativas quando as equações alométricas utilizadas são baseadas em banco de dados que não cobrem esse intervalo de diâmetro (BROWN et al., 1995). Ainda, o incremento em biomassa pode apresentar erros oriundos de perdas progressivas de biomassa, através de árvores com o fuste apodrecendo e com queda de galhos (CLARK et al., 2001). Por fim, a altura do ponto de medição do diâmetro também pode afetar significativamente as estimativas de variação em biomassa. A altura da medida deve ser feita sempre a altura do peito $(1,30 \mathrm{~cm})$ ou acima de irregularidades ou raízes de escoras ("sapopemas"), que freqüentemente são encontradas em árvores grandes em florestas tropicais (CLARK et al., 2001).

De maneira semelhante aos padrões gerais obtidos para taxas de reposição ("turnover") e crescimento, estudos desenvolvidos em florestas neotropicais têm mostrado evidências de aumento substancial na biomassa acima do solo, principalmente em áreas de floresta de terras baixas (PHILLIPS et al., 1998). Como citado anteriormente, esse aumento sugeriu que florestas tropicais maduras de terras baixas nessas regiões têm atuado como importantes sumidouros de carbono e até mesmo responsáveis por parte do desbalanço global de carbono chamado de "carbono perdido" ou "missing carbon". Tais teorias impactaram significativamente o conhecimento sobre o ciclo global do carbono e têm sido amplamente citados (MALHI; GRACE, 2000). 


\section{MATERIAL E MÉTODOS}

\section{1 Área de estudo}

O Parque Estadual da Serra do Mar (PESM) possui área total de 315.000 ha, sendo uma das maiores unidades de conservação de Mata Atlântica "sensu lato". Este estudo foi conduzido no núcleo Picinguaba, localizado no município de Ubatuba, SP (Figura 1).

O município de Ubatuba está situado no litoral norte do estado de São Paulo e abrange uma área total de $711 \mathrm{~km}^{2}$. Sua localização geográfica proporciona cerca de $200 \mathrm{~km}$ de extensão de costa litorânea, com mais de 75 praias e vegetação de floresta tropical Atlântica exuberante. O PESM no município de Ubatuba ocupa uma área de 47.500 ha, sob a responsabilidade do Instituto Florestal do Estado de São Paulo e a Secretaria do Meio Ambiente - SEMA (ALVES, 2000; PEDRONI, 2001). O núcleo Picinguaba $\left(23^{\circ} 31^{\prime}\right.$ a $23^{\circ} 34^{\prime} \mathrm{S}$ e $45^{\circ} 02^{\prime}$ a $\left.45^{\circ} 05^{\prime} \mathrm{W}\right)$ é a única região do PESM que atinge a orla marinha e apresenta um mosaico de formações florestais que vai desde floresta de restinga até Floresta Ombrófila Densa Montana (ASSIS, 1999).

Após a re-definição do sistema de classificação proposto por Veloso, Rangel e Lima (1991), referente ao projeto temático "Gradiente Funcional” (JOLY et al., 2008), o projeto passou a adotar as seguintes denominações para as fisionomias ocorrentes ao longo de uma hierarquia topográfica na latitude de estudo:

Floresta de Restinga: ocorre sob solo arenoso, no cordão do litoral, de 0 a 50 m de altitude;

Floresta Ombrófila Densa (FOD) de Terras Baixas: ocorre no sopé da Serra do Mar, de 50 a $100 \mathrm{~m}$ de altitude;

FOD Submontana: cobre áreas da Serra do Mar de 100 a 500 m de altitude;

FOD Montana: cobre áreas da Serra do Mar de 500 a 1.200 m de altitude.

O presente estudo está inserido dentro do projeto temático "Gradiente Funcional", nas áreas de floresta de restinga e floresta de terras baixas. Para esse, foram utilizadas cinco (5) parcelas permanentes, sendo uma (1) em área de floresta de restinga e quatro (4) em área de floresta de terras baixas. Ao longo do texto, a 
parcela permanente da floresta de restinga receberá a nomenclatura de "Parcela A" e as parcelas permanentes da FOD de terras baixas de "Parcelas B, C, D e E". Essa denominação é referente ao projeto temático "Gradiente Funcional" (JOLY et al., 2008).

A parcela A localiza-se próxima a sede de visitantes do núcleo Picinguaba (Figura 1), na praia da Fazenda. As parcelas $B, C, D$ e E foram alocadas no sertão do bairro da Fazenda (Figura 1). $O$ acesso de ambas as áreas é feito através da rodovia BR101 (Rio-Santos).

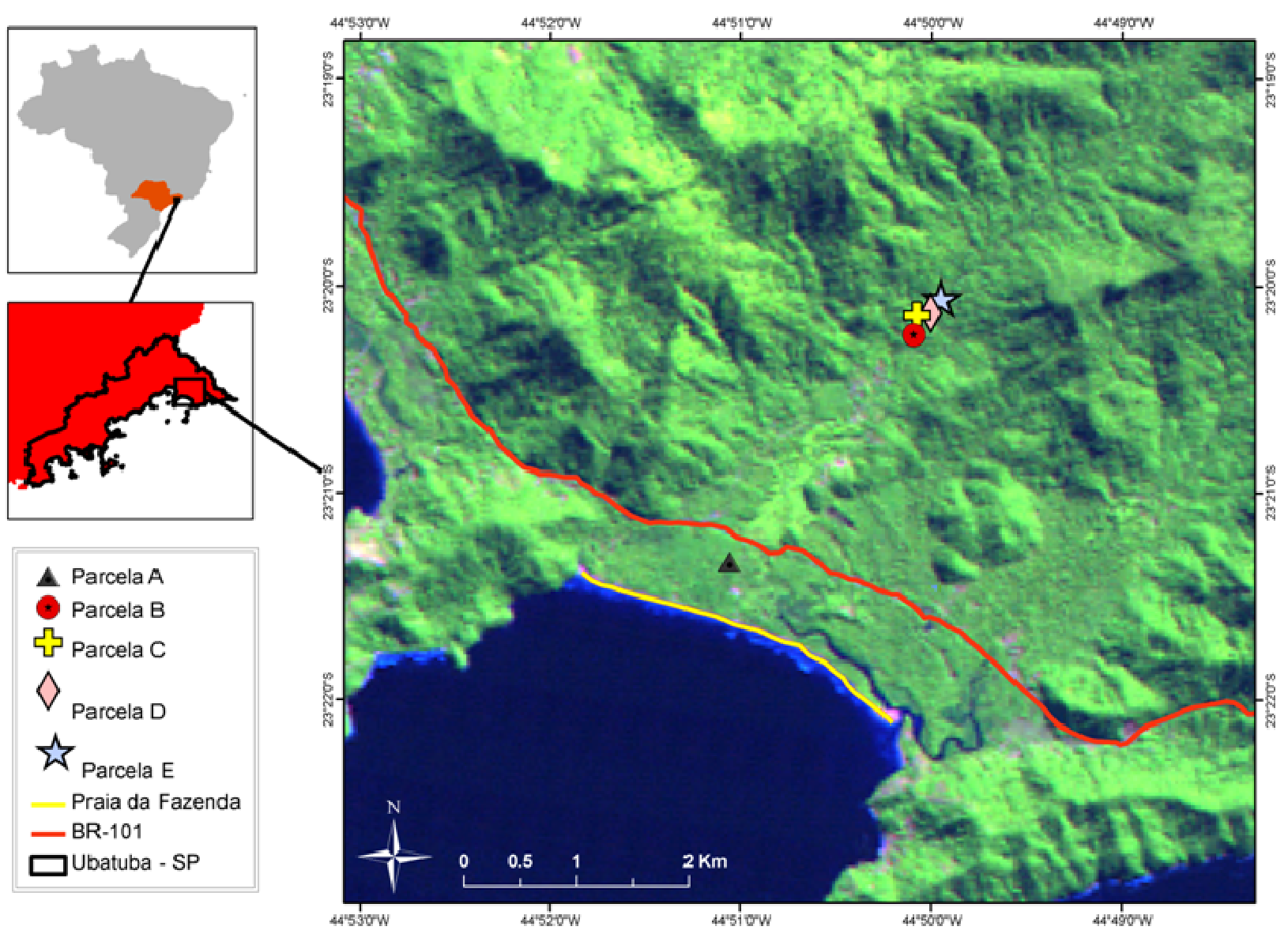

Figura 1 - Localização das parcelas permanentes na floresta tropical Atlântica, Ubatuba, SP. Fonte: Limite municipal e nacional - IBGE, Imagem: Landsat 5 TM, 07/2007

\subsection{Clima}

A precipitação média anual de Ubatuba no período entre 1961 e 1990 foi de 2624 $\mathrm{mm}$, com temperatura média máxima de $24,7^{\circ} \mathrm{C}$ e mínima igual a $17,6^{\circ} \mathrm{C}$ (PEDRONI, 2001). De 1993 até 2008, a precipitação média anual foi igual a $2475 \mathrm{~mm}$ e a temperatura média igual a $23,0^{\circ} \mathrm{C}$ (CIIAGRO). Os maiores índices pluviométricos 
ocorrem no verão, durante os meses de dezembro a fevereiro (Figura 2). Durante o inverno a pluviosidade é menor, nos meses de maio a agosto (Figura 2).

\section{3-2008}

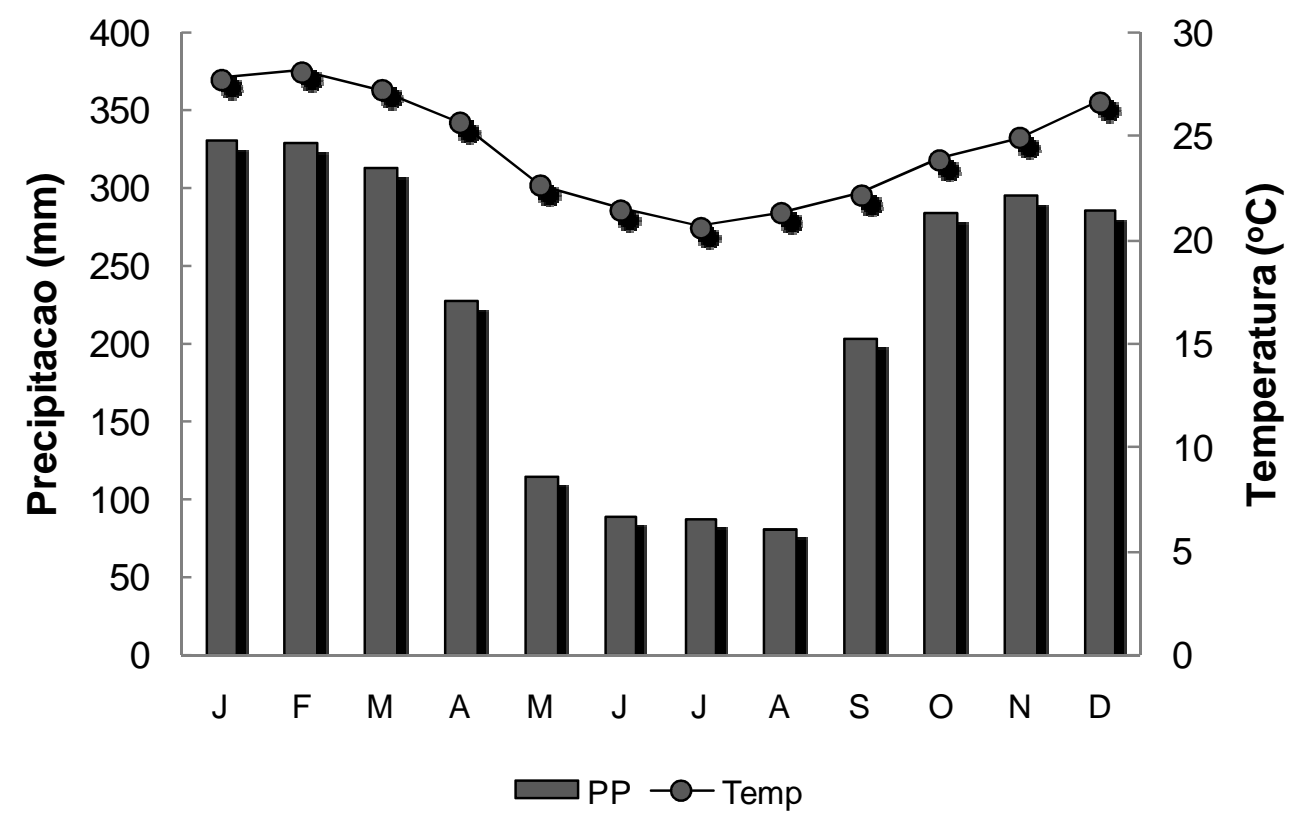

Figura 2 - Precipitação e temperatura de 1993 a 2008 no município de Ubatuba, SP. Fonte: CIIAGRO (http://www.ciiagro.sp.gov.br/ciiagroonline/)

\section{Período de amostragem - clima}

Uma análise histórica climatológica do município de Ubatuba (SP) foi realizada devido à influência dos eventos extremos na dinâmica das florestas tropicais (MALHI et al., 2009). Nota-se, no ano de 2001, uma redução significativa da precipitação anual com relação à média histórica. Nesse ano, a temperatura média foi igual a $23,2^{\circ} \mathrm{C}$. A precipitação anual foi igual a $1605 \mathrm{~mm}$ (CIIAGRO).

Durante o intervalo de avaliação deste estudo, o ano de 2006 e 2007, variações expressivas com relação à precipitação e temperatura média não foram observadas. No ano de 2006, a precipitação anual foi igual a $2235 \mathrm{~mm}$ (11\% de variação da média) e a temperatura média igual a 22,8 ${ }^{\circ} \mathrm{C}$ (CIIAGRO). Em 2007, a precipitação anual foi igual a $2118 \mathrm{~mm}$ (16\% de variação da média) e a temperatura média igual 
a $22,8 \stackrel{\circ}{\circ}$. Portanto, os anos que fazem parte do intervalo deste estudo são considerados típicos.

\subsection{Solo}

No contexto do projeto temático "Gradiente funcional", Martins et al. (2009) realizaram amostragens de solo e caracterizaram algumas das parcelas permanentes do projeto com relação aos atributos físicos e químicos do solo. Do total das cinco (5) parcelas envolvidas neste estudo, três (3) foram amostradas e caracterizadas. A Tabela 1 a seguir apresenta as propriedades físico-químicas da camada superficial (0 a $5 \mathrm{~cm}$ ) das parcelas $A$, B e E.

Tabela 1 - Propriedades físico-químicas da camada superficial $(0$ a $5 \mathrm{~cm})$ do solo das parcelas permanentes $\mathrm{A}$, B e $\mathrm{E}$

\begin{tabular}{|c|c|c|c|c|c|c|c|c|c|c|}
\hline Floresta & Parcela & $\mathrm{pH}$ & $\stackrel{P}{\mathbf{P} \cdot \mathbf{k g}^{-1}}$ & $\underset{\text { g.kg }}{K}$ & $\underset{\text { g.kg }}{S}$ & $\underset{\text { g.kg }}{\mathrm{Ca}}$ & $\underset{\mathrm{g} \cdot \mathrm{kg}^{-1}}{\mathrm{Mg}}$ & $\begin{array}{c}\text { SB } \\
\left(\text { mmolc.kg }^{-1}\right)\end{array}$ & $\begin{array}{c}\text { CTC } \\
\left(\mathrm{mmolc}^{-\mathrm{kg}^{-1}}\right)\end{array}$ & V\% \\
\hline Restinga & $A$ & 3,3 & 9,6 & 1,1 & 23,2 & 1,8 & 0,7 & 3,6 & 146,8 & 2,5 \\
\hline \multirow[t]{2}{*}{$\begin{array}{l}\text { Terras } \\
\text { baixas }\end{array}$} & B & 3,4 & 17,7 & 2,1 & 28,5 & 3,9 & 2,5 & 8,5 & 177,5 & 4,8 \\
\hline & $E$ & 3,4 & 15,2 & 2,1 & 32,1 & 2,9 & 1,5 & 6,5 & 159,8 & 4,1 \\
\hline
\end{tabular}

De acordo com Martins et al. (2009), os solos das áreas estudadas do núcleo Picinguaba apresentam baixas concentrações de nutrientes e valores de $\mathrm{pH}$. O solo da parcela A apresenta textura arenosa (cerca de $90 \%$ de areia) e das parcelas B e E argilo-arenosa e franco-argilo-arenosa respectivamente. Ainda, em ambas as parcelas observam-se baixos valores de saturação de bases (V\%), o que sugere altos teores de alumínio e hidrogênio ocupando as cargas da CTC (capacidade de carga catiônica). No geral, apesar da notada diferença entre as áreas de estudo nos valores de SB (soma de bases), CTC e V\%, as áreas apresentam solos ácidos e pobres em nutrientes. É possível concluir que são pouco férteis. 


\subsection{Breve histórico de ocupação}

A colonização do Brasil foi iniciada pela costa há aproximadamente 500 anos atrás, em terras cobertas por exuberantes florestas tropicais conhecidas atualmente como floresta Atlântica (DEAN, 1995). Atualmente, 100 milhões de Brasileiros vivem em mais de 3000 cidades construídas em terras onde anteriormente eram cobertas por esta floresta (SOS MATA ATLANTICA, 1999). A floresta Atlântica foi desmatada principalmente para o uso de madeira em toras, lenha, carvão, agricultura, pastagem e construção de cidades (MORELLATO; HADDAD, 2000). Essa ocupação desordenada resultou em vários remanescentes fragmentados com elevada pressão humana.

No núcleo Picinguaba do PESM, a ocupação ocorre desde o final do século XIX. Nessa época, o sertão da Fazenda possuía um engenho de açúcar e um moinho de fubá e a produção era escoada pelo rio da Fazenda e a Trilha do Corisco que dá acesso a cidade de Paraty-RJ (SÃO PAULO, 1998). Atualmente existem posses de moradia e roçados de uma população tradicional no Sertão da Fazenda. A Trilha do Corisco é utilizada somente para turismo. De acordo com Alves (2000), o histórico de perturbação humana na floresta onde se localizam as parcelas B, C, D e E não é conhecido com detalhes. Sabe-se que a comunidade tradicional costumava extrair algumas árvores para a construção de canoas e moradias. Ainda, não há registros de corte raso da floresta nesse local para a roça. A exploração ilícita de palmito (Euterpe edulis) ocorre no local há alguns anos.

A praia da Fazenda possui remanescentes de vegetação natural em boas condições, poucas casas e pouca visitação quando comparado com outras praias ao redor (TALORA; MAGRO; SCHILLING, 2007). Aparentemente, não foram observadas entradas de visitantes no local onde a parcela foi instalada. 


\subsection{Descrição da vegetação}

\section{Floresta de Restinga}

As florestas das planícies costeiras são formações edáficas que se relacionam intimamente com a natureza dos substratos em que ocorrem (RIZZINI, 1979). Por isso, como as condições geomorfológicas são muito variáveis nesse ambiente, encontra-se uma vegetação bastante diversificada (RIZZINI, 1979). Segundo Veloso e Klein (1961), os fatores que determinam as variações florísticas e estruturais dessas formações florestais da planície litorânea são: tipo de solo, disponibilidade de nutrientes, condições de drenagem e salinidade, além de ventos e abrasividade causada pelas areias.

De acordo com Assis (1999), esse ambiente diversificado tem sido objeto de muitos estudos de descrição e classificação da vegetação. As florestas de restinga, como são comumente chamadas, recebem uma série de outras denominações tais como "Mata de Myrtaceae", "Floresta periodicamente inundada" (PEREIRA ${ }^{1}, 1990$ apud ASSIS, 1999), "Formação de Mata de Restinga" (HENRIQUES, 1986), "Matas Arenosas" (WAECHTER², 1985 apud ASSIS, 1999).

Apresentam um regime peculiar, de inundação sazonal, sendo que em determinados períodos ano, os solos permanecem alagados devido à superficialidade do lençol freático (SCARANO, 2002). Ainda, são conhecidas por possuírem substratos arenosos, pobres e com baixa disponibilidade de nutrientes (SCARANO, 2002). Scaranello et. al. (2009, dados não publicados) notaram diferença significativa entre a altura do dossel desse tipo de formação florestal, em relação as outras fisionomias de FOD Atlântica que ocorrem ao longo do gradiente altitudinal da Serra do Mar. Provavelmente, as características peculiares citadas acima desse tipo de floresta podem determinar esses padrões de estrutura.

Assis (1999) identificou algumas características marcantes com relação a composição florística de um trecho de Floresta de Restinga amostrado próximo a área deste estudo. De acordo com o autor, foram encontradas 24 famílias, 40

\footnotetext{
${ }^{1}$ PEREIRA OJ. Caracterização fitofisionômica da restinga de Setiba-guarapari, Espírito Santo. In: Simpósio de ecossistemas da costa Sul e Sudoeste Brasileira. Águas de Lindóia, SP. Anais, ACIESP, v.71, n.3. p. 207-19. 1990.

${ }^{2}$ WAECHTER JL. Aspectos ecológicos da vegetação de restinga no Rio grande do Sul, Brasil. Comun. Mus. Ci. PUCRS, Série Bot, v.33, p.49-68. 1985.
} 
gêneros e 40 espécies na formação denominada de cordões litorâneos. Ainda, verificou que 2 espécies sobressaíram-se quanto ao índice de valor de importância (IVI): Pera glabrata por ser a mais abundante e Jacaranda puberula pelo maior porte médio dos indivíduos.

\section{Floresta de Terras Baixas}

A vegetação de terras baixas ocorre, segundo a classificação de Veloso, Rangel e Lima (1991), de 0 a $50 \mathrm{~m}$ de altitude em relação ao nível do mar. No sopé da Serra do Mar, próximo a área deste estudo, a floresta de terras baixas possui famílias típicas da Mata Atlântica do sudoeste do Brasil: Myrtaceae, Rubiaceae, Fabaceae e Lauraceae (SANCHEZ et al., 1999). A diversidade específica é alta e cerca de $32 \%$ das 117 espécies arbóreas com o diâmetro $>6 \mathrm{~cm}$ em um trecho de 0,4 ha são endêmicas da Mata Atlântica (SANCHEZ, 1994). Foi caracterizada como pouco perturbada por Sanchez et al. (1999), apesar do efeito "clareira" ocasionado pela margem do rio. Das $117 \mathrm{spp}$ identificadas, 8,3\% foram pioneiras, 33,3\% secundárias iniciais, 49,2\% secundárias tardias, e 9,2\% não foram classificadas.

A vegetação é densa e o sub-bosque pouco iluminado (ALVES, 2000). Apresenta árvores do dossel de grande porte (ALVES, 2000) e emergentes que podem chegar a quase $30 \mathrm{~m}$ de altura (SCARANELLO et al., 2009, dados não publicados).

\subsection{Amostragem}

De 2006 a 2007, 14 parcelas permanentes de um (1) hectare do projeto temático "Gradiente Funcional" foram estabelecidas (JOLY et al., 2008) proporcionalmente em cada tipo de floresta do gradiente altitudinal da Serra do Mar (4 parcelas por cada tipologia), uma em floresta de restinga próxima ao mar e outra em floresta de terras baixas explorada. Para este estudo, foram selecionadas quatro (4) parcelas permanentes em floresta de terras baixas e uma (1) em floresta de restinga. As parcelas permanentes foram divididas em sub-parcelas de $100 \mathrm{~m}^{2}(10 \times 10 \mathrm{~m})$. $\mathrm{O}$ tamanho de parcela permanente adotado nesse projeto é adequado e tem sido 
usado freqüentemente para amostragem de inventários florestais envolvendo estudos de dinâmica florestal (PHILLIPS et al., 1998).

As parcelas permanentes foram delimitadas por uma equipe de topógrafos especializados, onde a área de projeção de cada parcela foi determinada com 0 auxílio de GPS geodésico e estação total. Esse procedimento foi muito importante para evitar erros na área das parcelas, e posteriormente nos cálculos das médias. A delimitação foi feita com material permanente e de longa duração (JOLY et al., 2008).

Em cada parcela todos os indivíduos com DAP acima de 4,8 cm (circunferência a altura do peito - CAP $\geq 15 \mathrm{~cm}$ ) foram marcados com placas de alumínio, mapeados e mensurados (CAP, altura total, índice de iluminação de copa além de outras características). As placas de alumínio foram implantadas a 1,60 m do nível do solo. O mapeamento foi realizado com trena de $10 \mathrm{~m}$, e precisão de $10 \mathrm{~cm}$. A circunferência a altura do peito de cada indivíduo foi medido com o auxilio de uma fita graduada (precisão de $1 \mathrm{~mm})$. A medida foi realizada a altura do peito $(1,30 \mathrm{~m})$ para os indivíduos sem irregularidades no tronco a essa altura. Com o objetivo de evitar erros de medida, a localização do ponto de medição das árvores com irregularidades ou protuberâncias foi modificada para a distância mais próxima acima de 1,30 $\mathrm{m}$. Desse modo, a altura do ponto de medida modificado sempre foi anotada. Os indivíduos que apresentaram raízes tabulares ou irregularidades que ultrapassavam a altura dos integrantes da equipe foram medidos com o auxílio de uma escada de alumínio de sete (7) metros. Novamente, a altura do ponto de medição era anotada com cautela e o ponto de medida era marcado com uma placa de plástico branca. Bromélias e musgos presentes no ponto de medida eram afastados antes da medida da circunferência. Ainda, a fita métrica era passada por baixo quando lianas eram observadas no ponto de medição. A altura total foi estimada visualmente, a priori. Posteriormente, Scaranello et al. (2009, dados não publicados) ajustou modelos de relação diâmetro-altura e, a partir daí, as alturas foram estimadas com modelos regionais para cada tipo de floresta.

A disponibilidade de luz vertical foi avaliada através do índice de iluminação de copa (IC) proposto por Clark \& Clark (1992). Esse índice foi determinado através da estimativa visual da proporção da copa da árvore que recebe luz vinda lateral e/ou 
verticalmente. O índice categórico varia de 1 (copa totalmente sombreada, ausência de luz direta) a 5 (copa completamente exposta à luz) (CLARK; CLARK, 1992). Devido ao fato das árvores e palmeiras com DAP $>4,8 \mathrm{~cm}$ raramente apresentarem copa com IC menor que 3 nesse sistema de categorização, apenas as classes 3, 4 e 5 foram utilizadas neste estudo. Por fim, maiores detalhes das observações e outras variáveis coletadas nas parcelas permanentes se encontram em Joly et al. (2008).

Aproximadamente dois (2) anos após a implantação e medição das parcelas permanentes da floresta de restinga e de terras baixas (Tabela 2), foi realizado o segundo inventário em cada parcela permanente. Todos os indivíduos marcados com placas de alumínio foram novamente mensurados (CAP, índice de iluminação de copa além de outras características). Em todas as re-medições das sub-parcelas, uma varredura cuidadosa foi feita para encontrar os novos indivíduos (recrutas) que excederam o diâmetro mínimo de inclusão. A mortalidade dos indivíduos foi confirmada somente quando os troncos não apresentaram copa, rebrotas e sinais de deterioração aparente ao longo de todo o fuste. Por fim, os indivíduos desaparecidos só foram anotados após excessivas buscas.

Tabela 2 - Data do início dos inventários e intervalo de amostragem das parcelas permanentes na floresta de restinga e de terras baixas

\begin{tabular}{ccccc}
\hline Floresta & Parcela & 10 inv. & 20 inv. & Intervalo (anos) \\
\hline Restinga & $\mathrm{A}$ & $11 / 2005$ & $01 / 2008$ & 2,2 \\
Terras Baixas & $\mathrm{B}$ & $12 / 2005$ & $02 / 2008$ & 2,2 \\
& $\mathrm{C}$ & $02 / 2006$ & $02 / 2008$ & 2,1 \\
& $\mathrm{D}$ & $03 / 2006$ & $03 / 2008$ & 2,0 \\
& $\mathrm{E}$ & $04 / 2006$ & $04 / 2008$ & 2,0 \\
\hline \hline
\end{tabular}

\subsection{Processamento dos dados}

Após a coleta de dados em campo, a próxima etapa foi realizar o refinamento dos dados para iniciar os cálculos das taxas de incremento em diâmetro a altura do peito (DAP) e variação da biomassa acima do solo. A metodologia de processamento utilizada neste estudo, foi reunida e consolidada tomando como referência as abordagens utilizadas em Feeley et al. (2007) e Lewis et al. (2009). A seguir, serão 
descritos todos os passos utilizados para filtragem dos dados utilizados neste estudo:

$1^{\circ}$ etapa. Remoção das pteridófitas do banco de dados devido aos problemas relacionados ao crescimento cambial, além de representarem baixa densidade de indivíduos e representarem menos de $1 \%$ da biomassa viva acima do solo (Alves et al., dados não publicados).

2ำ etapa. Indivíduos que, por algum motivo, não apresentaram medida de diâmetro no $1^{\circ}$ inventário e foram identificados como mortos no $2^{\circ}$ inventário. Neste caso, 0 cálculo do DAP no $1^{\circ}$ inventário foi realizado da seguinte forma: DAP $\mathrm{t} 1$ novo valor = DAP t2 - taxa de incremento médio da classe de DAP.

$3^{\circ}$ etapa. Tratamento dos valores extremos e erros de medidas. Nesta etapa, foram filtrados somente os erros de medidas, ou seja, ausência de dados identificada e erros devido a anotação. Para a correção do DAP no $1^{\circ}$ inventário, foi utilizada a seguinte formula: DAP t1 novo valor = DAP t2 - taxa de incremento médio da classe de DAP. Adicionalmente, tanto para a $3^{\circ}$ etapa quanto para a $2^{\circ}$ a média da taxa de incremento por classe de DAP foi calculada excluindo todos os valores extremos.

4ํe etapa. Recrutamento de indivíduos "fantasmas", ou seja, de indivíduos que foram encontrados no $2^{\circ}$ inventário com fuste sem placa que não se enquadram como recrutas (DAP muito grande). O valor de referência para esses casos foi o valor máximo da distribuição $(95,7 \%)$ do incremento da primeira classe de DAP utilizada neste estudo $(<10 \mathrm{~cm})$.

5 etapa. Mudanças no ponto de medição que excederam o limite de $20 \mathrm{~cm}$. Nesta etapa, o DAP no $2^{\circ}$ inventário foi calculado da seguinte maneira: DAP $2^{\circ}=$ DAP $1^{\circ}$ inventário + incremento médio da mesma classe de DAP.

6ำ etapa. Tratamento dos valores extremos e erros de medidas, após etapa 3 e correção do ponto de medição (valores extremos ainda identificados). Nesta etapa, foi calculada a distribuição do crescimento em DAP ( $\mathrm{mm}$ ano-1) e excluído valores fora do intervalo de $95 \%$ da distribuição. 


\subsection{Aspectos da dinâmica florestal}

\section{Taxa de incremento diamétrico}

O DAP de cada árvore foi mensurado no estabelecimento das parcelas e no segundo inventário. A fórmula utilizada para o cálculo da taxa média de incremento absoluto do diâmetro do caule, em milímetros, foi a seguinte:

$\mathrm{TI}=(\mathrm{DAP} \mathrm{t} 2-\mathrm{DAP} \mathrm{t} 1) / \Delta \mathrm{t}$

Onde,

TI: Taxa de incremento diamétrico $\left(\mathrm{mm}^{\mathrm{ano}}{ }^{-1}\right)$

DAP t1: diâmetro a 1,30 m medido no 1ํinventário

DAP t2: diâmetro a 1,30 medido no $2^{\circ}$ inventário

$\Delta \mathrm{t}$ : intervalo em anos.

\section{Mortalidade}

A mortalidade foi considerada como o indivíduo morto propriamente dito ou 0 desaparecimento dos indivíduos marcados de uma medida para outra. Existiram quatro diferentes situações relatadas em campo: indivíduo morto em pé, indivíduo morto caído com a placa encontrada, indivíduo morto caído com a placa desaparecida (localizado através das coordenadas) e indivíduo desaparecido. Os indivíduos descritos como morto no primeiro inventário, mas que apresentaram rebrota aparente no segundo inventário foram considerados como vivos (CONDIT; HUBBELL; FOSTER, 1993). A taxa anual de mortalidade foi calculada através do modelo exponencial proposto por Swaine e Lieberman (1987):

$m(\lambda)=100(\ln$ No $-\ln N 1) / t$

Onde:

$\mathrm{m}(\lambda)=$ taxa anual de mortalidade $(\%)$

N0 = número de indivíduos obtido no primeiro censo; 
N1 = número de indivíduos sobreviventes no segundo censo;

$\mathrm{t}=$ tempo em anos;

A partir da taxa de mortalidade calculada através do modelo exponencial, foi calculada a "meia vida" para cada área, ou seja, o tempo que é necessário para uma determinada população perder $50 \%$ de todos seus indivíduos assumindo uma constante probabilidade de mortalidade. A meia vida foi calculada através da seguinte fórmula (LIEBERMAN et al., 1985):

$t(1 / 2)=\ln (2) / \ln (1-(m / 100))$

\section{Recrutamento}

Os indivíduos que atingiram $4,8 \mathrm{~cm}$ de DAP no $2^{\circ}$ inventário foram marcados, mapeados e medido o DAP, o índice de iluminação de copa (IC) e altura total. O recrutamento foi calculado a partir do número de indivíduos que atingiram o DAP de inclusão em relação à densidade de indivíduos vivos do primeiro censo; seguindo a presente equação:

$\mathrm{i}=\{\ln ((\mathrm{No}+\mathrm{I}) / \mathrm{No}) / \mathrm{t}\}{ }^{*} 100$

Onde

I = número de ingressantes no segundo censo.

\section{Reposição "turnover"}

Uma medida de "dinamismo" da floresta foi desenvolvida e proposta por Phillips et al. (1994), calculada em função das taxas de mortalidade e recrutamento. A medida de reposição (turnover) então foi calculada como uma média dessas duas taxas. Utilizando esse valor médio assume-se que a comunidade está próxima ao equilíbrio constante em termos de densidade de indivíduos (PHILLIPS et al., 1994). 


\subsection{Estoque e mudanças na biomassa acima do solo (BAS)}

O estoque de biomassa acima do solo das árvores foi estimado utilizando as equações (4) e (5), desenvolvidas para florestas tropicais úmidas ("moist forests") por Chave et al. (2005) a partir de medidas destrutivas. A equação 4 (Chave et al. (2005): 2-var) utiliza o DAP e a densidade específica da madeira como variáveis independentes e a 5 (Chave et al. (2005): 3-var) DAP, densidade específica da madeira e altura total. A densidade específica da madeira utilizado neste estudo foi proveniente de dados secundários (Alves et al, dados inéditos). A altura total foi obtida a partir dos modelos de diâmetro-altura desenvolvidos para cada tipo de floresta (SCARANELLO et al., dados não publicados). Através da lista de espécies encontrada nas parcelas permanentes deste estudo, valores de densidade média por tipo de floresta foram gerados (Alves et al., dados inéditos). Assim, os valores de densidade utilizados para a estimativa da BAS na floresta de restinga e de terras baixas foram 0,644 e $0,630 \mathrm{~g} \mathrm{~cm}^{-3}$, respectivamente. Para as estimativas da BAS das palmeiras, a equação alométrica (5) desenvolvida por Hughes et al. (1999) foi utilizada. Nesta equação, somente o DAP é utilizado como variável independente para a estimativa de biomassa das palmeiras (HUGHES et al. 1999).

Tipo de Floresta: "Moist Forest " Chave et al. (2005)

BAS $_{\text {est. }}=\rho \times \exp \left(-1,499+2,148 \ln (\right.$ DAP $\left.)+0,207(\ln (\text { DAP }))^{2}-0,0281(\ln (\text { DAP }))^{3}\right)$

BAS $_{\text {est. }}=0,0509 \times \rho \times$ DAP $^{2} \times$ A.T.

Palmeiras - Hughes et al. (1999)

BAS $_{\text {est. }}=\exp \left(\left(\left(5,7236+0,9285 \ln \left(\mathrm{DAP}^{2}\right)\right) \times 1,05001\right) / 10^{3}\right.$

Onde:

BAS $_{\text {est }}=$ biomassa acima do solo em $\mathrm{Kg}$

$\rho=$ densidade específica da madeira $\left(\mathrm{g} \mathrm{cm}^{-3}\right)$

A.T. $=$ altura total $(m)$

A partir das estimativas da BAS das árvores e palmeiras nas parcelas permanentes e as correções de refinamento descritas no item 3.7 deste capítulo, foram efetuados 
os cálculos da variação da BAS. Neste estudo, a mudança líquida na BAS foi considerada como:

M.L.BAS = BAS (incremento) - BAS mortalidade

Onde:

M.L.BAS = mudanças líquida da BAS $\left(\mathrm{Mg} \mathrm{ha}^{-1} \mathrm{ano}^{-1}\right)$

BAS (incremento): acúmulo de BAS dos indivíduos vivos + recrutas ( $\mathrm{Mg} \mathrm{ha}^{-1}$ ano $^{-1}$ )

BAS mortalidade: perdas de BAS pela mortalidade $\left(\mathrm{Mg} \mathrm{ha}^{-1} \mathrm{ano}^{-1}\right)$

\subsection{Análise dos dados}

Neste estudo, a opção de não transformar os dados foi adotada. Após os testes dos requisitos mínimos para a utilização de estatística paramétrica, tais como a distribuição normal dos dados e homocedasticidade, foi tomada a decisão de utilizar a estatística paramétrica ou não paramétrica. Com isso, algumas variáveis foram testadas utilizando estatística paramétrica e outras não-paramétrica, como descrito a seguir. Todos os testes foram realizados utilizando o software Sigma Plot ${ }^{\circledR}$ v. 11.

\section{Estrutura}

As diferenças na distribuição dos indivíduos nas classes de tamanho entre as áreas e entre os anos de estudo foram testadas com o teste de Kolmogorov-Smirnov. As diferenças na densidade de indivíduos e área basal entre as áreas ou entre as formas de vidas foram testadas através da utilização do teste-t. O estoque de BAS foi comparado entre as áreas através do teste de Mann-Withney.

Apesar de não ser o tamanho adequado para cálculos de estoque de BAS, a parcela permanente da floresta de restinga foi subdividida em 4 unidades amostrais de 0,25 hectare para comparar os dados de estrutura florestal. Desse modo, além do estoque de BAS, a densidade total de indivíduos e área basal foram comparadas utilizando as quatro unidades amostrais da parcela $A$ e as parcelas $B, C, D$ e E. As 
médias provenientes das unidades amostrais sempre virão acompanhadas do valor referente a unidade amostral de um (1) hectare da floresta de restinga no texto.

\section{Taxa de incremento diamétrico}

As diferenças nas taxas de incremento diamétrico entre as formas de vida (palmeira e árvores) e áreas (restinga e terras baixas) foram testadas através do teste de comparação de dois grupos de Mann-Withney. As diferenças nas taxas de crescimento entre as classes de diâmetro foram testadas através da análise de variância de Kruskall-Wallis e posterior teste de comparações múltiplas de Dunn (ZAR, 1996). Ainda, para avaliar a relação entre as taxas de crescimento e o índice de iluminação de copa (IC) foi realizado o teste do coeficiente de correlação de Spearman (ZAR, 1996).

Para cada tipo de floresta, a máxima longevidade foi estimada como descrito a seguir: 1) o incremento diamétrico foi calculado como descrito acima após o tratamento dos dados; 2) três estimativas de incremento anual foram geradas para cada área, baseadas respectivamente na mediana, quartil e decil superior; 3) as três estimativas separadas de longevidade foram geradas pela divisão do DAP da maior árvore encontrada pelas taxas de incremento geradas (mediana, quartil e decil superior). Finalmente, foi calculada a mediana dessas três (3) medidas para fornecer uma única estimativa da longevidade de cada tipo de floresta (LAURANCE et al., 2004b). Esse procedimento foi adotado para cada classe de DAP, portanto, para as classes iniciais $(<10 \mathrm{~cm}, 10-30 \mathrm{~cm}, 30-50 \mathrm{~cm})$ os diâmetros de referência adotados foram os superiores $(9,9,29,9$ e 49,9 cm). Para a última classe de DAP $(\geq 50 \mathrm{~cm})$, a maior árvore de cada área foi adotada como referência. Essa abordagem de medida de longevidade da floresta foi adotada devido ao fato do crescimento ser relativo, principalmente em função das classes de DAP. Ainda, a abordagem adotada e descrita acima foi escolhida porque o simples fato de utilizar o crescimento médio por classe de DAP para estimar a longevidade da floresta pode resultar em interpretações incorretas (SWAINE; HALL; ALEXANDER, 1987). 


\section{Mortalidade e recrutamento}

As taxas de mortalidade foram avaliadas e comparadas através das médias e dos intervalos de confiança de 95 \% (CONDIT; HUBBELL; FOSTER, 1995) gerados através de probabilidade binomiais (ZAR, 1996). Desse modo, os intervalos de confiança foram transformados para taxas de mortalidade segundo a equação 2. 0 mesmo procedimento foi realizado para as taxas de recrutamento. Com isso, as diferenças das taxas de mortalidade e recrutamento entre as classes de diâmetro, índice de iluminação de copa, formas de vida e também entre as áreas foram comparadas segundo a metodologia descrita acima.

Como descrito anteriormente, existiram quatro diferentes tipos de mortalidade registrada neste estudo. A partir daí, foram selecionadas três (3) classes de mortalidade para a análise: morta em pé, morta caída e morta desaparecida. Para analisar o padrão espacial da mortalidade, além disso, entre as classes de mortalidade, gerou-se um mapa de agrupamento de mortas em pé e morta caída para ambas as áreas. 


\section{RESULTADOS}

\subsection{Estrutura florestal}

Floresta de restinga vs. terras baixas

No primeiro inventário deste estudo (2006), a densidade total (árvores e palmeiras) de indivíduos com o DAP $\geq 4,8 \mathrm{~cm}$ foi significativamente maior na floresta de restinga que na floresta de terras baixas (test-t: 3,884, $P=0,00$; Tabela 3). A densidade total de indivíduos com DAP $\geq 4,8 \mathrm{~cm}$ na floresta de restinga foi igual a 1635 indivíduos.ha $^{-1}\left(1601 \pm 178\right.$ indivíduos.ha $\left.^{-1}\right)$ e na floresta de terras baixas a densidade média foi igual a $1221 \pm 80$ indivíduos.ha ${ }^{-1}$. Por outro lado, a densidade total de indivíduos com DAP $\geq 10 \mathrm{~cm}$ não apresentou diferenças significativas entre as áreas (test-t: 2,334, P=0,06; Tabela 3).

Tabela 3 - Densidade total (árvores e palmeiras) dos indivíduos com DAP $\geq 4,8 \mathrm{~cm}$ e $10 \mathrm{~cm}$ em ambos os inventários deste estudo (2006 e 2008), na floresta de restinga e terras baixas

\begin{tabular}{|c|c|c|c|}
\hline & & \multicolumn{2}{|c|}{ Densidade (indivíduos ha ${ }^{-1}$ ) } \\
\hline & & 2006 & 2008 \\
\hline \multirow[t]{2}{*}{ Floresta de restinga ( 1 ha) } & $\geq 4,8 \mathrm{~cm}$ & 1635 & 1596 \\
\hline & $\geq 10 \mathrm{~cm}$ & 778 & 763 \\
\hline \multirow[t]{2}{*}{ Floresta de restinga $(0,25 \mathrm{ha})$} & $\geq 4,8 \mathrm{~cm}$ & $1601 \pm 178^{\mathrm{a}}$ & $1576 \pm 194^{\mathrm{a}}$ \\
\hline & $\geq 10 \mathrm{~cm}$ & $758 \pm 133$ & $751 \pm 125$ \\
\hline \multirow[t]{3}{*}{ Floresta de terras baixas } & $\geq 4,8 \mathrm{~cm}$ & $1221 \pm 80^{\mathrm{b}}$ & $1198 \pm 85^{\mathrm{b}}$ \\
\hline & $\geq 10 \mathrm{~cm}$ & $600 \pm 29$ & $601 \pm 23$ \\
\hline & & $\mathrm{P}<0,05$ & $\mathrm{P}<0,05$ \\
\hline
\end{tabular}

Aproximadamente 2 anos após o primeiro inventário, a densidade total de indivíduos com o DAP $\geq 4,8 \mathrm{~cm}$ variou pouco em ambas as áreas (Tabela 3). Observou-se uma diminuição do número de indivíduos durante o período de amostragem na floresta de restinga e de terras baixas. Para os indivíduos com o DAP $>10 \mathrm{~cm}$, o mesmo padrão foi observado para a floresta de restinga, porém a densidade média total na floresta de terras baixas aumentou um (1) indivíduo de um inventário para o outro (Tabela 3). 
Apesar de o DAP médio ser um pouco superior (Apêndice 1, Tabela 1) na floresta de terras baixas, a mediana do DAP foi muito semelhante em ambas as áreas (Tabela 4). O maior DAP mensurado foi na floresta de terras baixas, igual a $115,6 \mathrm{~cm} . \mathrm{Na}$ floresta de restinga o DAP máximo foi igual a $76,4 \mathrm{~cm}$. Após o teste de distribuição diamétrica de Komolgorov-Smirnov, diferenças significativas foram encontradas entre as duas florestas. As diferenças foram observadas entre a parcela $A$ (restinga) e todas as quatro parcelas da floresta de terras baixas (Apêndice 1, Tabela 1). A mediana do DAP, média, valor máximo e mínimo não variou de um inventário para o outro e diferenças significativas também não foram encontradas entre a distribuição de DAP de um inventário para o outro em ambas as áreas (apêndice 1, Tabela 1).

Tabela 4 - Resumo do DAP $(\mathrm{cm})$ e da altura total $(\mathrm{m})$ na floresta de restinga e de terras baixas

\begin{tabular}{|c|c|c|c|c|c|}
\hline & \multicolumn{2}{|c|}{ DAP $(\mathbf{c m})$} & \multicolumn{3}{|c|}{ Altura total (m) } \\
\hline & $\max$ & mediana & $\min$ & $\max$ & mediana \\
\hline $\begin{array}{l}\text { Floresta de } \\
\quad \text { restinga }\end{array}$ & 76,4 & $10,3^{\mathrm{a}}$ & 5,8 & 18,4 & 10,2 \\
\hline $\begin{array}{l}\text { Floresta de terras } \\
\text { baixas }\end{array}$ & 115,6 & $\begin{array}{c}10,4^{\mathrm{b}} \\
\mathrm{P}<0,05\end{array}$ & 6,1 & 29,7 & 10,0 \\
\hline
\end{tabular}

A altura total estimada também revelou diferenças na estrutura entre as florestas estudadas. A floresta de terras baixas apresentou a maior altura estimada e conseqüentemente as maiores árvores emergentes (29,7 m; parcela B). Na floresta de restinga a maior altura estimada foi de 18,4 m. A altura mínima estimada também foi superior na floresta de terras baixas (Tabela 4). A mediana, valor máximo e mínimo da altura total não apresentou variações notáveis de um inventário para o outro.

Com relação a área basal, considerando os indivíduos com o DAP $\geq 4,8 \mathrm{~cm}$, diferenças significativas não foram observadas (test-t:-0,435, P=0,68) entre os dois tipos de floresta (Tabela 5). Após dois anos, foi observada uma diminuição da área basal média na floresta de terras baixas (Tabela 5). Na floresta de restinga a área basal permaneceu constante (Tabela 5). Para os indivíduos com o DAP $\geq 10 \mathrm{~cm}$ 
diferenças significativas também não foram encontradas (test-t:-0,734, P=0,49) na área basal entre as áreas.

Tabela 5 - Área basal total $\left(\mathrm{m}^{2} \mathrm{ha}^{-1}\right)$ dos indivíduos com DAP $\geq 4,8$ e $10 \mathrm{~cm}$ nos dois inventários, na floresta de restinga e de terras baixas

\begin{tabular}{|c|c|c|c|}
\hline & & \multicolumn{2}{|c|}{ Área basal $\left(\mathrm{m}^{2} \mathrm{ha}^{-1}\right)$} \\
\hline & & 2006 & 2008 \\
\hline \multirow[t]{2}{*}{ Floresta de restinga (1 ha) } & $\geq 4,8 \mathrm{~cm}$ & 28,3 & 28,3 \\
\hline & $\geq 10 \mathrm{~cm}$ & 24,8 & 24,9 \\
\hline \multirow[t]{2}{*}{ Floresta de restinga $(0,25$ ha $)$} & $\geq 4,8 \mathrm{~cm}$ & $28,3 \pm 3,6$ & $28,3 \pm 3,2$ \\
\hline & $\geq 10 \mathrm{~cm}$ & $24,8 \pm 4,0$ & $24,9 \pm 3,6$ \\
\hline \multirow[t]{3}{*}{ Floresta de terras baixas } & $\geq 4,8 \mathrm{~cm}$ & $29,2 \pm 2,1$ & $28,8 \pm 1,9$ \\
\hline & $\geq 10 \mathrm{~cm}$ & $26,5 \pm 2,1$ & $26,5 \pm 1,8$ \\
\hline & & $\mathrm{P}>0,05$ & $\mathrm{P}>0,05$ \\
\hline
\end{tabular}

Utilizando a equação que estima a BAS a partir do DAP e densidade específica desenvolvida por Chave et al. (2005), diferenças significativas não foram encontradas no estoque (Tabela 6) entre as áreas considerando indivíduos com $\mathrm{DAP} \geq 4,8 \mathrm{~cm}$ e $10 \mathrm{~cm}$ (Mann-Witney US: 2,00, $\mathrm{P}=0,11$ ). Entretanto, quando a variável "altura total" foi inserida nas estimativas de BAS diferenças significativas foram encontradas (Mann-Witney US: 0,00, $P=0,03$ ). Considerando os indivíduos com o DAP $\geq 4,8 \mathrm{~cm}$, a BAS foi significativamente superior na floresta de terras baixas do que na floresta de restinga (Tabela 6). Para o estoque dos indivíduos com o DAP $\geq 10 \mathrm{~cm}$ o mesmo padrão foi observado (M-W US: 0,00, P=0,03). 
Tabela 6 - Mediana, valor mínimo e máximo do estoque de BAS para indivíduos com DAP $\geq 4,8$ e 10 $\mathrm{cm}$, na floresta de restinga e de terras baixas. $O$ valor referente à parcela de 1 -ha de restinga representa o valor referente ao estoque de somente uma unidade amostral (1 ha). 2-var: estimativa de BAS através da equação 4. 3-var: estimativa de BAS através da equação 5

\begin{tabular}{|c|c|c|c|c|c|c|c|}
\hline & & \multicolumn{6}{|c|}{ Estoque de BAS $\left(\mathrm{Mg} \mathrm{ha}^{-1}\right)$} \\
\hline & & \multicolumn{3}{|c|}{ 2-var. } & \multicolumn{3}{|c|}{ 3-var. } \\
\hline & & $\min$ & $\max$ & mediana & $\min$ & $\max$ & mediana \\
\hline \multirow[t]{2}{*}{ Floresta de restinga (1 ha) } & $\geq 4,8 \mathrm{~cm}$ & - & - & 261,9 & - & - & 166,3 \\
\hline & $\geq 10 \mathrm{~cm}$ & - & - & 247,2 & - & - & 154,7 \\
\hline \multirow[t]{2}{*}{ Floresta de restinga $(0,25 \mathrm{ha})$} & $\geq 4,8 \mathrm{~cm}$ & 222,1 & 300,4 & $262,4^{\mathrm{a}}$ & 145,6 & 190,3 & $165,8^{\mathrm{a}}$ \\
\hline & $\geq 10 \mathrm{~cm}$ & 201,7 & 287,7 & $249,8^{\mathrm{b}}$ & 132,0 & 181,0 & $154,3^{\mathrm{c}}$ \\
\hline \multirow[t]{3}{*}{ Floresta de terras baixas } & $\geq 4,8 \mathrm{~cm}$ & 290,7 & 336,4 & $314,1^{\mathrm{a}}$ & 197,8 & 223,8 & $212,3^{\mathrm{b}}$ \\
\hline & $\geq 10 \mathrm{~cm}$ & 280,8 & 326,0 & $303,7^{\mathrm{b}}$ & 190,0 & 215,7 & $204,0^{\mathrm{d}}$ \\
\hline & & & & $\mathrm{P}>0,05$ & & & $\mathrm{P}<0,05$ \\
\hline
\end{tabular}

Árvores vs. Palmeiras

No primeiro inventário deste estudo, a densidade de palmeiras com $D A P \geq 4,8 \mathrm{~cm}$ na floresta de restinga foi igual a 168 indivíduos ha ${ }^{-1}\left(167 \pm 49\right.$ indivíduos ha $\left.{ }^{-1}\right)$. A floresta de terras baixas apresentou densidade média de palmeiras $\geq 4,8 \mathrm{~cm}$ de DAP igual a $182 \pm 50$ indivíduos ha $^{-1}$. Quando o DAP de inclusão é modificado para $10 \mathrm{~cm}$, a densidade de palmeiras decresce significativamente (Tabela 7).

Apenas a densidade de palmeiras com DAP $\geq 10 \mathrm{~cm}$ na floresta de terras baixas aumentou de um inventário para o outro passando de $57 \pm 21$ indivíduos ha ${ }^{-1}$ para $64 \pm 18$ indivíduos ha $^{-1}$. Seguindo o mesmo padrão da densidade, a área basal, o estoque de biomassa, a mediana do DAP, a mediana da altura total e a altura máxima estimada das palmeiras também foram menores quando comparadas com as árvores (apêndice 1, Tabela 1). 
Tabela 7 - Densidade média de árvores e palmeiras e desvio padrão dos indivíduos com DAP $\geq 4,8$ e $10 \mathrm{~cm}$, em ambos os inventários e áreas de estudo

\begin{tabular}{|c|c|c|c|c|c|}
\hline & & \multicolumn{4}{|c|}{ Densidade (indivíduos ha ${ }^{-1}$ ) } \\
\hline & & \multicolumn{2}{|c|}{2006} & \multicolumn{2}{|c|}{2008} \\
\hline & & árvores & palmeiras & árvores & palmeiras \\
\hline \multirow[t]{2}{*}{ Floresta de restinga (1 ha) } & $\geq 4,8 \mathrm{~cm}$ & 1467 & 168 & 1450 & 146 \\
\hline & $\geq 10 \mathrm{~cm}$ & 766 & 12 & 753 & 10 \\
\hline \multirow[t]{2}{*}{ Floresta de restinga $(0,25 \mathrm{ha})$} & $\geq 4,8 \mathrm{~cm}$ & $1434 \pm 225$ & $167 \pm 49$ & $1429 \pm 224$ & $147 \pm 47$ \\
\hline & $\geq 10 \mathrm{~cm}$ & $746 \pm 49$ & $12 \pm 3$ & $741 \pm 121$ & $10 \pm 5$ \\
\hline \multirow[t]{2}{*}{ Floresta de terras baixas } & $\geq 4,8 \mathrm{~cm}$ & $1039 \pm 30$ & $182 \pm 50$ & $1022 \pm 32$ & $177 \pm 54$ \\
\hline & $\geq 10 \mathrm{~cm}$ & $543 \pm 14$ & $57 \pm 21$ & $537 \pm 10$ & $64 \pm 18$ \\
\hline
\end{tabular}

\section{Classes de DAP}

A densidade total de indivíduos, em ambas as áreas e inventários, decresceram com o aumento da classe de DAP (Tabela 8). A distribuição dos indivíduos nas diferentes classes de DAP no primeiro inventário encontra-se na Figura 3. Na floresta de restinga a classe $<10 \mathrm{~cm}$, de $10-30 \mathrm{~cm}$, de $30-50 \mathrm{~cm} \mathrm{e} \geq 50 \mathrm{~cm}$ contribui com $52,4 \%, 42,6 \%, 4,7 \%$ e $0,3 \%$ do total dos indivíduos de árvores e palmeiras. $\mathrm{Na}$ floresta de terras baixas a distribuição foi semelhante: 50,9\%, 41,3\%, 6,0\% e 1,8\%.

$\mathrm{Na}$ floresta de restinga, apenas a classe de 30-50 cm apresentou acréscimo de indivíduos na população de um inventário para o outro (Tabela 8). As demais classes decresceram de tamanho, menos a classe $\geq 50 \mathrm{~cm}$ que permaneceu constante (Tabela 8). Na floresta de terras baixas as classes $10-30 \mathrm{~cm}$ e $\geq 50 \mathrm{~cm}$ apresentaram aumento de tamanho na população (Tabela 8). As demais classes decresceram (Tabela 8).

Em ambas as áreas, a classe de DAP que apresentou a maior área basal foi a classe 10-30 cm (apêndice 1, Tabela 4). Mesmo não apresentando diferenças significativas entre a área basal total, como dito acima, diferenças significativas foram encontradas na área basal total da classe $\geq 50$ entre as áreas (apêndice 1, Tabela 3). 
Apesar de contribuir pouco (1,8\%) com a densidade total de indivíduos, a classe $\geq$ $50 \mathrm{~cm}$ estoca 33,7\% (Chave et al. (2005), 3 var.) do total da BAS na floresta de terras baixas (Tabela 9). Por outro lado, na floresta de restinga a classe que apresentou maior estoque de BVAS foi a 10-30 cm (Tabela 9). Essa classe contribuiu com $42,6 \%$ da densidade total de indivíduos e $54,7 \%$ do total de estoque de BAS (Chave et al. (2005), 3 var.). A maior classe de DAP na floresta de restinga estocou apenas $8,6 \%$ da BAS total.

A distribuição do estoque de BAS nas classes de DAP encontra-se na Figura 4 (Chave et al. 2005, 2 var.) e na Figura 5 (Chave et al. 2005, 3 var.). Através das Figuras 4 e 5 é possível observar padrões diferenciados de estoque com relação a classe de DAP. Na floresta de restinga, a distribuição tende a normalidade, com valores maiores de estoque nas classes 10-30 cm e 30-50 cm (Figura 4 e 5). Por outro lado, na floresta de terras baixas o estoque de BAS aumenta com as classes de DAP (Figura 4 e 5).

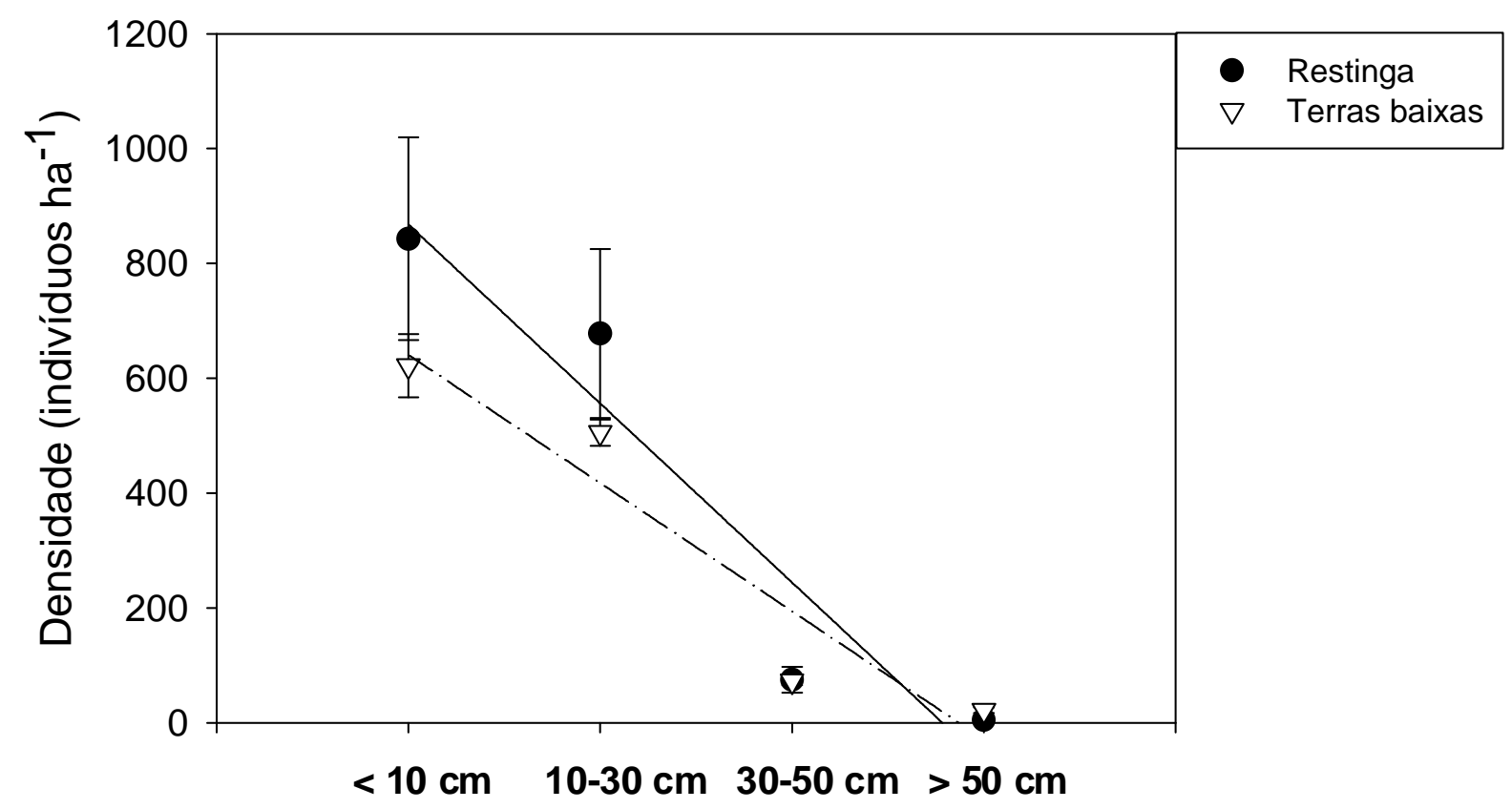

Figura 3 - Distribuição média dos indivíduos (árvores e palmeiras) por classe de DAP no primeiro inventário de estudo, na floresta de restinga (linha contínua) e de terras baixas (linha pontilhada). As barras indicam o desvio padrão da média 
Tabela 8 - Densidade média e desvio padrão dos indivíduos (árvores e palmeiras) por classe de DAP, em ambos os inventários e áreas de estudo

\begin{tabular}{|c|c|c|c|}
\hline & & \multicolumn{2}{|c|}{ Densidade (indivíduos ha ${ }^{-1}$ ) } \\
\hline & & 2006 & 2008 \\
\hline \multirow[t]{4}{*}{ Floresta de restinga ( 1 ha) } & $<10 \mathrm{~cm}$ & 857 & 833 \\
\hline & $10-30 \mathrm{~cm}$ & 696 & 680 \\
\hline & $30-50 \mathrm{~cm}$ & 77 & 78 \\
\hline & $\geq 50 \mathrm{~cm}$ & 5 & 5 \\
\hline \multirow[t]{4}{*}{ Floresta de restinga $(0,25 \mathrm{ha})$} & $<10 \mathrm{~cm}$ & $843 \pm 177$ & $825 \pm 197$ \\
\hline & $10-30 \mathrm{~cm}$ & $678 \pm 147$ & $668 \pm 141$ \\
\hline & $30-50 \mathrm{~cm}$ & $75 \pm 23$ & $78 \pm 18$ \\
\hline & $\geq 50 \mathrm{~cm}$ & $5 \pm 4$ & $5 \pm 4$ \\
\hline \multirow[t]{4}{*}{ Floresta de terras baixas ( 1 ha) } & $<10 \mathrm{~cm}$ & $622 \pm 55$ & $597 \pm 64$ \\
\hline & $10-30 \mathrm{~cm}$ & $505 \pm 23$ & $506 \pm 16$ \\
\hline & $30-50 \mathrm{~cm}$ & $73 \pm 7$ & $71 \pm 9$ \\
\hline & $\geq 50 \mathrm{~cm}$ & $22 \pm 5$ & $24 \pm 5$ \\
\hline
\end{tabular}

Tabela 9 - Mediana, valor mínimo, valor máximo e \% de contribuição em relação ao total do estoque de BAS por classe de DAP. 2-var: estimativa de BAS através da equação 4. 3-var: estimativa de BAS através da equação 5

\begin{tabular}{|c|c|c|c|c|c|c|c|c|c|}
\hline & & \multicolumn{8}{|c|}{ Estoque de BAS $\left(\mathrm{Mg} \mathrm{ha}^{-1}\right)$} \\
\hline & & \multicolumn{4}{|c|}{ 2-var. } & \multicolumn{4}{|c|}{ 3-var. } \\
\hline & & $\min$ & $\max$ & mediana & $\%$ & $\min$ & $\max$ & mediana & $\%$ \\
\hline \multirow[t]{4}{*}{ Floresta de restinga ( 1 ha) } & $<10 \mathrm{~cm}$ & - & - & 14,6 & 5,6 & - & - & 11,7 & 7,0 \\
\hline & $10-30 \mathrm{~cm}$ & - & - & 132,3 & 50,5 & - & - & 90,8 & 54,6 \\
\hline & $30-50 \mathrm{~cm}$ & - & - & 92,3 & 35,3 & - & - & 53,0 & 31,9 \\
\hline & $\geq 50 \mathrm{~cm}$ & - & - & 22,7 & 8,7 & - & - & 10,8 & 6,5 \\
\hline \multirow[t]{5}{*}{ Floresta de restinga $(0,25 \mathrm{ha})$} & $<10 \mathrm{~cm}$ & 11,8 & 20,4 & 13,1 & 5,4 & 9,4 & 15,7 & 10,5 & 6,8 \\
\hline & $10-30 \mathrm{~cm}$ & 107,5 & 174,4 & 123,6 & 50,6 & 74,7 & 119,3 & 84,8 & 54,7 \\
\hline & $30-50 \mathrm{~cm}$ & 72,8 & 137,8 & 79,3 & 32,5 & 42,7 & 79,3 & 46,3 & 29,9 \\
\hline & $\geq 50 \mathrm{~cm}$ & 0,0 & 34,3 & 28,2 & 11,5 & 0,0 & 16,7 & 13,3 & 8,6 \\
\hline & $<10 \mathrm{~cm}$ & 9,4 & 11,4 & 10,1 & 3,2 & 7,6 & 8,9 & 8,0 & 3,8 \\
\hline \multirow[t]{3}{*}{ Floresta de terras baixas } & $10-30 \mathrm{~cm}$ & 82,7 & 103,0 & 93,3 & 29,6 & 59,5 & 72,3 & 66,2 & 31,1 \\
\hline & $30-50 \mathrm{~cm}$ & 91,7 & 105,6 & 101,0 & 32,1 & 61,4 & 73,0 & 66,8 & 31,4 \\
\hline & $\geq 50 \mathrm{~cm}$ & 84,3 & 131,8 & 110,2 & 35,0 & 53,7 & 83,9 & 71,7 & 33,7 \\
\hline
\end{tabular}




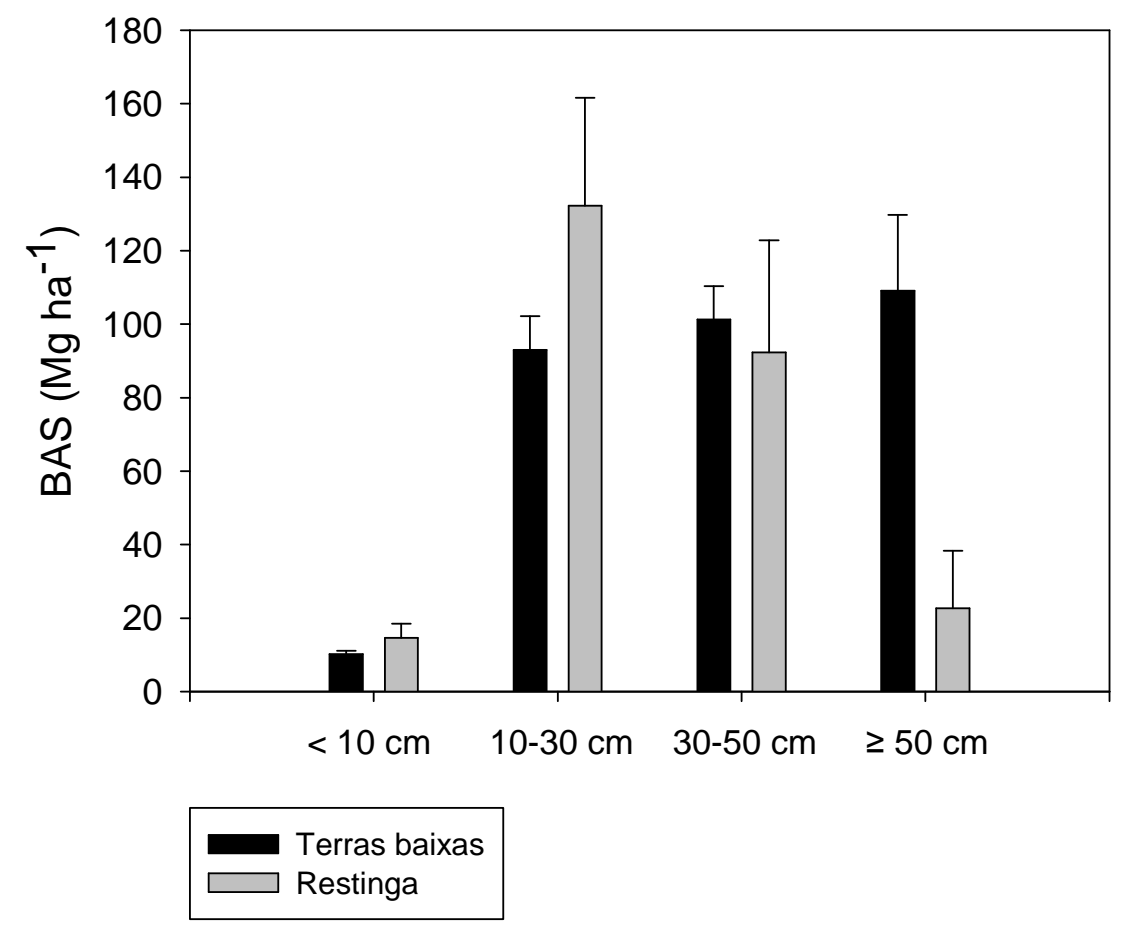

Figura 4 - Distribuição da média do estoque de BAS por classe de DAP no primeiro inventário e em ambas as áreas de estudo. As barras indicam o desvio padrão da média. Chave et al. (2005): 2-var

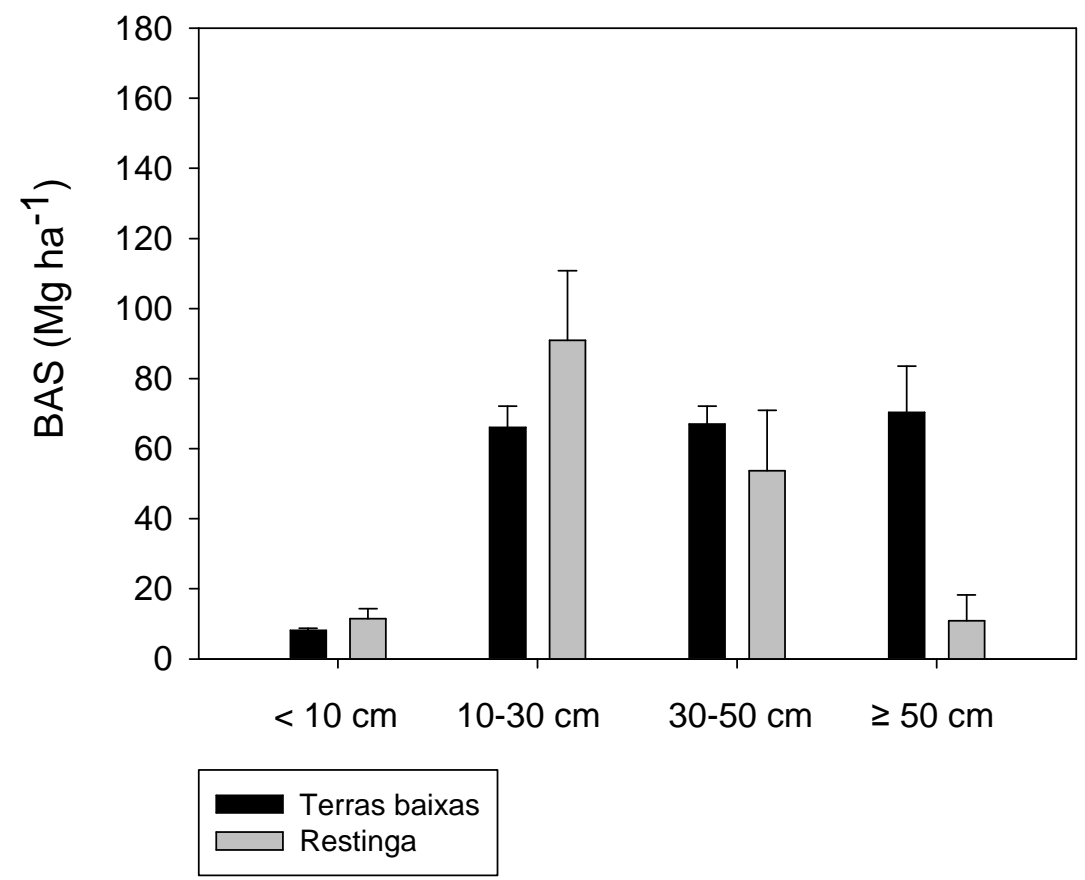

Figura 5 - Distribuição da média do estoque de BAS por classe de DAP no primeiro inventário e em ambas as áreas de estudo. As barras indicam o desvio padrão da média. Chave et al. (2005): 3-var 
Índice de iluminação de copa (IC)

O padrão geral observado da distribuição dos indivíduos por classe de IC foi: maior densidade de indivíduos na menor classe (3, considerada neste estudo) e menor densidade na maior classe (5). A Figura 6 ilustra o "boxplot" do DAP de cada classe de IC de árvores e palmeiras, na floresta de restinga e de uma parcela da terras baixas (parcela C). A mediana do DAP aumentou com a classe de IC para as árvores e palmeiras da floresta de terras baixas e apenas para as árvores na floresta de restinga.
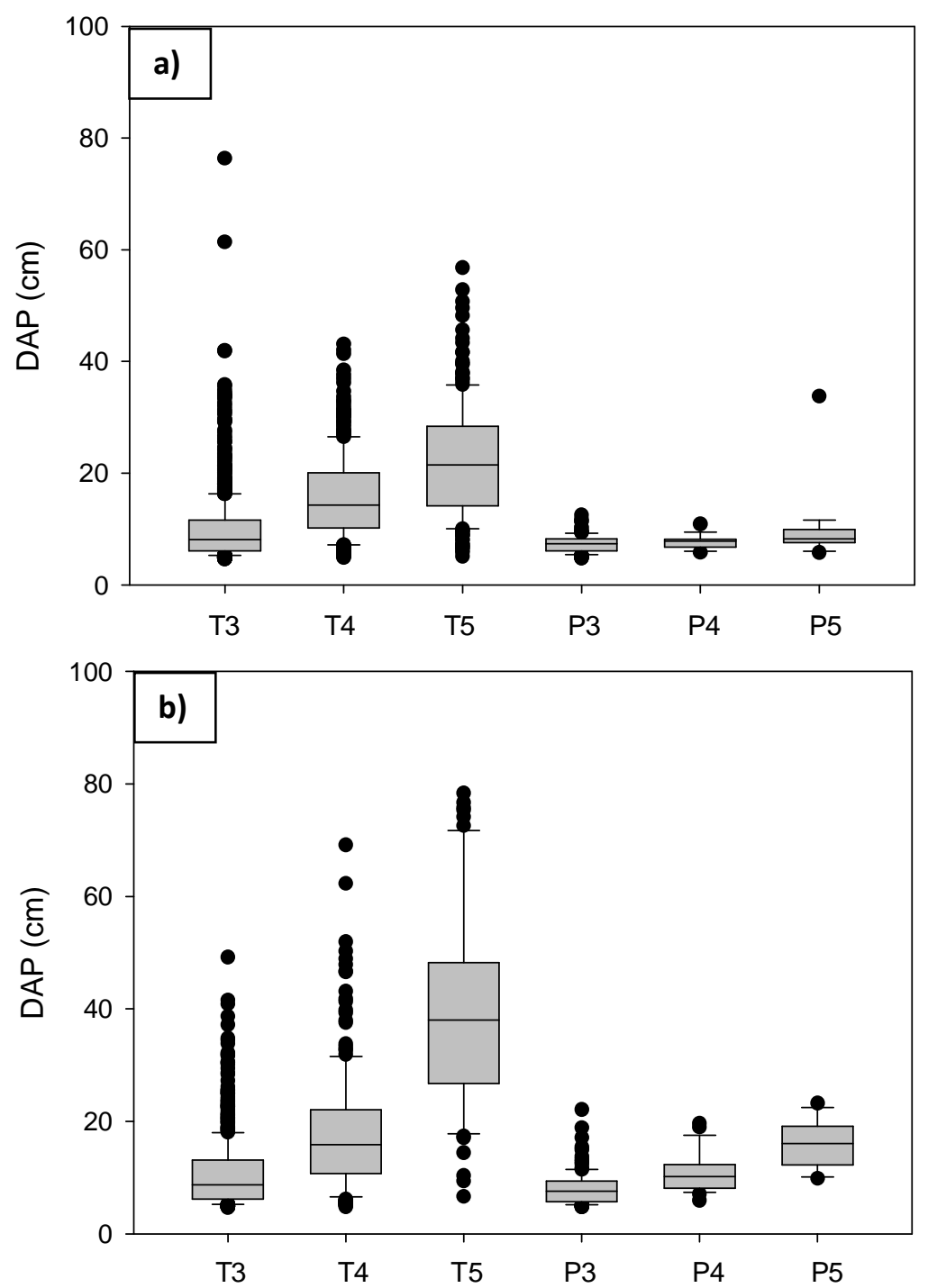

Figura 6 - "Boxplot" da distribuição do DAP $(\mathrm{cm})$ de cada classe de IC na parcela A (a) e C (b). T3, T4 e T5: árvores da classe IC3, IC4 e IC5. P3, P4 e P5: palmeiras da classe IC3, IC4 e IC5. Em cada caixa, a linha central horizontal indica a mediana e as extremidades os quartis 


\subsection{Taxa de incremento diamétrico}

Floresta de Restinga vs. Terras baixas

A taxa de incremento diamétrico das árvores não diferiu entre a floresta de restinga e de terras baixas para os indivíduos com DAP $\geq 5$ e $10 \mathrm{~cm}$ (Mann-Whitney, $P>0,05$, Tabela 10). Seguindo o mesmo padrão, a taxa de incremento diamétrico das palmeiras também não apresentou diferenças significativas entre as áreas em ambos os DAP de inclusão (Mann-Whitney, P>0,05, Tabela 11).

A maior idade calculada a partir da abordagem utilizando as taxas de incremento foi encontrada na floresta de terras baixas, uma árvore com 115,6 cm de DAP e 356 anos. Na floresta de restinga a idade da maior árvore, de $76,4 \mathrm{~cm}$ de DAP, foi de 287 anos.

Tabela 10 - Resumo da taxa de incremento diamétrico $\left(\mathrm{mm}^{\mathrm{ano}}{ }^{-1}\right)$ das árvores com o DAP $\geq 4,8$ e 10 $\mathrm{cm}$ em ambas as áreas de estudo

\begin{tabular}{|c|c|c|c|c|c|c|c|}
\hline & & \multicolumn{6}{|c|}{ Taxa de incremento diamétrico $\left(\mathrm{mm} \mathrm{ano}^{-1}\right)$} \\
\hline & & $\min$ & $\max$ & mediana & media & d.p. & $n$ \\
\hline \multirow[t]{2}{*}{ Floresta de restinga } & $\geq 4,8 \mathrm{~cm}$ & $-12,2$ & 14,9 & 1,0 & 1,2 & 1,7 & 1393 \\
\hline & $\geq 10 \mathrm{~cm}$ & $-12,2$ & 14,9 & 1,2 & 1,3 & 2,0 & 732 \\
\hline \multirow[t]{2}{*}{ Floresta de terras baixas } & $\geq 4,8 \mathrm{~cm}$ & $-8,4$ & 21,7 & 0,8 & 1,2 & 2,3 & 3955 \\
\hline & $\geq 10 \mathrm{~cm}$ & $-8,4$ & 21,7 & 0,9 & 1,5 & 2,9 & 2075 \\
\hline
\end{tabular}

\section{Árvores vs. Palmeiras}

$\mathrm{Na}$ floresta de restinga, diferenças significativas foram encontradas nas taxas de incremento diamétrico entre árvores e palmeiras com o DAP $\geq 10 \mathrm{~cm}$ (MannWhitney, $P=0,03)$. A mediana da taxa de incremento diamétrico das árvores foi significativamente maior que a mediana da taxa de incremento das palmeiras (Tabela 10 e 11). As taxas de incremento dos indivíduos com DAP $\geq 4,8 \mathrm{~cm}$ não apresentaram diferenças entre as formas de vida.

A floresta de terras baixas também apresentou diferenças entre as formas de vida com relação a taxa de incremento, em ambos os DAP de inclusão (Mann-Whitney, $P=0,00)$. Novamente, a mediana da taxa de incremento diamétrico das árvores foi 
significativamente superior as taxas de incremento diamétrico das palmeiras (Tabela 10 e 11).

Tabela 11 - Resumo da taxa de incremento diamétrico $\left(\mathrm{mm}^{2} \mathrm{ano}^{-1}\right)$ das palmeiras com o DAP $\geq 4,8$ e $10 \mathrm{~cm}$ em ambas as áreas de estudo

\begin{tabular}{|c|c|c|c|c|c|c|c|}
\hline & & \multicolumn{6}{|c|}{ Taxa de incremento diamétrico $\left(\mathrm{mm} \mathrm{ano}^{-1}\right)$} \\
\hline & & $\min$ & $\max$ & mediana & media & d.p. & $n$ \\
\hline \multirow[t]{2}{*}{ Floresta de restinga } & $\geq 4,8 \mathrm{~cm}$ & $-1,1$ & 10,3 & 0,8 & 1,2 & 1,7 & 143 \\
\hline & $\geq 10 \mathrm{~cm}$ & $-1,1$ & 4,0 & 0,2 & 0,4 & 1,5 & 10 \\
\hline \multirow[t]{2}{*}{ Floresta de terras baixas } & $\geq 4,8 \mathrm{~cm}$ & $-2,6$ & 13,6 & 1,0 & 1,8 & 2,6 & 670 \\
\hline & $\geq 10 \mathrm{~cm}$ & $-2,6$ & 11,7 & 0,3 & 0,8 & 2,3 & 223 \\
\hline
\end{tabular}

\section{Classes de DAP}

A relação entre a taxa de incremento diamétrico e o DAP apresentou padrões diferenciados entre as formas de vida. Para as árvores, observou-se um aumento da taxa de incremento diamétrico com as classes de DAP (Figura 7). Para as palmeiras nota-se um padrão inverso (Figura 8). 


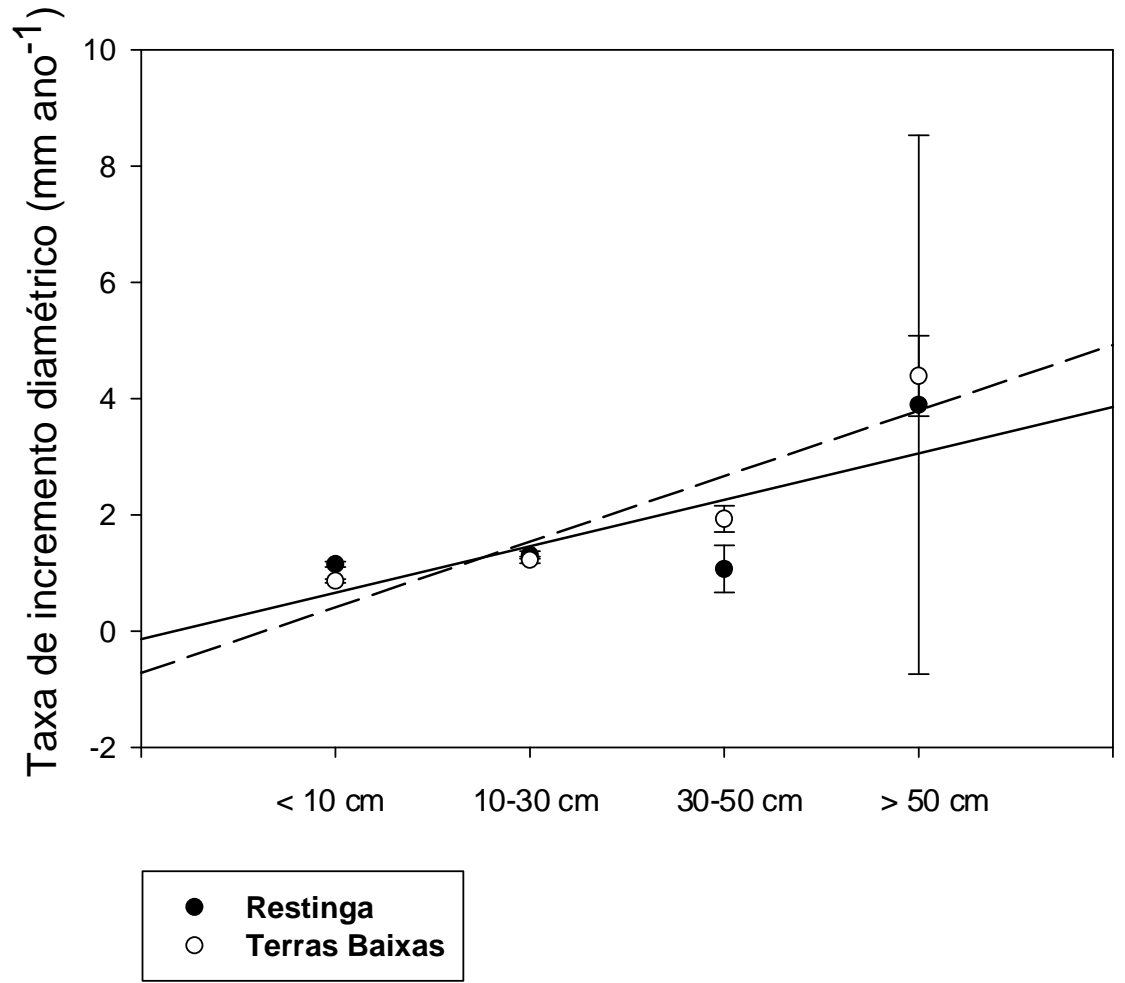

Figura 7 - Taxa de incremento diamétrico média $\left(\mathrm{mm}^{\mathrm{ano}} \mathrm{o}^{-1}\right)$ das árvores na floresta de restinga (linha contínua) e de terras baixas (linha pontilhada). As barras indicam erro padrão médio

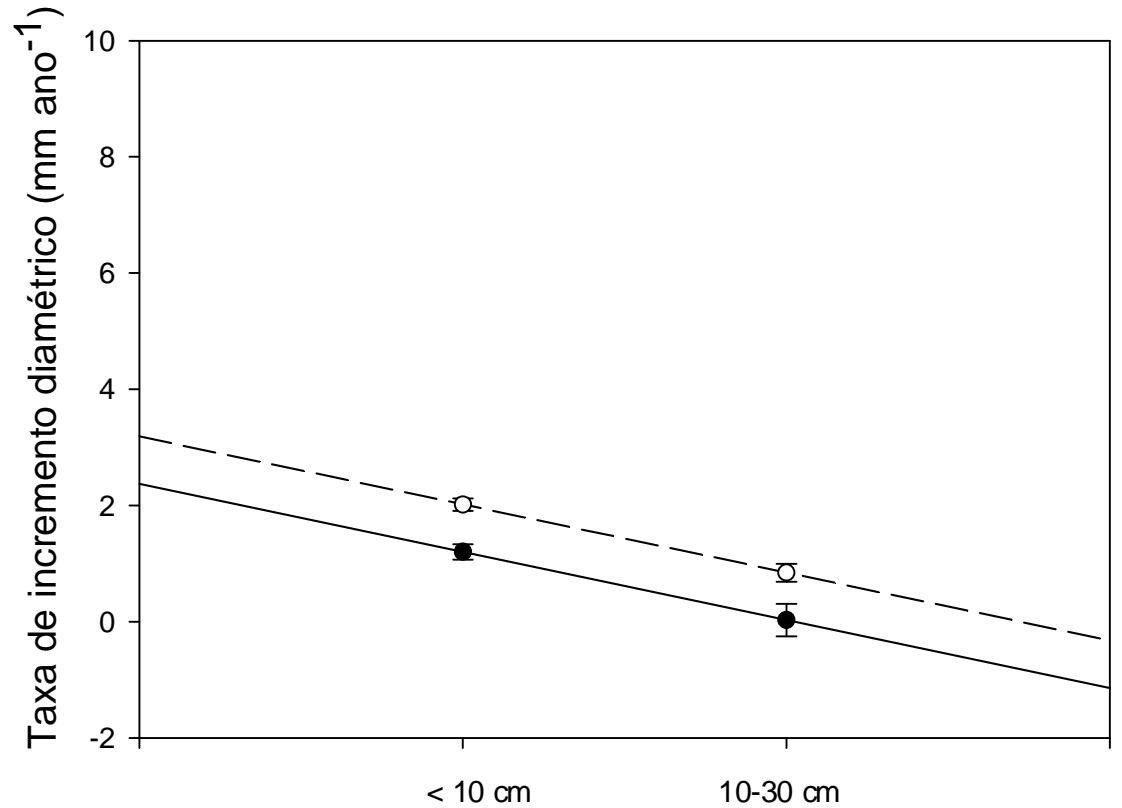

- Restinga

Terras Baixas

Figura 8 - Taxa de incremento diamétrico média $\left(\mathrm{mm}^{\mathrm{ann}} \mathrm{o}^{-1}\right)$ das palmeiras na floresta de restinga (linha contínua) e de terras baixas (linha pontilhada). As barras indicam erro padrão médio 
Através da análise de variância de Kruskall-Wallis, diferença significativa foi encontrada na taxa de incremento diamétrico das árvores entre as classes de DAP na floresta de restinga ( $P=0,04$; Tabela 12). Por outro lado, o teste de comparações múltiplas de Dunn revelou diferenças apenas entre as classes $<10 \mathrm{~cm} \mathrm{e} \geq 50 \mathrm{~cm}$; e entre $30-50 \mathrm{~cm}$ e $\geq 50 \mathrm{~cm}$. Na floresta de terras baixas, diferenças também foram encontradas na taxa de incremento diamétrico das árvores entre as classes de DAP $(P=0,00 ;$ Tabela 12). O teste de comparações múltiplas de Dunn revelou diferenças entre todas as classes de DAP (Tabela 12).

Para as palmeiras, as maiores taxas de incremento diamétrico foram observadas na primeira classe de DAP (Tabela 13). Diferenças na taxa de incremento diamétrico entre as classes de DAP foram observadas em ambas as florestas ( $P=0,01$ floresta de restinga; $P=0,00$ floresta de terras baixas; Tabela 13).

Tabela 12 - Resumo da taxa de incremento diamétrico $\left(\mathrm{mm} \mathrm{ano}^{-1}\right)$ das árvores por classe de DAP em ambas as áreas de estudo

\begin{tabular}{|c|c|c|c|c|c|c|c|}
\hline & \multirow[b]{2}{*}{ C.DAP } & \multicolumn{6}{|c|}{ Taxa de incremento diamétrico $\left(\mathrm{mm} \mathrm{ano}^{-1}\right)$} \\
\hline & & $\min$ & $\max$ & mediana & media & d.p. & $n$ \\
\hline \multirow[t]{5}{*}{ Floresta de restinga } & $<10 \mathrm{~cm}$ & $-1,1$ & 5,5 & $0,9^{\mathrm{a}}$ & 1,2 & 1,2 & 661 \\
\hline & $10-30 \mathrm{~cm}$ & $-1,8$ & 7,0 & $1,2^{\mathrm{ac}}$ & 1,3 & 1,6 & 653 \\
\hline & $30-50 \mathrm{~cm}$ & $-12,2$ & 9,7 & $0,9^{\mathrm{a}}$ & 1,1 & 3,5 & 75 \\
\hline & $\geq 50 \mathrm{~cm}$ & $-7,6$ & 14,9 & $4,2^{\mathrm{C}}$ & 3,9 & 9,3 & 4 \\
\hline & & & & $\mathrm{P}<0,05$ & & & \\
\hline \multirow[t]{5}{*}{ Floresta de terras baixas } & $<10 \mathrm{~cm}$ & $-2,3$ & 7,9 & $0,6^{\mathrm{a}}$ & 0,9 & 1,4 & 1880 \\
\hline & $10-30 \mathrm{~cm}$ & $-4,0$ & 12,2 & $0,8^{b}$ & 1,2 & 2,3 & 1709 \\
\hline & $30-50 \mathrm{~cm}$ & $-8,4$ & 15,4 & $1,6^{c}$ & 1,9 & 3,8 & 279 \\
\hline & $\geq 50 \mathrm{~cm}$ & $-8,3$ & 21,7 & $3,5^{\mathrm{d}}$ & 4,4 & 6,5 & 87 \\
\hline & & & & $P<0,05$ & & & \\
\hline
\end{tabular}


Tabela 13 - Resumo da taxa de incremento diamétrico das palmeiras por classe de DAP em ambas as áreas de estudo

\begin{tabular}{|c|c|c|c|c|c|c|c|}
\hline & \multirow[b]{2}{*}{ C.DAP } & \multicolumn{6}{|c|}{ Taxa de incremento diamétrico $\left(\mathrm{mm} \mathrm{ano}^{-1}\right)$} \\
\hline & & $\min$ & $\max$ & mediana & media & d.p. & $n$ \\
\hline \multirow[t]{3}{*}{ Floresta de restinga } & $<10 \mathrm{~cm}$ & $-0,9$ & 5,6 & $0,8^{\mathrm{a}}$ & 1,2 & 1,5 & 132 \\
\hline & $10-30 \mathrm{~cm}$ & $-1,1$ & 1,3 & $0,0^{b}$ & 0,0 & 0,8 & 9 \\
\hline & & & & $P<0,05$ & & & \\
\hline \multirow[t]{3}{*}{ Floresta de terras baixas } & $<10 \mathrm{~cm}$ & $-2,3$ & 7,9 & $1,3^{\mathrm{a}}$ & 2,0 & 2,2 & 432 \\
\hline & $10-30 \mathrm{~cm}$ & $-2,6$ & 11,7 & $0,3^{b}$ & 0,8 & 2,3 & 224 \\
\hline & & & & $P<0,05$ & & & \\
\hline
\end{tabular}

Índice de iluminação de copa (IC)

Semelhante as classes de DAP, a taxa de incremento diamétrico e a disponibilidade vertical de luz (IC) apresentaram padrões diferenciados entres as formas de vida (Figura 9 e 10). A taxa de incremento diamétrico das árvores apresentou correlação positiva significativa com o IC na floresta de restinga ( $\left.R_{\text {Spearman: }} 0,128 ; P=0,00\right)$ e nas terras baixas ( $R_{\text {Spearman }}: 0,206 ; P=0,00$ ). Por outro lado, a taxa de incremento diamétrico das palmeiras apresentou correlação negativa significativa com o IC na floresta de restinga ( $\left.R_{\text {Spearman: }}-0,165 ; P=0,04\right)$ e na floresta de terras baixas $\left(R_{\text {Spearman: }}-0,242 ; P=0,00\right)$. Portanto, árvores que estão mais expostas a luz tendem a crescer mais rapidamente do que árvores que estão menos expostas a luz (Figura 9 e Tabela 14) e palmeiras que estão mais expostas a luz tendem a crescem mais lentamente (Figura 10 e Tabela 15). 


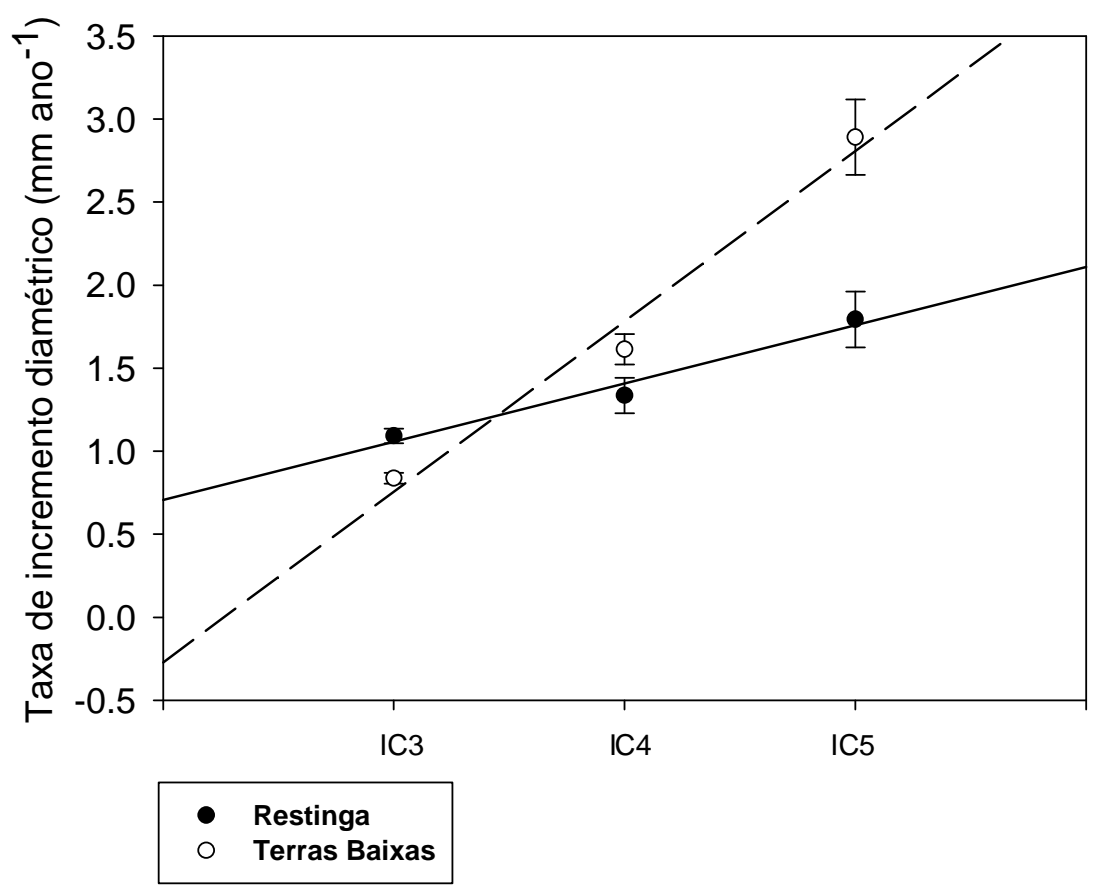

Figura 9 - Taxa de incremento diamétrico média $\left(\mathrm{mm} \mathrm{ano}^{-1}\right)$ por classe de IC das árvores na floresta de Restinga (linha contínua) e na Terras baixas (linha pontilhada). As barras indicam o erro padrão médio

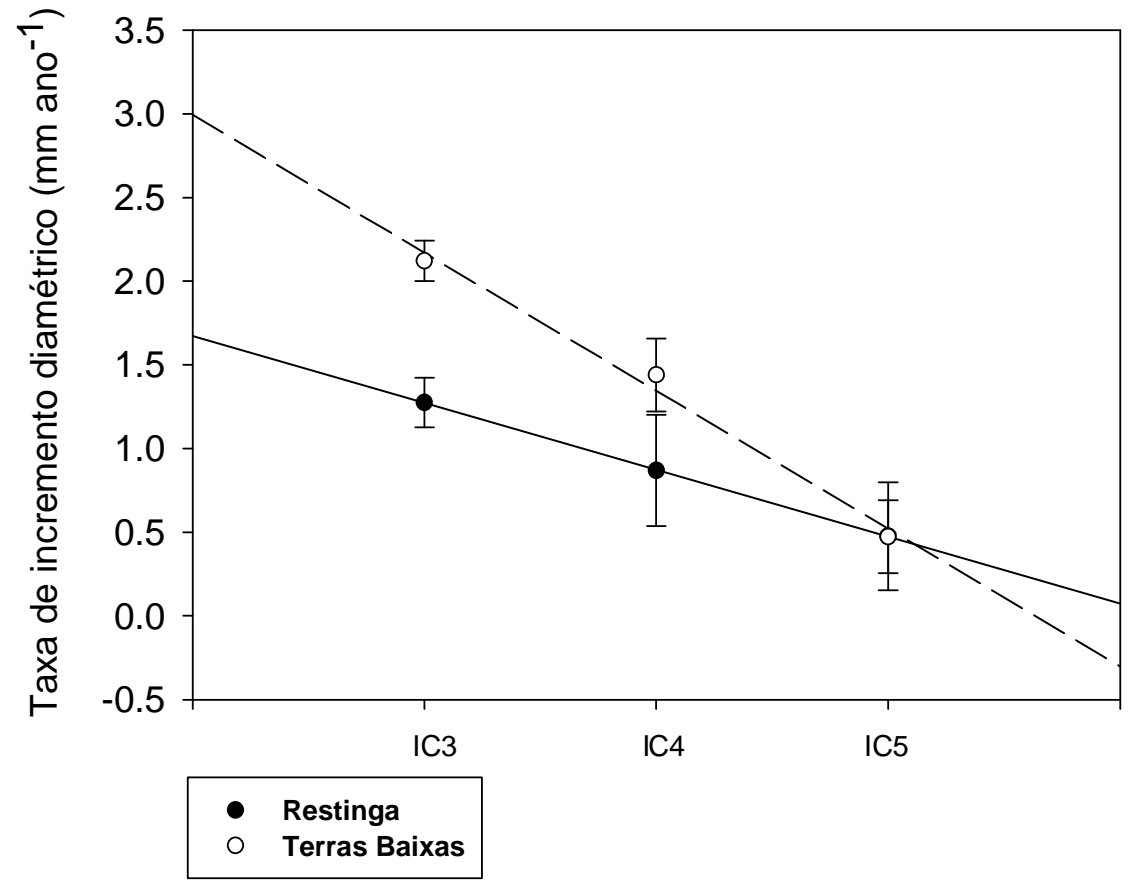

Figura 10 - Taxa de incremento diamétrico média $\left(\mathrm{mm} \mathrm{ano}^{-1}\right)$ por classe de IC das palmeiras na floresta de Restinga (linha contínua) e na Terras baixas (linha pontilhada). As barras indicam o erro padrão médio 
Tabela 14 - Resumo da taxa de incremento diamétrico $\left(\mathrm{mm}^{\mathrm{ano}}{ }^{-1}\right)$ das árvores por classe de IC em ambas as áreas de estudo

\begin{tabular}{|c|c|c|c|c|c|c|c|}
\hline & \multirow[b]{2}{*}{ IC } & \multicolumn{6}{|c|}{ Taxa de incremento diamétrico $\left(\mathrm{mm}\right.$ ano $\left.{ }^{-1}\right)$} \\
\hline & & $\min$ & $\max$ & mediana & media & d.p. & $n$ \\
\hline \multirow[t]{3}{*}{ Floresta de restinga } & 3 & $-1,8$ & 7,0 & 0,9 & 1,1 & 1,3 & 876 \\
\hline & 4 & $-10,7$ & 7,2 & 1,1 & 1,3 & 1,9 & 323 \\
\hline & 5 & $-5,2$ & 14,9 & 1,4 & 1,8 & 2,3 & 192 \\
\hline \multirow[t]{3}{*}{ Floresta de terras baixas } & 3 & $-6,8$ & 12,3 & 0,6 & 0,8 & 1,7 & 2832 \\
\hline & 4 & $-8,3$ & 14,1 & 1,1 & 1,6 & 2,5 & 751 \\
\hline & 5 & $-8,4$ & 22,0 & 2,0 & 2,9 & 4,5 & 386 \\
\hline
\end{tabular}

Tabela 15 - Resumo da taxa de incremento diamétrico $\left(\mathrm{mm} \mathrm{ano}^{-1}\right)$ das palmeiras por classe de IC em ambas as áreas de estudo

\begin{tabular}{|c|c|c|c|c|c|c|c|}
\hline & \multirow[b]{2}{*}{ IC } & \multicolumn{6}{|c|}{ Taxa de incremento diamétrico $\left(\mathrm{mm} \mathrm{ano}^{-1}\right)$} \\
\hline & & $\min$ & $\max$ & mediana & media & d.p. & $n$ \\
\hline \multirow[t]{3}{*}{ Floresta de restinga } & 3 & $-0,8$ & 5,6 & 0,9 & $\overline{1,3}$ & 1,6 & 111 \\
\hline & 4 & $-1,1$ & 4,6 & 0,6 & 0,9 & 1,4 & 17 \\
\hline & 5 & $-0,9$ & 4,0 & 0,3 & 0,5 & 1,2 & 14 \\
\hline \multirow[t]{3}{*}{ Floresta de terras baixas } & 3 & $-2,6$ & 12,3 & 1,2 & 2,1 & 2,6 & 460 \\
\hline & 4 & $-1,8$ & 11,5 & 0,9 & 1,4 & 2,5 & 127 \\
\hline & 5 & $-2,4$ & 9,5 & 0,1 & 0,5 & 2,0 & 83 \\
\hline
\end{tabular}




\subsection{Mortalidade, "meia vida" e recrutamento}

Floresta de Restinga vs. Terras baixas

Apesar da taxa de mortalidade ser um pouco superior na floresta de restinga, em ambos os DAP de inclusão, os limites inferiores e superiores não revelaram diferenças significativas na taxa de mortalidade entre os dois tipos de floresta (Tabela 16). Ainda, observa-se um padrão de diminuição da taxa de mortalidade quando o DAP de inclusão passa a ser $10 \mathrm{~cm}$.

A meia vida da floresta de terras baixas foi superior em ambos os DAP de inclusão. Para os indivíduos com DAP $\geq 4,8 \mathrm{~cm}$, a meia vida da floresta de terras baixas foi igual a 34,3 anos e na floresta de restinga igual a 27,9 anos. Para o DAP $\geq 10 \mathrm{~cm}$, a meia vida da floresta de terras baixas foi igual a 41,5 anos e na floresta de restinga igual a 38,4 anos.

Tabela 16 - Taxa de mortalidade $(\lambda)$, limite inferior (LI) e superior (LS), população inicial (N0), número de mortos $(M)$ e meia vida $\left(t_{(1 / 2)}\right)$ em anos na floresta de restinga e de terras baixas, para os indivíduos com DAP $\geq 4,8$ e $\geq 10 \mathrm{~cm}$

\begin{tabular}{|c|c|c|c|c|c|c|c|}
\hline & & \multicolumn{5}{|c|}{ Taxa de mortalidade } & \multirow{2}{*}{$\begin{array}{c}\begin{array}{c}\text { Meia } \\
\text { vida }\end{array} \\
t_{(1 / 2)}\end{array}$} \\
\hline & & $\lambda(\%)$ & $L I(\%)$ & LS (\%) & NO & $M$ & \\
\hline \multirow[t]{2}{*}{ Floresta de restinga } & $\geq 4,8 \mathrm{~cm}$ & 2,46 & 2,00 & 3,01 & 1635 & 86 & 27,9 \\
\hline & $\geq 10 \mathrm{~cm}$ & 1,79 & 1,36 & 2,35 & 778 & 30 & 38,4 \\
\hline \multirow[t]{2}{*}{ Floresta de terras baixas } & $\geq 4,8 \mathrm{~cm}$ & 2,00 & 1,70 & 2,36 & 4884 & 201 & 34,3 \\
\hline & $\geq 10 \mathrm{~cm}$ & 1,66 & 1,35 & 2,04 & 2398 & 82 & 41,5 \\
\hline
\end{tabular}

Seguindo o mesmo padrão, as taxas de recrutamento dos indivíduos que atingiram DAP igual $4,8 \mathrm{~cm}$ não revelaram diferenças entre as florestas estudadas (Tabela 17). Por outro lado, diferenças significativas foram encontradas para os indivíduos que atingiram DAP igual a $10 \mathrm{~cm}$ (Tabela 17). Na floresta de terras baixas a taxa de recrutamento foi superior para os indivíduos com DAP $\geq 10 \mathrm{~cm}$, quando comparado com a floresta de restinga (Tabela 17). 
Tabela 17 - Taxa de recrutamento (i), limite inferior (LI) e superior (LS) e número de recrutas (R) na floresta de restinga e de terras baixas, para os indivíduos com DAP $\geq 4,8$ e $\geq 10 \mathrm{~cm}$

\begin{tabular}{|c|c|c|c|c|c|}
\hline & & \multicolumn{4}{|c|}{ Taxa de recrutamento } \\
\hline & & i (\%) & $L I(\%)$ & LS (\%) & $R$ \\
\hline \multirow[t]{2}{*}{ Floresta de restinga } & $\geq 4,8 \mathrm{~cm}$ & 1,42 & 1,15 & 1,75 & 52 \\
\hline & $\geq 10 \mathrm{~cm}$ & 0,93 & 0,63 & 1,29 & 16 \\
\hline \multirow[t]{2}{*}{ Floresta de terras baixas } & $\geq 4,8 \mathrm{~cm}$ & 1,36 & 1,16 & 1,61 & 142 \\
\hline & $\geq 10 \mathrm{~cm}$ & 1,87 & 1,60 & 2,20 & 96 \\
\hline
\end{tabular}

\section{Árvores vs. Palmeiras}

Na floresta de restinga, a taxa de mortalidade das palmeiras foi significativamente maior que das árvores em ambos os DAP de inclusão (Tabela 18). Para as palmeiras com o DAP $\geq 10$ a taxa de mortalidade foi igual a 8,29\%, com limite inferior de 2,30 e superior de 22,13\%. A taxa de mortalidade das árvores com esse DAP de inclusão foi igual a 1,69\%, com limite inferior de 1,25\% e superior de 2,23\%.

$\mathrm{Na}$ floresta de terras baixas, diferença significativa só foi encontrada na taxa de mortalidade dos indivíduos com DAP $\geq 10 \mathrm{~cm}$ (Tabela 18). Porém, diferentemente da floresta de restinga, a taxa de mortalidade das palmeiras foi inferior a taxa de mortalidade das árvores (Tabela 18). A taxa de mortalidade das palmeiras com DAP $\geq 10 \mathrm{~cm}$ foi igual a 0,63\%, com limite inferior de 0,23 e superior de 1,42\%. Para as árvores desse DAP de inclusão, a taxa de mortalidade foi igual a 1,77\% com limite inferior de $1,44 \%$ e superior de $2,17 \%$. 
Tabela 18 - Taxa de mortalidade ( $\lambda$ ), limite inferior (LI) e superior (LS), população inicial (N0), número de mortos $(M)$ e meia vida $\left(t_{(1 / 2)}\right)$ em anos na floresta de restinga e de terras baixas, para árvores e palmeiras com DAP $\geq 4,8 \mathrm{e} \geq 10 \mathrm{~cm}$

\begin{tabular}{|c|c|c|c|c|c|c|c|c|}
\hline \multirow{6}{*}{ Floresta de restinga } & & & & Taxa & mortali & de & & $\begin{array}{l}\text { Meia } \\
\text { vida }\end{array}$ \\
\hline & & & $\lambda(\%)$ & $L I(\%)$ & LS (\%) & NO & $M$ & $t_{(1 / 2)}$ \\
\hline & \multirow{2}{*}{ árvore } & $\geq 4,8 \mathrm{~cm}$ & 1,96 & 1,60 & 2,42 & 1467 & 62 & 35,0 \\
\hline & & $\geq 10 \mathrm{~cm}$ & 1,69 & 1,25 & 2,23 & 766 & 28 & 40,6 \\
\hline & \multirow{2}{*}{ palmeira } & $\geq 4,8 \mathrm{~cm}$ & 7,01 & 5,24 & 9,13 & 168 & 24 & 9,5 \\
\hline & & $\geq 10 \mathrm{~cm}$ & 8,29 & 2,30 & 22,13 & 12 & 2 & 8,0 \\
\hline \multirow[t]{4}{*}{$\begin{array}{c}\text { Floresta de terras } \\
\text { baixas }\end{array}$} & \multirow[t]{2}{*}{ árvore } & $\geq 4,8 \mathrm{~cm}$ & 1,89 & 1,61 & 2,24 & 4157 & 162 & 36,3 \\
\hline & & $\geq 10 \mathrm{~cm}$ & 1,77 & 1,44 & 2,17 & 2171 & 79 & 38,9 \\
\hline & \multirow{2}{*}{ palmeira } & $\geq 4,8 \mathrm{~cm}$ & 2,63 & 2,06 & 3,42 & 727 & 39 & 26,1 \\
\hline & & $\geq 10 \mathrm{~cm}$ & 0,63 & 0,23 & 1,42 & 227 & 3 & 109,1 \\
\hline
\end{tabular}

Como conseqüência das altas taxas de mortalidade, a meia vida das palmeiras na floresta de restinga foi bastante inferior a das árvores (Tabela 18). Por outro lado, na floresta de terras baixas as palmeiras apresentaram meia vida igual a 109,1 anos, superior a das árvores devido a baixa taxa de mortalidade (Tabela 18).

Tabela 19 - Taxa de recrutamento (i), limite inferior (LI) e superior (LS) e número de recrutas (R) na floresta de restinga e de terras baixas, para árvores e palmeiras com DAP $\geq 4,8$ e $\geq 10$ $\mathrm{cm}$

\begin{tabular}{|c|c|c|c|c|c|c|}
\hline \multirow{4}{*}{ Floresta de restinga } & \multirow{4}{*}{ árvore } & & \multicolumn{4}{|c|}{ Taxa de recrutamento } \\
\hline & & \multirow[b]{2}{*}{$\geq 4,8 \mathrm{~cm}$} & \multirow{2}{*}{$\begin{array}{l}i(\%) \\
1,49\end{array}$} & \multirow{2}{*}{$\begin{array}{c}L I(\%) \\
1,20\end{array}$} & \multirow{2}{*}{$\begin{array}{c}\text { LS (\%) } \\
1,84\end{array}$} & \multirow{2}{*}{$\begin{array}{l}R \\
49\end{array}$} \\
\hline & & & & & & \\
\hline & & $\geq 10 \mathrm{~cm}$ & 0,94 & 0,64 & 1,31 & 16 \\
\hline & & $\geq 4,8 \mathrm{~cm}$ & 0,81 & 0,30 & 1,76 & 3 \\
\hline & palmeıra & $\geq 10 \mathrm{~cm}$ & 0,00 & 0,00 & 0,00 & 0 \\
\hline \multirow[t]{4}{*}{ Floresta de terras baixas } & \multirow{2}{*}{ árvore } & $\geq 4,8 \mathrm{~cm}$ & 1,20 & 1,02 & 1,42 & 106 \\
\hline & & $\geq 10 \mathrm{~cm}$ & 1,43 & 1,17 & 1,75 & 66 \\
\hline & \multirow{2}{*}{ palmeira } & $\geq 4,8 \mathrm{~cm}$ & 2,30 & 1,83 & 2,96 & 36 \\
\hline & & $\geq 10 \mathrm{~cm}$ & 5,91 & 4,66 & 7,39 & 30 \\
\hline
\end{tabular}


$\mathrm{Na}$ floresta de restinga, apesar das altas taxas de mortalidade, as palmeiras apresentaram as menores taxas de recrutamento (Tabela 19). Para os indivíduos com DAP $\geq 10 \mathrm{~cm}$ a taxa de recrutamento foi nula, com nenhum indivíduo recrutado.

A floresta de terras baixas, novamente, apresentou padrão diferenciado. As palmeiras, em ambos os DAP de inclusão, apresentaram as maiores taxas de recrutamento (Tabela 19). Diferenças significativas foram encontradas na taxa de recrutamento entre as formas de vida em ambos os DAP de inclusão (Tabela 19).

\section{Classes de DAP}

A taxa de mortalidade da comunidade, apesar de não apresentar diferenças significativas, decresceu com o aumento das classes de DAP em ambas as florestas estudadas (Figura 11). Na floresta de restinga os indivíduos grandes, da classe DAP $\geq 50 \mathrm{~cm}$, tiveram taxa de mortalidade igual a zero (0).

O mesmo padrão é encontrado quando diferenciamos as formas de vida (Figura 12 e 13). Por outro lado, diferenças significativas foram encontradas nas taxas de mortalidade das palmeiras entre as classes de DAP $<10 \mathrm{~cm}$ e $10-30 \mathrm{~cm}$ na floresta de terras baixas (Figura 13). A taxa de mortalidade da primeira classe foi igual a $3,56 \%$, significativamente superior a taxa de mortalidade da segunda classe igual a $0,63 \%$. 


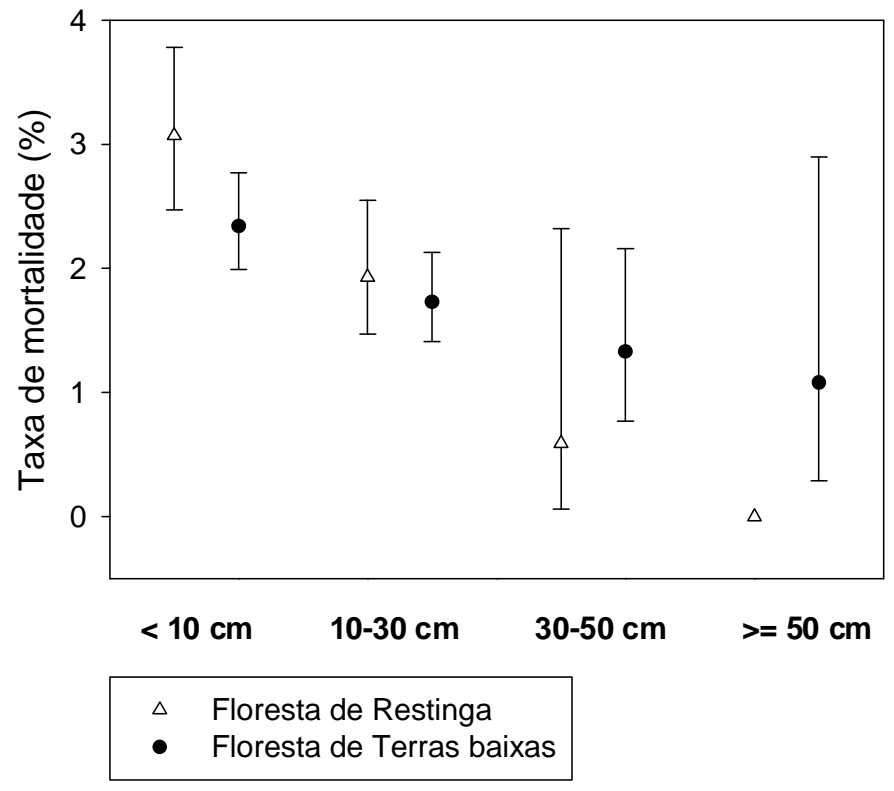

Figura 11 - Taxa de mortalidade ( $\lambda$ ), limite inferior (LI) e superior (LS) na floresta de restinga e de terras baixas, por classe de DAP (árvores e palmeiras)

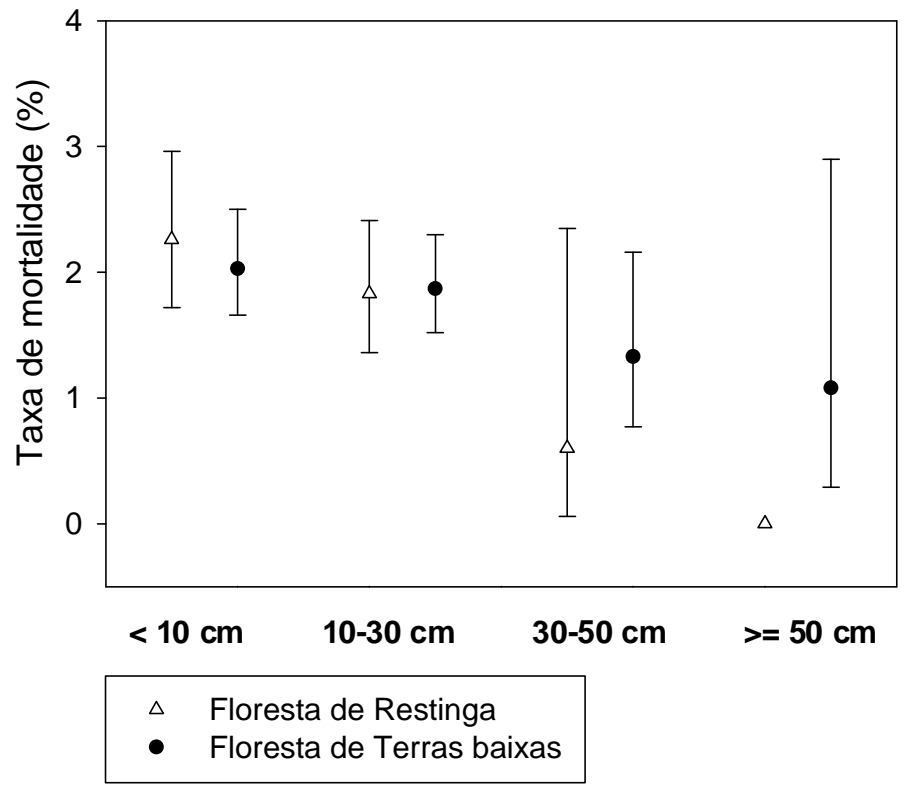

Figura 12 - Taxa de mortalidade ( $\lambda$ ), limite inferior (LI) e superior (LS) na floresta de restinga e de terras baixas das árvores por classe de DAP 


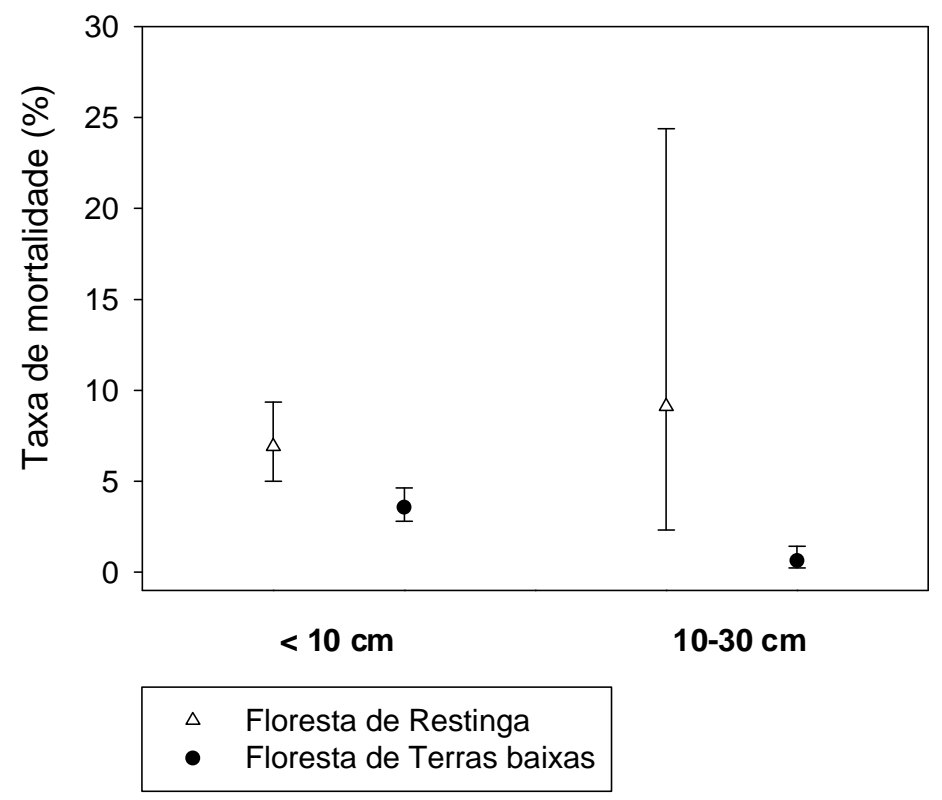

Figura13 - Taxa de mortalidade $(\lambda)$, limite inferior (LI) e superior (LS) na floresta de restinga e de terras baixas, das palmeiras por classe de DAP

Índice de iluminação de copa (IC)

Com padrão semelhante as classes de DAP, a taxa de mortalidade da comunidade na floresta de terras baixas apresentou decréscimo com o aumento da disponibilidade de luz vertical, apesar de nenhuma diferença significativa ter sido encontrada (Figura 14). Na floresta de restinga as diferenças também não foram significativas e nenhum padrão foi observado (Figura 14). Ainda, quando diferenciamos as formas de vida, nenhuma diferença significativa é observada nas taxas de mortalidade entre as classes de IC (Figuras 15 e 16). 


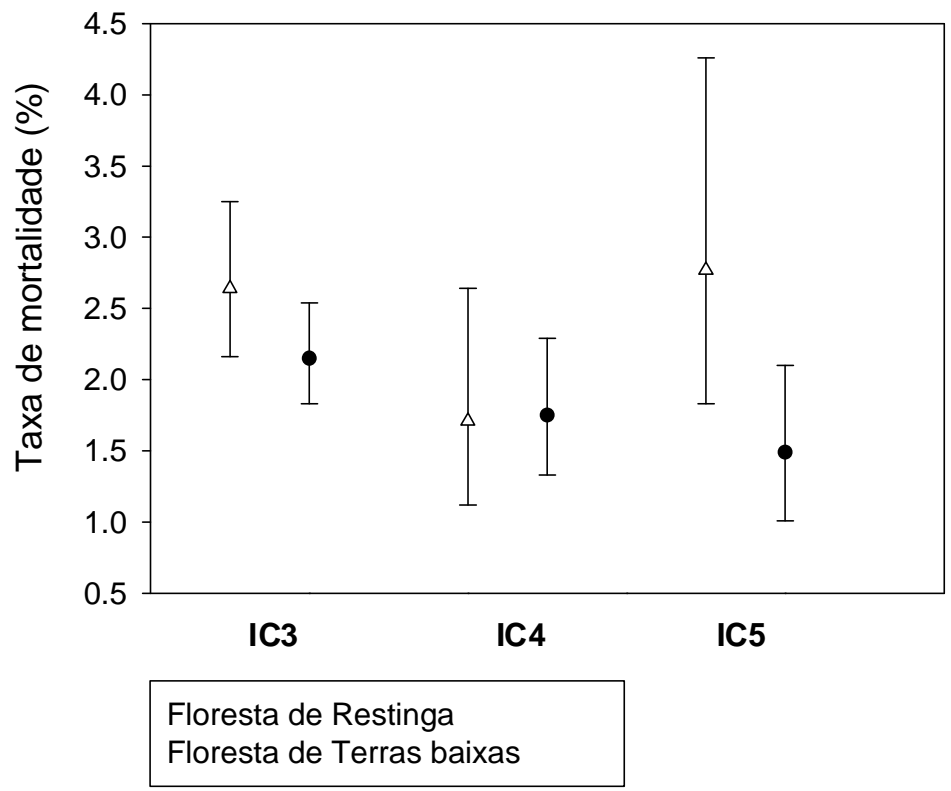

Figura 14 - Taxa de mortalidade ( $\lambda$ ), limite inferior (LI) e superior (LS) das árvores e palmeiras na floresta de restinga e de terras baixas por classe de IC

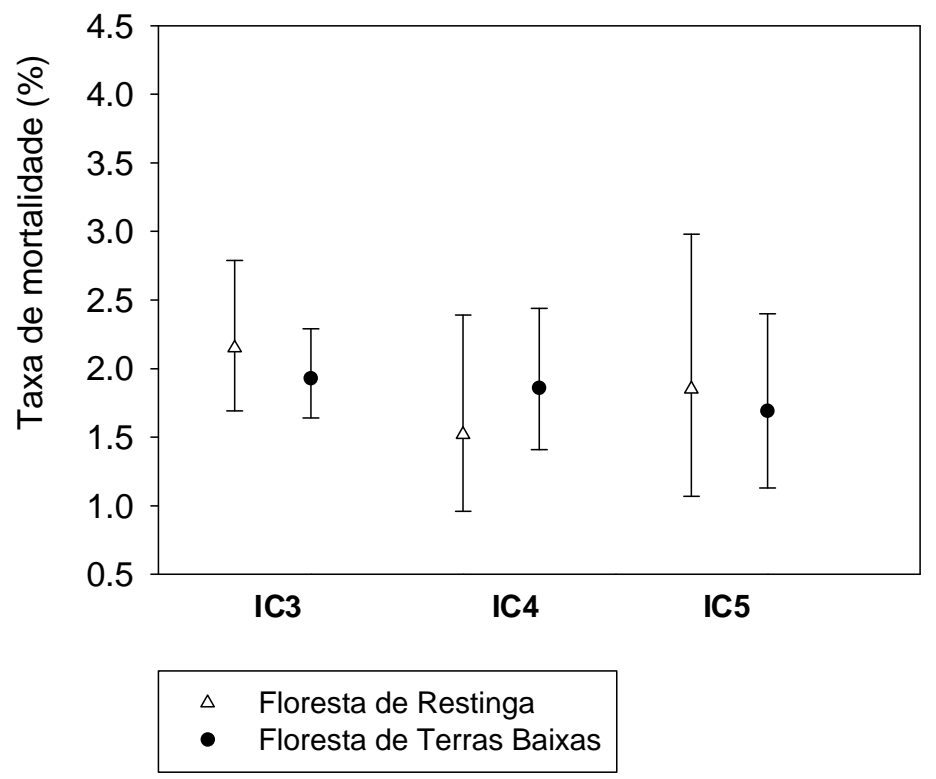

Figura 15 - Taxa de mortalidade $(\lambda)$, limite inferior (LI) e superior (LS) das árvores na floresta de restinga e de terras baixas por classe de IC 


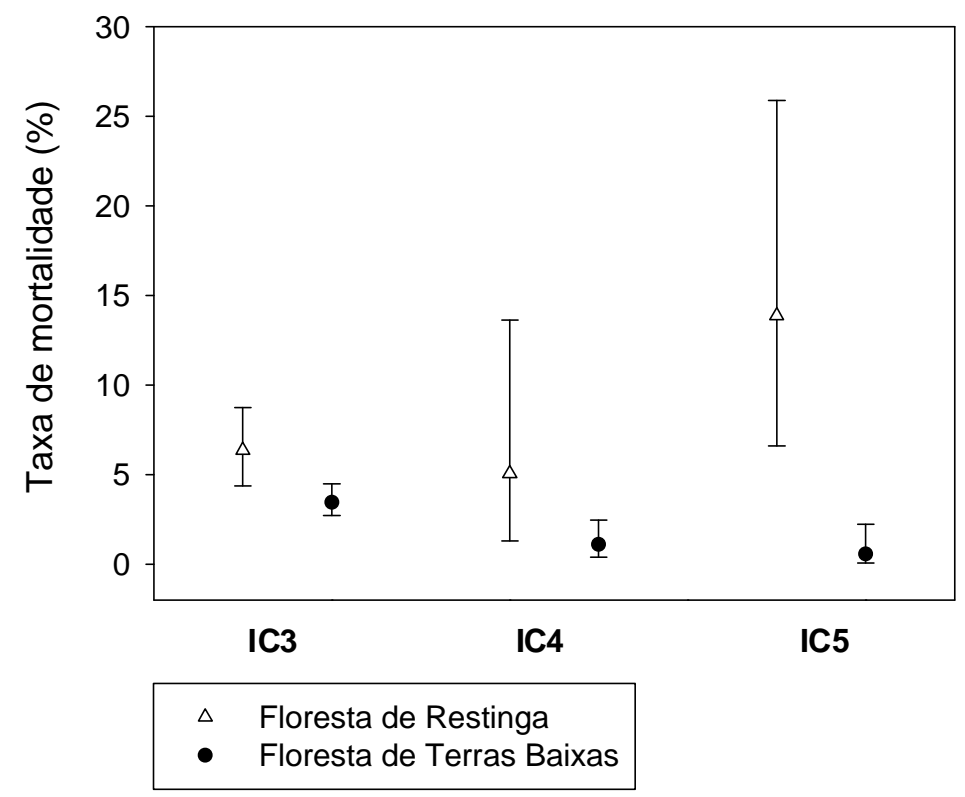

Figura 16 - Taxa de mortalidade ( $\lambda$ ), limite inferior (LI) e superior (LS) das palmeiras na floresta de restinga e de terras baixas por classe de IC

Variabilidade espacial e classes de mortalidade

As Figuras 17 e 18 e 1, 2 e 3 (apêndice 2) mostram a disposição dos indivíduos (árvores e palmeiras) mortos, nas diferentes classes de mortalidade, em cada parcela permanente deste estudo.

Do total de indivíduos mortos da comunidade na floresta de restinga, 54\% morreram em pé, $38 \%$ caídos e $8 \%$ desaparecidos. Na floresta de terras baixas a classe que mais contribuiu foi a de indivíduos mortos caídos com $42 \%$, seguido da classe mortos em pé com $39 \%$ e desaparecidos $19 \%$.

Com relação as formas de vida, na floresta de restinga as árvores e palmeiras apresentaram o mesmo padrão de mortalidade com $55 \%$ e $50 \%$ do total dos indivíduos mortos em pé respectivamente. Por outro lado, na floresta de terras baixas as palmeiras morreram mais caídas (52\%) e as árvores mais em pé (43\%).

É possível notar na parcela B (Figura 18), por exemplo, a mortalidade de um indivíduo da maior classe de diâmetro que resultou em um possível efeito dominó levando a morte de outros indivíduos (caídos). Na floresta de restinga, por outro 
lado, é possível notar padrões de agrupamento de indivíduos mortos em pé, classe de maior contribuição (Figura 17).

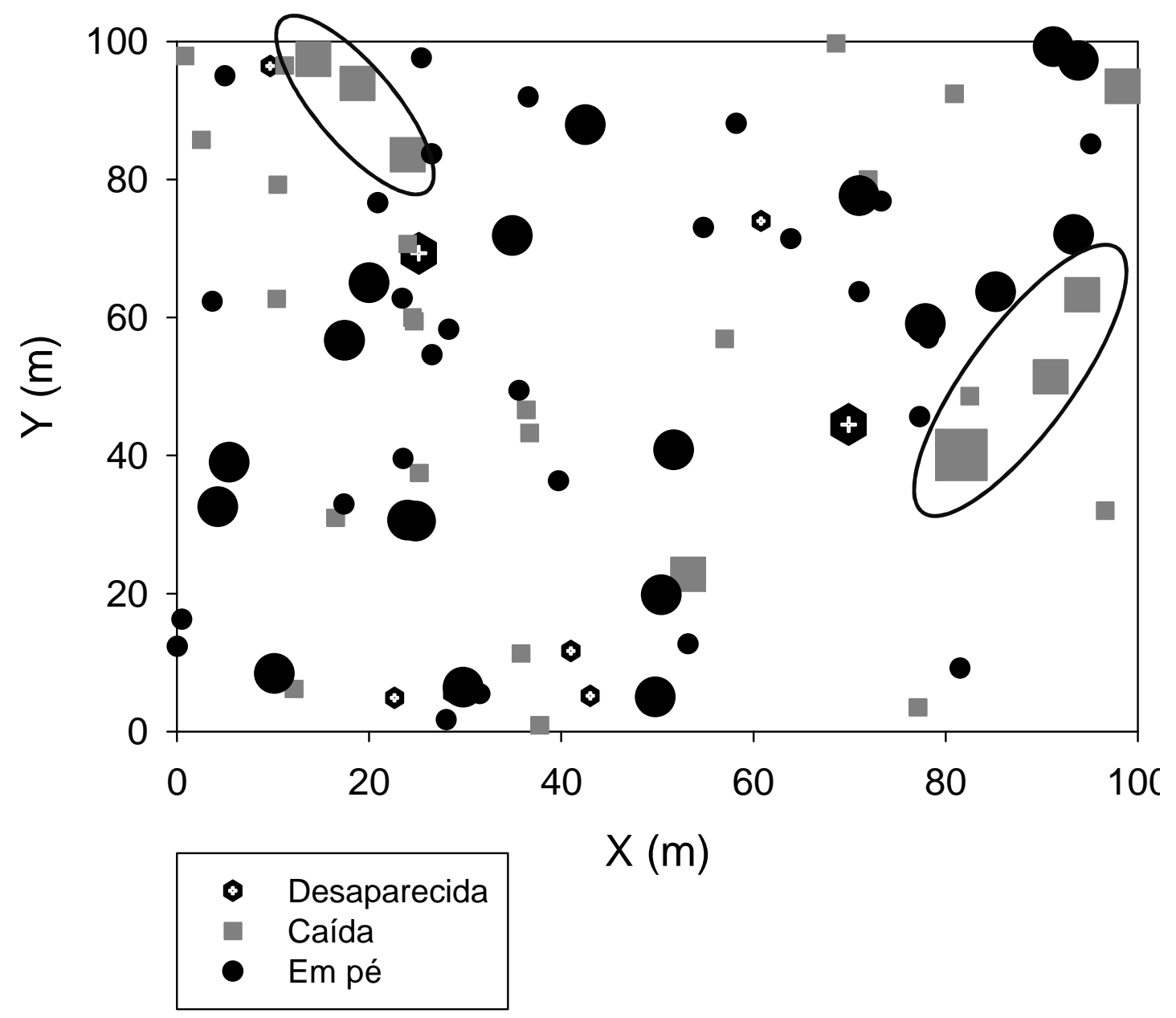

Figura 17 - Distribuição espacial dos indivíduos mortos na parcela A, nas diferentes classes de mortalidade. Os símbolos se apresentam em 3 tamanhos: menor representa a classe de DAP $<10 \mathrm{~cm}$, o intermediário $10-30 \mathrm{~cm}$ e o maior de $30-50 \mathrm{~cm}$. Os círculos representam um possível "efeito dominó" 


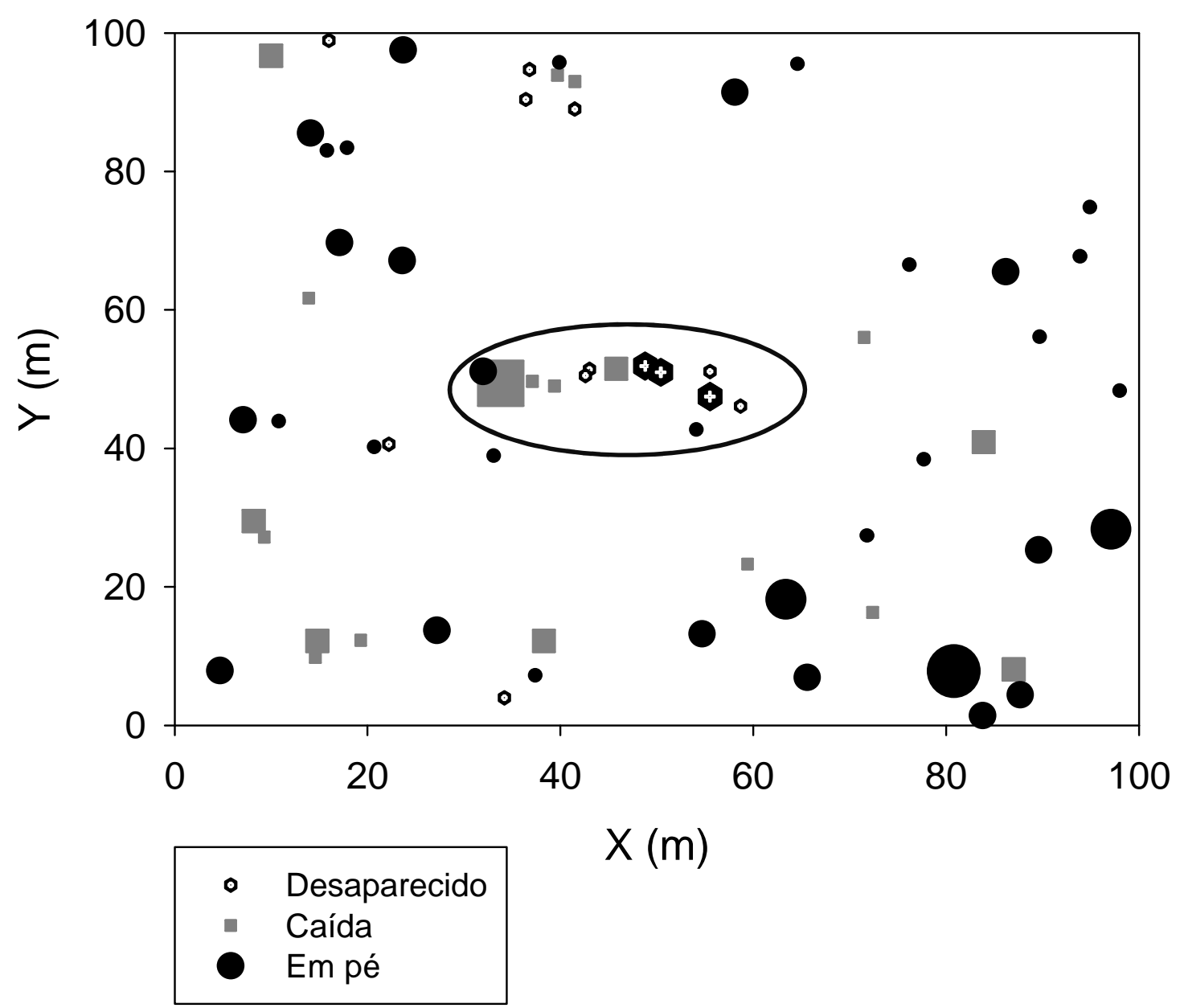

Figura 18 - Distribuição espacial dos indivíduos mortos na parcela B, nas diferentes classes de mortalidade. Os símbolos se apresentam em 4 tamanhos: menor representa a classe de DAP $<10 \mathrm{~cm}$, os intermediários $10-30 \mathrm{~cm}$ e $30-50 \mathrm{~cm}$ e o maior representa a classe $\geq 50$ $\mathrm{cm}(\mathrm{n}=2)$. Os círculos representam um possível "efeito dominó"

Variação entre as parcelas permanentes da FTB

A taxa de mortalidade das árvores, apesar de não ter revelado diferenças entre as áreas e os outros atributos associados, apresentou diferença significativa entre a parcela $B$ e a $E$ da floresta de terras baixas para os indivíduos com $D A P \geq 4,8 \mathrm{~cm}$ (apêndice 1, Tabela 5 e 8; Figura 19). A taxa de mortalidade decresceu da parcela B para a E, passando de $2,54 \%$ para $1,44 \%$. Provavelmente essa diferença pode estar associada a mortalidade e queda da árvore da classe $\geq 50 \mathrm{~cm}$ na parcela $B$, e que ocasionou um possível "efeito dominó" (Figura 19) levando a morte de outros indivíduos caídos e desaparecidos. 
A taxa de recrutamento dos indivíduos com $D A P \geq 4,8 \mathrm{~cm}$, apesar de não ter apresentado diferenças significativas, também decresceu da parcela B para E. A taxa de recrutamento foi igual a $1,50 \%, 1,16 \%, 1,10 \%$ e $1,08 \%$ nas parcelas $B, C, D$ e $E$ respectivamente. As taxas de mortalidade e recrutamento não apresentaram diferenças entre a parcela $A$ e as demais da floresta de terras baixas (Figura 19).

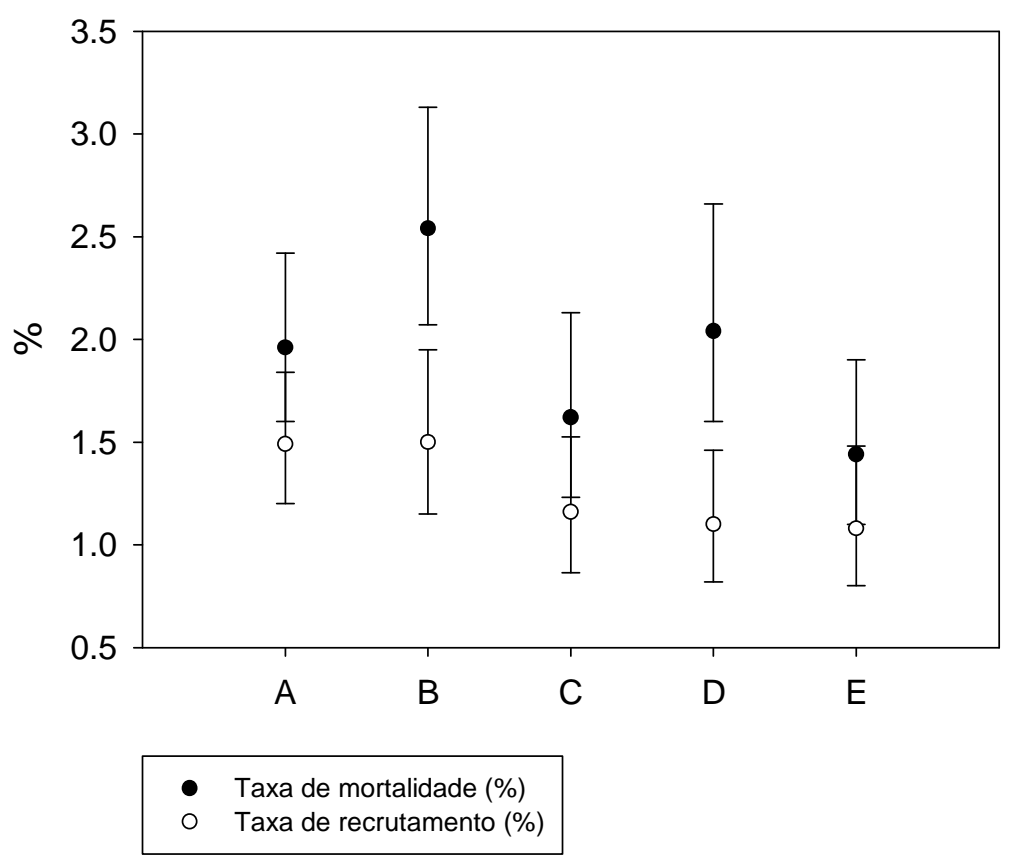

Figura 19 - Taxas de mortalidade e recrutamento das árvores com DAP $\geq 4,8 \mathrm{~cm}$ nas parcelas A, B, C, D e E. As barras indicam o limite inferior e superior 


\subsection{Mudanças na BAS}

Floresta de Restinga vs. Terras baixas

No geral o compartimento de biomassa viva acima do solo acumulou biomassa, com o crescimento e recrutamento excedendo as perdas devido a mortalidade, exceto na parcela permanente $B$ da floresta de terras baixas (Tabela 20). A mudança líquida na BAS da floresta de restinga foi igual a $0,32 \mathrm{Mg} \mathrm{ha}^{-1}$ ano $^{-1}$, inferior a média das mudanças líquidas na floresta de terras baixas que chegou a $0,64 \mathrm{Mg} \mathrm{ha}^{-1}$ ano $^{-1} \mathrm{e}$ variou de $-1,72 \mathrm{Mg} \mathrm{ha}^{-1} \mathrm{ano}^{-1}$ a $1,84 \mathrm{Mg} \mathrm{ha}^{-1} \mathrm{ano}^{-1}$. Na floresta de terras baixas o ganho por incremento dos sobreviventes foi superior, apesar da adição pelos recrutas ter sido maior na floresta de restinga (Tabela 20). As perdas devido a mortalidade também foram superiores na floresta de terras baixas (Tabela 20).

Tabela 20 - Incremento em BASi (sobreviventes), ganho de BASr devido ao recrutamento, perdas de BASm devido a mortalidade e mudanças líquidas na BAS dos indivíduos com o DAP $\geq$ $4,8 \mathrm{~cm}$ de cada parcela permanente deste estudo. A "média" representa a média da floresta de terras baixas (Chave et al. (2005): 3-var)

\begin{tabular}{lcccccc}
\hline & & BASi & BASr & BASm & $\begin{array}{c}\text { Mudanças } \\
\text { líquidas }\end{array}$ \\
\hline \multirow{2}{*}{ Floresta de restinga } & & \multicolumn{5}{c}{$M^{\prime}$ ha $^{-1}$ ano $^{-1}$} \\
\cline { 3 - 6 } Floresta de terras baixas & Parcela A & $\mathbf{2 , 3 2}$ & $\mathbf{0 , 1 8}$ & $\mathbf{2 , 1 8}$ & $\mathbf{0 , 3 2}$ \\
& & & & & \\
& Parcela B & 3,28 & 0,11 & 5,12 & $-1,72$ \\
& Parcela C & 3,86 & 0,08 & 2,97 & 0,97 \\
& Parcela D & 3,23 & 0,13 & 1,90 & 1,46 \\
& Parcela E & 3,41 & 0,09 & 1,66 & 1,84 \\
& média & $\mathbf{3 , 4 5}$ & $\mathbf{0 , 1 0}$ & $\mathbf{2 , 9 1}$ & $\mathbf{0 , 6 4}$ \\
\hline \hline
\end{tabular}

Classes de DAP

A Figura 20 ilustra o incremento em BAS dos sobreviventes por classe de DAP, em cada parcela permanente e a média da floresta de terras baixas. Através de sua análise é possível notar a contribuição de cada classe no incremento total da comunidade. 
$\mathrm{Na}$ floresta de restinga, a classe de DAP que mais acumulou biomassa durante 0 período de estudo foi a classe de 10-30 $\mathrm{cm}$ (Figura 20). Por outro lado, na floresta de terras baixas, em média, a classe das árvores grandes $(\geq 50 \mathrm{~cm})$ contribuiu com a maior parte do acúmulo total em BAS. Essa classe apresentou incremento negativo na floresta de restinga (Figura 20). A floresta de terras baixas também apresentou maior acúmulo de BAS na classe de $30-50 \mathrm{~cm}$. Finalmente, devido a densidade superior, a floresta de restinga apresentou maior acúmulo de BAS nas classes $<10$ $\mathrm{cm}$ e de $10-30 \mathrm{~cm}$.

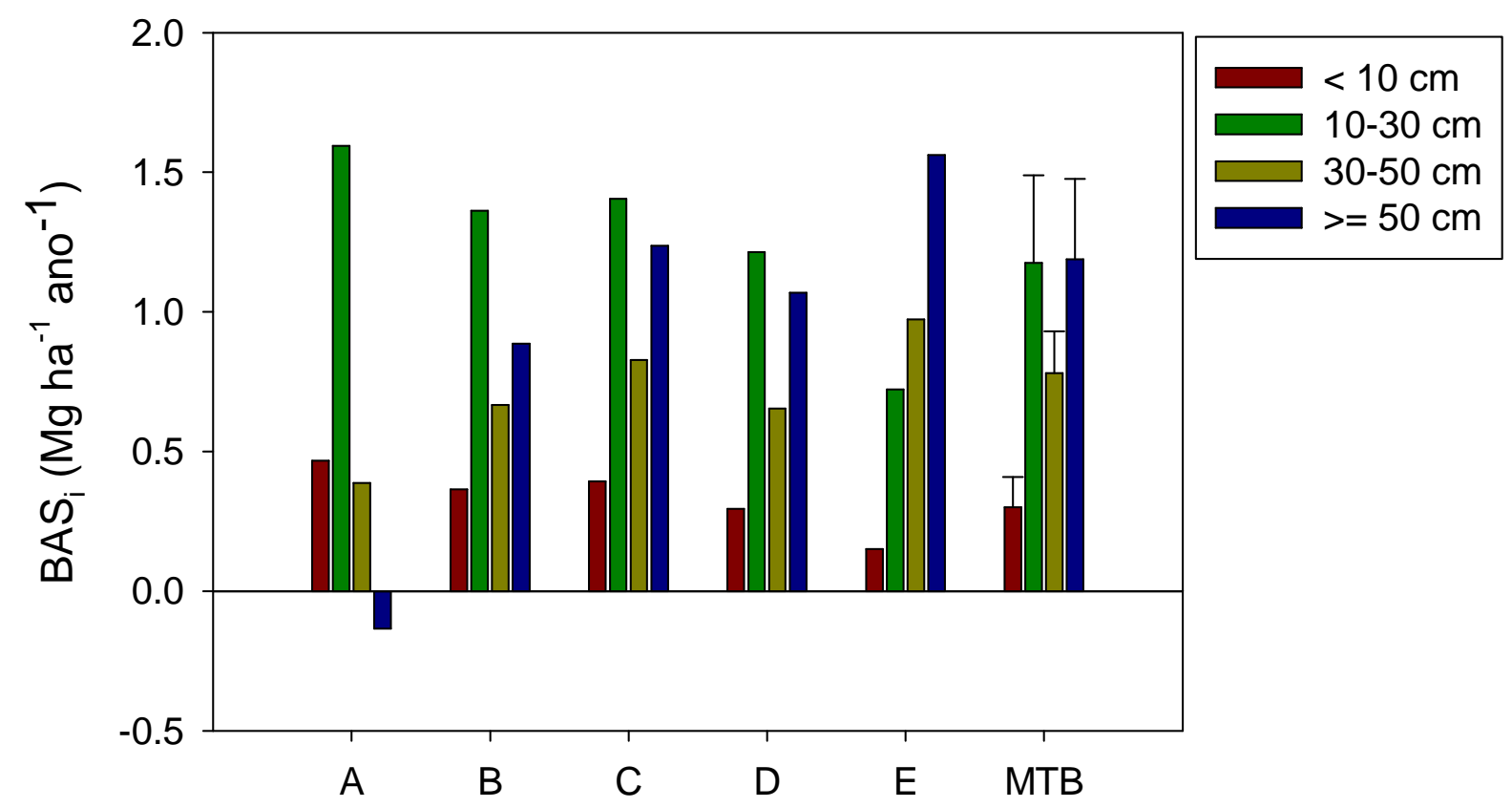

Figura 20 - Incremento em BAS (sobreviventes) por classe de DAP, em cada parcela permanente deste estudo (Chave et al. (2005): 3-var). MTB: média da floresta de terras baixas (barras indicam desvio padrão) 


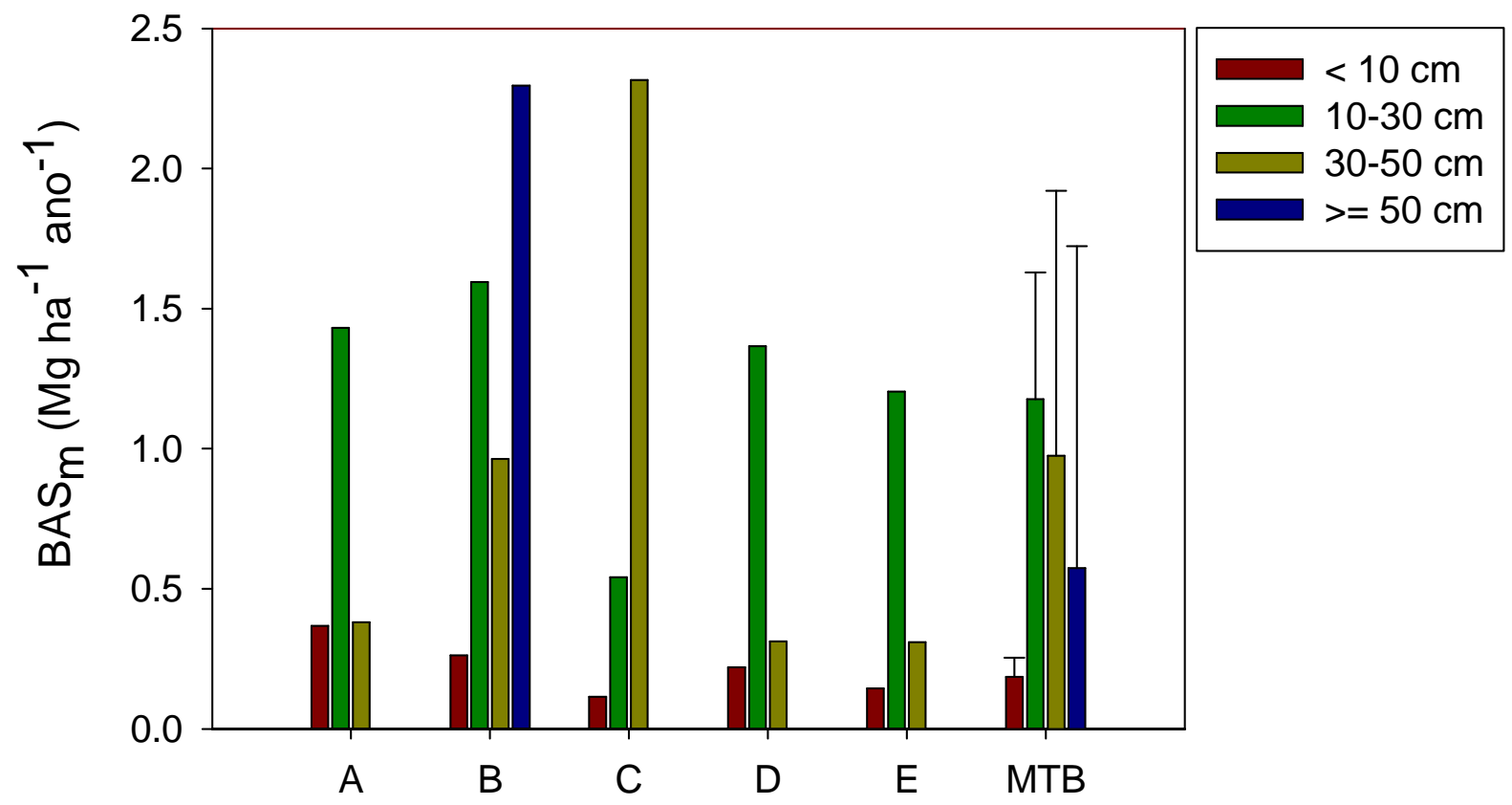

Figura 21 - Perdas de BAS (mortalidade) por classe de DAP, em cada parcela permanente deste estudo (Chave et al. (2005): 3-var). MTB: média da floresta de terras baixas (barras indicam desvio padrão)

Com relação as perdas devido a mortalidade, em ambas as áreas a classe de 10-30 $\mathrm{cm}$ apresentou as maiores perdas (Figura 21). A floresta de restinga apresentou maiores perdas nas classes $<10 \mathrm{~cm}$ e de $10-30 \mathrm{~cm}$. Por outro lado, a floresta de terras baixas perdeu maior biomassa nas classes de $30-50 \mathrm{~cm}$ e $\geq 50 \mathrm{~cm}$ (Figura 21).

\section{Variação entre as parcelas permanentes da FTB}

Dentro das parcelas permanentes da floresta de terras baixas, alguns padrões diferenciados com relação as mudanças na BAS puderam ser identificados. A variação líquida da BAS apresentou um gradiente decréscimo da parcela $B$ para a parcela $E$ (Tabela 20). A variação líquida passou de $-1,72 \mathrm{Mg} \mathrm{ha}^{-1}$ ano $^{-1}$ na parcela $B$ para $1,84 \mathrm{Mg} \mathrm{ha}^{-1} \mathrm{ano}^{-1}$ na parcela E. Ainda, as perdas devido a mortalidade também apresentaram um gradiente decréscimo passando de $5,12 \mathrm{Mg} \mathrm{ha}^{-1} \mathrm{ano}^{-1} \mathrm{da}$ parcela $\mathrm{B}$ para $1,66 \mathrm{Mg} \mathrm{ha}^{-1} \mathrm{ano}^{-1}$ na parcela $\mathrm{E}$. A parcela permanente que 
apresentou maior acúmulo bruto de BAS foi a parcela $\mathrm{C}$, conseqüência da maior taxa de incremento em diâmetro.

A acentuada perda de BAS da classe $\geq 50 \mathrm{~cm}$ (Figura 21) devido a mortalidade resultou na variação líquida negativa da parcela B (Tabela 20). Apesar da parcela permanente $C$ apresentar maior acúmulo bruto dos sobreviventes (Tabela 20), a classe de 30-50 cm apresentou perdas consideráveis de BAS (Figura 21), semelhante as perdas da maior classe na parcela B.

\subsection{Taxa de substituição ou "tunover" florestal}

Considerando os indivíduos arbóreos com DAP $\geq 4,8 \mathrm{~cm}$, todas as parcelas permanentes deste estudo se apresentam em declínio durante o período de estudo (Figura 22 a). O "turnover" florestal foi maior na floresta de restinga, para esse DAP de inclusão (Figura 23 a). Por outro lado, com o DAP de inclusão passando para 10 $\mathrm{cm}$, as parcelas $\mathrm{C}$ e $\mathrm{E}$ da floresta de terras baixas se apresentam em equilíbrio (Figura 22 b). O "turnover" florestal passa a ser maior na floresta de terras baixas (Figura 23 b). Por fim, a parcela permanente B apresentou o maior "turnover" florestal em ambos os DAP de inclusão (Figuras 23 a e b).

A relação entre a taxa de "turnover" e a variação líquida em BAS também revelou padrões interessantes (Figura 24). A variação líquida em biomassa decresceu com 0 aumento da taxa de "turnover" florestal, indicando que áreas com menor taxa de reposição acumulam mais biomassa acima do solo do que áreas com maior taxa de reposição (Figura 24). 

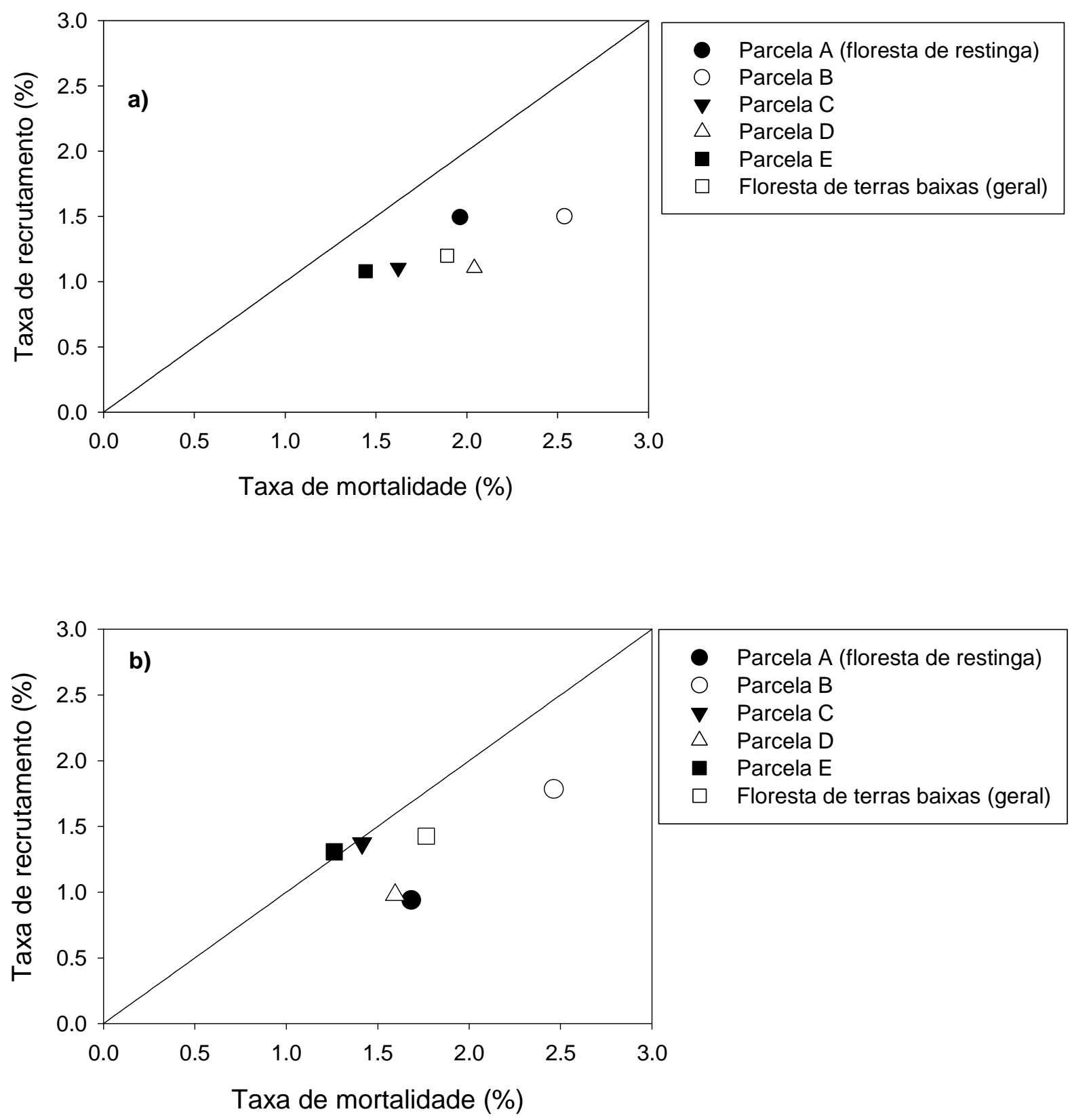

Figura 22 - Relação entre a taxa de mortalidade e recrutamento em cada parcela permanente deste estudo e da floresta de terras baixas (geral) das árvores com DAP $\geq 4,8$ (a) e DAP $\geq 10$ $\mathrm{cm}(\mathrm{b})$ 

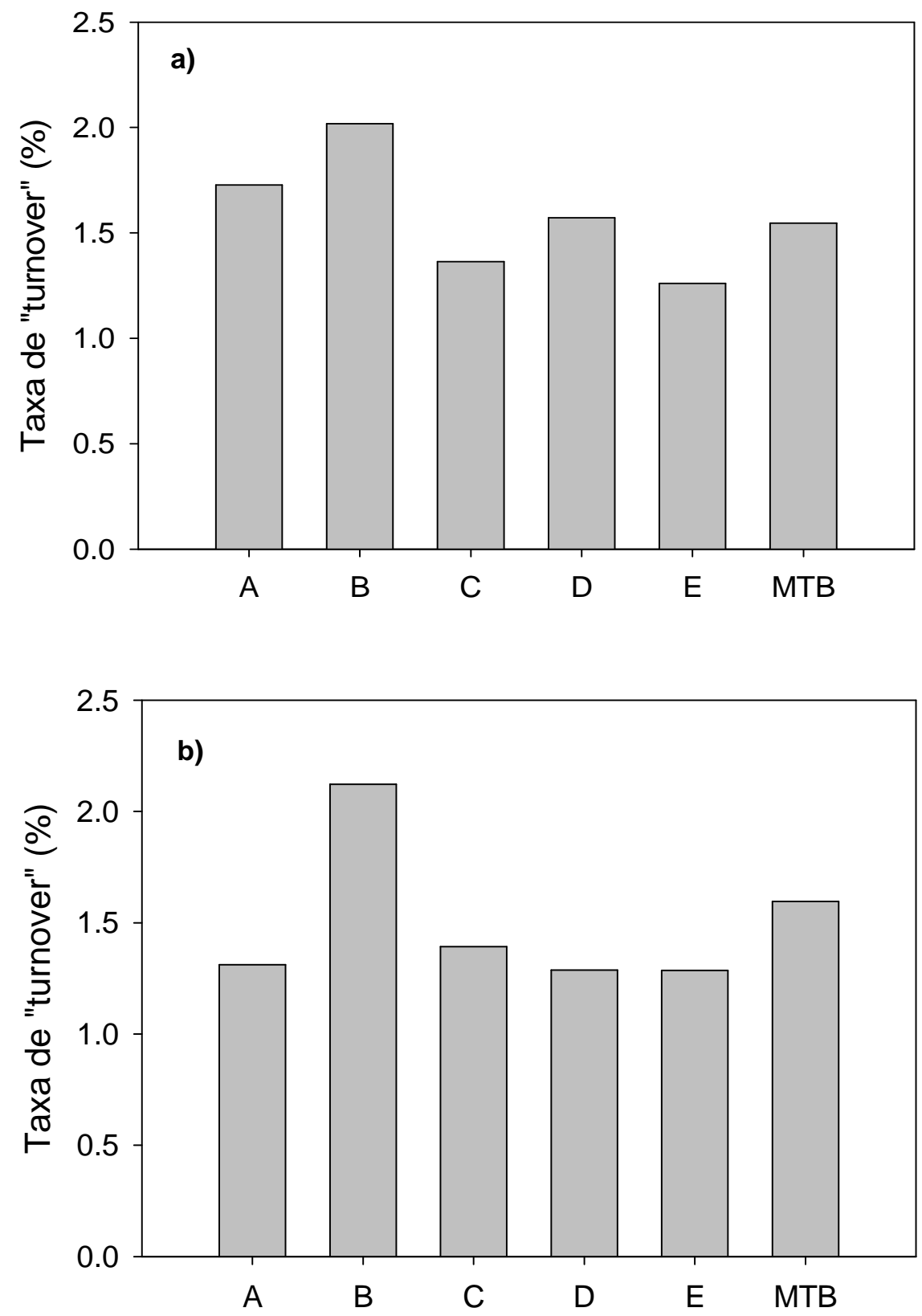

Figura 23 - Taxa de "turnover" (\%) de cada parcela permanente deste estudo das árvores com DAP $\geq$ 4,8 (a) e DAP $\geq 10 \mathrm{~cm}(\mathrm{~b})$ 


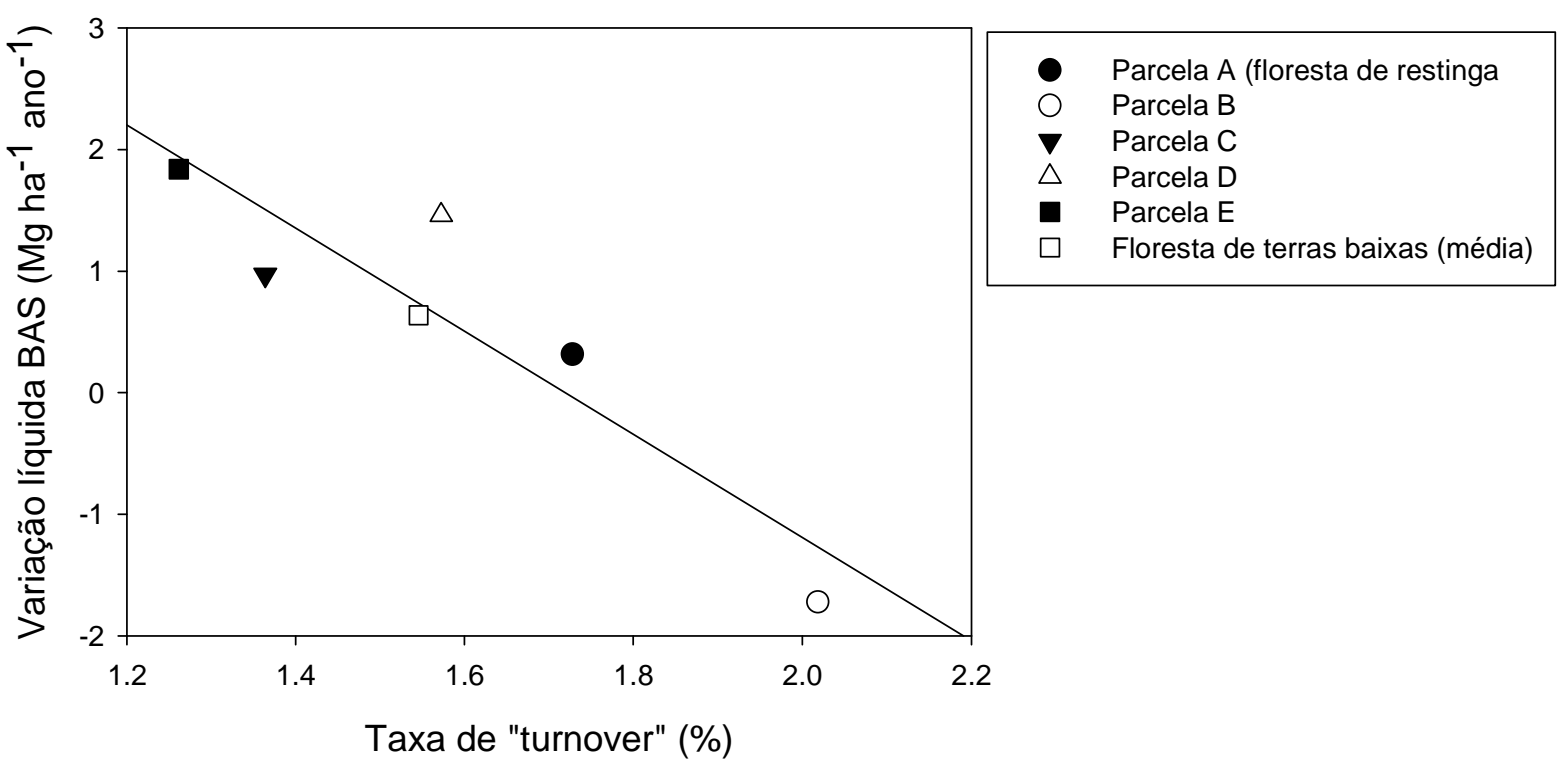

Figura 24 - Relação entre a taxa de "turnover" (\%) e a variação líquida da BAS (Mg ha ${ }^{-1}$ ano $\left.^{-1}\right)$ de cada parcela permanente deste estudo e da floresta de terras baixas (geral) (DAP $\geq 4,8$ $\mathrm{cm})$. Regressão linear: Variaçao líquida BAS $\left(\mathrm{Mg} \mathrm{ha}^{-1} \mathrm{ano}^{-1}\right)=7,29-4,24^{\star} \mathrm{Taxa}$ de turnover (\%). $R^{2}=0,82$ 


\section{DISCUSSÃO}

\subsection{Estrutura florestal}

A estrutura florestal da floresta de restinga e de terras baixas foi acentuadamente diferente. A floresta de restinga possui maior densidade de indivíduos, quando comparada com a floresta de terras baixas. Essa diferença é marcada pela alta densidade de indivíduos na menor classe de DAP $(<10 \mathrm{~cm})$.

A distribuição dos indivíduos nas diferentes classes de DAP também foi diferente entre as florestas, além da altura máxima estimativa. A floresta de restinga apresentou poucas árvores na maior classe de DAP e de menor altura estimada ( 19 m), por outro lado a floresta de terras baixas apresentou maior densidade de indivíduos na maior classe de DAP e mais altos ( 30 m). Esse fato contribuiu em grande parte para as diferenças encontradas na quantidade de biomassa estocada acima do solo entre as florestas, que por sua vez foi muito sensível a alometria como já descrito por Vieira et al. (2008) nas áreas de floresta Atlântica deste estudo.

A biomassa estimada da floresta de restinga com a equação alométrica de duas variáveis, ou seja, com diâmetro e densidade específica da madeira, não diferiu da biomassa estimada da floresta de terras baixas, que quase se igualaram. A quantidade de indivíduos de menor tamanho na floresta de restinga, além da mesma relação diâmetro-altura individual considerada pelo modelo, proporcionou esse estoque relativamente semelhante.

Por outro lado, quando a altura total foi inserida na estimativa da biomassa as diferenças no estoque foram detectadas. Tal fato mostra que a altura é uma boa variável a ser considerada na equação, quando se quer comparar os estoques de diferentes florestas. Desse modo, a floresta de terras baixas apresentou a maior quantidade de matéria seca acumulada acima do solo. Além da maior altura estimada, a maior quantidade de indivíduos maiores e de maior DAP contribuíram para essa diferença.

A distribuição do estoque de biomassa nas classes de DAP também revelou padrões diferenciados entre as áreas. Na floresta de restinga a classe de DAP que apresentou o maior estoque de BAS foi a de 10 a $30 \mathrm{~cm}$, contribuindo com $54,7 \%$ do 
total. Na floresta de terras baixas foi a classe $\geq 50 \mathrm{~cm}$, contribuindo com $33,7 \%$ do total.

Os resultados mostraram que a diferença na estatura entre as florestas, além da densidade relativa dos indivíduos grandes, contribuiu para a diferença no estoque de biomassa. Na floresta de restinga, a baixa estatura e densidade de indivíduos na maior classe de DAP estão relacionadas com as condições edáficas desse tipo de ambiente. Sob solo classificado como "Neossolo Quartzarênico" a floresta de restinga possui o substrato mais pobre em nutrientes de todo o gradiente altitudinal da floresta Atlântica, com elevado teor de areia (MARTINS et al., 2009). Ainda, a floresta é sazonalmente inundada durante os eventos de chuva forte e particularmente durante a estação chuvosa onde os solos permanecem encharcados por várias semanas (SCARANO, 2002).

A hidrologia do solo é um fator ambiental que pode desempenhar um forte papel na formação da estrutura e composição das florestas tropicais (JIRKA et al., 2007). Diferenças significativas no regime de água do solo entre os distintos tipos de florestas indicam que a hidrologia do solo impacta a distribuição da vegetação na paisagem (JIRKA et al., 2007). Provavelmente a floresta de baixa estatura que cresce nesse tipo de ambiente é dominada por espécies adaptadas e/ou limitadas a esse tipo de estresse (PAROLIN, 2002).

A alta densidade de indivíduos, mais pronunciada quando se considera os indivíduos com DAP $\geq 4,8 \mathrm{~cm}$, também pode ser resultado da maior incidência de luz que atinge o estrato inferior da floresta de restinga. Tal fato foi demonstrado também em áreas de Campinarana na Amazônia onde, na floresta de baixa estatura, a penetração de luz através do dossel foi relativamente alta quando comparada com a floresta de terra firme devido aos baixos valores de índice de área foliar mensurados (JIRKA et al., 2007).

As florestas de restinga e de terras baixas não apresentaram diferenças na área basal total. A maior densidade de indivíduos da maior classe na floresta de terras baixas, que contribuiu com elevado valor de área basal, compensou a diferença da alta densidade de indivíduos menores observada na floresta de restinga. A classe de 
DAP que mais contribuiu para o total da área basal foi a de 10 a $30 \mathrm{~cm}$, em ambas as áreas.

A densidade e a área basal variaram pouco de um inventário para o outro. Apesar da variação pouco acentuada, a densidade dos indivíduos decresceu em ambas as áreas. Na floresta de terras baixas a área basal seguiu o mesmo padrão, porém na floresta de restinga o incremento dos sobreviventes excedeu a leve diminuição da densidade, permanecendo a área basal constante durante o período de estudo.

\subsection{Taxa de incremento diamétrico}

Além das variações na estratégia de história de vida das espécies, são três os principais fatores limitantes do crescimento de uma árvore: (1) Água; (2) Radiação e (3) Nutrientes (BAKER; SWAINE; BURSLEM, 2003).

Devido a relativa proximidade entre as áreas de estudo (Figura 1), a precipitação total que atinge ambas as áreas é semelhante. Apesar do estrato inferior da floresta de restinga receber mais luz, a quantidade de radiação global que atinge o dossel de ambas as florestas é praticamente a mesma. Ainda, como vista anteriormente, a quantidade de nutrientes no solo é maior na floresta de terras baixas. Porém, em ambas as áreas, mesmo apresentando variação entre uma área e outra, a quantidade de nutrientes e capacidade de troca catiônica é muito baixa, o que indica que ambos os solos são pobres e pouco férteis.

Neste trabalho, diferenças nas taxas de incremento diâmétrico entre as áreas não foram encontradas. As diferenças também não foram encontradas para as palmeiras, onde estão representadas por poucas espécies. Esse fato provavelmente indica que as diferenças relativas a composição florística notadas entre os dois tipos de floresta (ASSIS, 1999), que reflete variações na estratégia de história de vida das árvores, não afetou significativamente a taxa de incremento da comunidade arbórea.

A relação entre a classe de tamanho e a taxa de incremento das árvores foi bastante clara nos dois tipos de floresta. A taxa de incremento médio aumentou com o diâmetro, mostrando maiores taxas na classe $\geq 50 \mathrm{~cm}$ e menores taxas na classe < $10 \mathrm{~cm}$. Segundo Swaine, Hall e Alexander (1987), essa relação pode ser explicada 
através de quatro teorias: (1) árvores grandes possuem maior probabilidade de terem suas copas completamente iluminadas; (2) árvores grandes possuem grande produção primária (copas grandes); (3) indivíduos de crescimento lento possuem maior probabilidade de terem sido eliminados quando pequenos; e (4) as maiores classes de tamanho excluem espécies de sub-dossel, na qual tipicamente possuem baixas taxas de crescimento.

Em florestas tropicais, a luz é tipicamente o principal fator limitante para 0 crescimento (CHAZDON; FETCHER, 1984; WHITMORE, 1996). A disponibilidade de luz vertical também se correlacionou positivamente com a taxa de incremento. Em ambas as florestas houve um aumento gradual da taxa de incremento com 0 aumento da classe de IC. A radiação luminosa diminui exponencialmente com o decréscimo da altura em florestas tropicais (YODA, 1978) e o aumento da iluminação do dossel da floresta possui um impacto claro e positivo no crescimento das árvores. Em La Selva, Costa Rica, e na região Noroeste da Amazônia, Peru, correlações positivas também foram encontradas entre as taxas de crescimento e o índice de iluminação de copa (CLARK; CLARK, 1992; KEELING et al., 2008).

Por outro lado, para as palmeiras essa relação mostrou um padrão diferenciado. A taxa de incremento diamétrico decresceu com o aumento do DAP, mostrando as maiores taxas na primeira classe de tamanho. O mesmo padrão foi observado com relação a disponibilidade de luz vertical, onde as maiores taxas de incremento foram observadas na classe 3 , de menor disponibilidade de luz.

A relação entre o DAP e a altura total das palmeiras é clara, linear e forte (ALVES; MARTINS; SANTOS, 2004; SCARANELLO et al., dados não publicados). Apesar de teoricamente não apresentarem crescimento secundário (cambial), as palmeiras a princípio investem na expansão do tronco próxima ao solo (ALVES; MARTINS; SANTOS, 2004). Por isso palmeiras de menor diâmetro tendem a ser mais estáveis estruturalmente que palmeiras de maior altura (ALVES; MARTINS; SANTOS, 2004; $\mathrm{RICH}$, 1986). Essa adição de tecidos no câmbio para aumentar a força, aparentemente continua ao longo dos outros estágios ontogênicos, porém a uma taxa diferenciada que decresce ao passo que chega a idade adulta, onde provavelmente passa a investir mais em crescimento apical. Por isso a ocorrência 
das baixas taxas de incremento diamétrico na maior classe de tamanho $(10-30 \mathrm{~cm})$ e também na maior classe de luz vertical (IC).

\subsection{Mortalidade e recrutamento}

Os intervalos de confiança mostraram que os dois tipos de floresta deste estudo apresentaram taxas de mortalidade da comunidade semelhantes. No geral, as taxas de mortalidade quando se considerou o DAP $\geq 4,8 \mathrm{~cm}$ de inclusão foram mais elevadas em ambas as áreas. A alta taxa de mortalidade dos indivíduos pequenos contribuiu para essa tendência. A mortalidade elevada de indivíduos pequenos tem sido reportada em alguns estudos em florestas tropicais (LANG; KNIGHT, 1983; CONDIT et al., 1999). A principal causa é a intensa competição entre indivíduos de menor tamanho.

Por outro lado, uma diferença marcante no padrão de mortalidade foi encontrada entre as formas de vida. Na floresta de restinga, a mortalidade das palmeiras foi maior para ambos os DAP de inclusão. Tal fato resultou em notáveis diferenças na meia vida das palmeiras, em relação as árvores. Para reduzir a metade uma população inicial, com a elevada taxa de mortalidade, as palmeiras levam 9,5 anos (DAP $\geq 4,8 \mathrm{~cm}$ ). Em contrapartida, as árvores levam 35 anos.

Para acompanhar a discussão das possíveis causas da elevada taxa de mortalidade das palmeiras na floresta de restinga, é preciso recorrer às causas. Do total de palmeiras mortas $14 \%$ foram desaparecidas, $41 \%$ caídas e $45 \%$ morreram em pé. A baixa quantidade de palmeiras mortas desaparecidas exclui a hipótese de qualquer interferência humana, relacionada com a extração ilegal de E. edulis (espécie predominante). O solo da restinga é instável, e variações grandes no lençol freático e chuvas de grande volume de água podem impactar o solo e proporcionar esse padrão de alta mortalidade quando comparado com as árvores. Adicionalmente, a alta umidade do solo, aliado as altas temperaturas pode acelerar as taxas de decomposição do tronco da palmeira, considerada de baixa densidade.

Embora não exista a relação clara entre a taxa de mortalidade e as classes de tamanho (LIEBERMAN; LIEBERMAN, 1987; MANOKARAN; KOCHUMMEN, 1987; SWAINE; HALL; ALEXANDER, 1987) em florestas tropicais, na floresta de restinga a 
maior classe de DAP não apresentou nenhuma árvore morta. Ainda, de todas as parcelas da floresta de terras baixas apenas a parcela $B$ teve um indivíduo com 0 DAP $\geq 50 \mathrm{~cm}$ morto. A taxa de mortalidade das palmeiras da classe $10-30 \mathrm{~cm}$ foi significativamente superior a da classe $<10 \mathrm{~cm}$ na floresta de terras baixas.

Curiosamente, a taxa de mortalidade da parcela B (início do gradiente) foi superior a taxa de mortalidade da parcela $\mathrm{E}$ (final do gradiente), com um gradiente decréscimo. Uma possível causa para esse fato foi a morte de uma árvore grande que caiu sobre outras formando o chamado "efeito dominó".

Com relação ao ingresso de indivíduos, a floresta de terras baixas teve maior taxa de recrutamento para os indivíduos que atingiram o DAP igual a $10 \mathrm{~cm}$. Para o DAP de $4,8 \mathrm{~cm}$, diferenças não foram encontradas.

As palmeiras na floresta de restinga apresentaram baixas taxas de recrutamento, indicando declínio acentuado da população devido as altas taxas de mortalidade. $\mathrm{Na}$ floresta de terras baixas, por outro lado, as palmeiras apresentaram maior taxa de recrutamento do que as árvores, que excederam significativamente as taxas de mortalidade.

\subsection{Mudanças na BAS}

Ambas as áreas acumularam biomassa durante o período de estudo. A floresta de terras baixas apresentou o maior ganho líquido em biomassa. Tal fato foi reflexo da contribuição dos indivíduos sobreviventes. $O$ incremento em biomassa dos indivíduos vivos foi maior na floresta de terras baixas, apesar da menor densidade de indivíduos. As árvores grandes, de maior abundância nas terras baixas, contribuíram significativamente para o maior incremento nesse tipo de floresta. Por outro lado, o incremento em biomassa através da entrada de novos indivíduos foi maior na floresta de restinga, que teve a maior quantidade de indivíduos recrutados.

A perda de biomassa devido a mortalidade também foi maior na floresta de terras baixas. Na floresta de restinga boa parte da perda devido a mortalidade é resultado de indivíduos da classe de 10 a $30 \mathrm{~cm}$. Na floresta de terras baixas a parcela B teve 
um indivíduo da maior classe morto de um inventário para o outro, contribuindo significativamente para essa diferença.

Consistentemente, a perda de biomassa devido a mortalidade foi maior que o ganho de biomassa através do crescimento dos indivíduos vivos na parcela B. Embora a mortalidade de árvores seja muito rara nas grandes classes de tamanho (KELLER et al., 1996), a biomassa de uma única árvore gigante (> $70 \mathrm{~cm}$ DAP) pode chegar a mais de 100 vezes maior que de uma pequena (4,8 a $10 \mathrm{~cm}$ DAP). Tal fato sugere que uma única árvore caída das maiores classes de tamanho possui um importante papel na mudança da biomassa nessa floresta do que muitas mortes de árvores pequenas.

grande impacto da morte infreqüente de grandes arvores nas flutuações da biomassa na floresta tropical Atlântica também sugere outro ponto relacionado a associação entre estrutura da floresta e flutuação da biomassa. O impacto da morte de uma árvore grande por ter mais efeitos substanciais na biomassa total perdida na floresta de terras baixas do que na restinga, na qual possui poucas árvores grandes.

O incremento dos sobreviventes também apresentou padrões diferenciados entre os dois tipos de floresta. Na floresta de restinga, as classes < 10 e de 10 a $30 \mathrm{~cm}$ acumularam maior biomassa do que na floresta de terras baixas, resultado da maior densidade de indivíduos em ambas as classes. Por outro lado, na floresta de terras baixas as classes de 30 a 50 e $\geq 50 \mathrm{~cm}$ acumularam mais biomassa do que na floresta de restinga, indicando que, devido ao dossel ser mais fechado na floresta de terras baixas, os indivíduos que possuem a copa totalmente exposta a luz tendem a acumular mais biomassa.

Curiosamente, a variação líquida da BAS apresentou um gradiente decréscimo entre as parcelas permanentes da floresta de terras baixas. Diferenças sutis com relação aos aspectos da dinâmica entre as parcelas permanentes desse gradiente podem ter influenciado nesse acréscimo. 


\subsection{Taxa de reposição ou "turnover" florestal}

O "turnover" é definido como uma taxa na qual a densidade das árvores mudam através de uma população (fluxo) em relação a um conjunto de árvores na população, estimado pela taxa média na qual eles recrutam ou morrem (PHILLIPS et al., 2004). Para o DAP de inclusão de $4,8 \mathrm{~cm}$, a floresta de restinga apresentou a maior taxa de "turnover". Por outro lado, quando o DAP de inclusão passa a ser 10 $\mathrm{cm}$, esse padrão muda. Porém, essas diferenças são sutis e mascaradas pela alta taxa de "turnover" da parcela B.

Os resultados evidenciaram claramente que a parcela B mostrou ser a parcela mais dinâmica de todas as outras. Eventos relacionados ao tempo, tais como ventos fortes podem ter influenciado para esse alto dinamismo, além da posição relativa próxima ao rio da Fazenda (maior exposição aos ventos fortes). Um evento extremo de ventos fortes pode ter ocasionado a queda dessa árvore gigante na parcela $B$, $e$ de outras da classe de 30 a $50 \mathrm{~cm}$ na parcela $C$. Fatores não relacionados a recursos, tais como tempestade de ventos (NELSON et al., 1994) e topografia (GALE; BARFORD, 1999) podem também contribuir para altas taxas de "turnover".

Os resultados desse estudo também revelaram uma estreita relação entre a taxa de "turnover" florestal e as variações líquidas em BAS. Tal fato sugere que o impacto das mudanças na biomassa no padrão geral de balanço de carbono em florestas tropicais é dependente das taxas de "turnover", principalmente das taxas de mortalidade (BAKER et al., 2004).

\subsection{Outras florestas tropicais}

Existe um padrão claro e diferenciado com relação a estrutura e dinâmica entre a floresta tropical Atlântica e outras florestas tropicais no Brasil e no Mundo (Tabelas 21, 22, 23 e 24), a partir dos resultados desse intervalo de estudo. Primeiro, a floresta tropical Atlântica apresenta a maior densidade de indivíduos (DAP $\geq 10 \mathrm{~cm}$ ). Tal fato é ainda mais acentuado na floresta de restinga. Apesar da alta densidade, a área basal e o estoque de biomassa são mais baixos na floresta tropical Atlântica (Tabela 21) em comparação com a Amazônia e outras florestas tropicais no mundo. 
A biomassa acima do solo (DAP $\geq 10 \mathrm{~cm}$ ) em florestas tropicais varia de menos de 200 a mais de $400 \mathrm{Mg} \mathrm{ha}^{-1}$ (CLARK et al., 2000). Diversos fatores podem contribuir para explicar essa variabilidade, sendo a disponibilidade de água um dos mais importantes (BAKER et al., 2003). Por outro lado, no caso da Floresta Tropical Atlântica, a precipitação não aparenta ser o principal fator limitante e sim sua distribuição ao longo das estações. Ainda, a baixa abundância de árvores gigantes provavelmente é um dos principais fatores responsáveis pelo baixo estoque de biomassa em relação aos outros tipos de floresta (OLIVEIRA; SANTOS; TABARELLI, 2008).

A taxa média de incremento em diâmetro (Tabela 22) e de "turnover" (Tabela 24) também revelaram padrões interessantes. Presumidamente a floresta tropical Atlântica aparenta ser uma floresta pouco dinâmica, quando comparada com outras florestas tropicais do mundo e principalmente com a Amazônia. Esse baixo dinamismo da floresta Atlântica pode estar diretamente correlacionado com a alta densidade de indivíduos e a distribuição da precipitação ao longo do ano (VIEIRA et al. 2004).

Por fim, a floresta tropical Atlântica mostrou acumular pouca biomassa proveniente dos indivíduos vivos quando comparada com a Amazônia e outras florestas tropicais no mundo (Tabela 23). Além do baixo acúmulo bruto, as perdas devido a mortalidade também foram relativamente menores devido ao baixo dinamismo. Tal fato resultou em variações líquidas intermediárias, quando comparadas com as outras florestas tropicais (Tabela 23). Rolim et al. (2005) chegou a reportar valores negativos de variações liquidas na biomassa acima do solo, porém com efeito de seca pronunciada em ano de "El-niño" (Tabela 23). 
Tabela 21 - Densidade (indivíduos ha $\left.{ }^{-1}\right)$, área basal $\left(\mathrm{m}^{2} \mathrm{ha}^{-1}\right)$ e biomassa acima do solo (BAS, $\left.\mathrm{Mg} \mathrm{ha}^{-1}\right)$ das áreas utilizadas neste estudo e de diversas florestas tropicais no Brasil e no mundo (DAP de inclusão igual a $10 \mathrm{~cm}$ )

\begin{tabular}{|c|c|c|c|c|c|}
\hline Referência & Floresta & País & Densidade (ind. ha ${ }^{-1}$ ) & Área basal $\left(m^{2} h a\right)$ & BAS $\left(\right.$ Mg ha $\left.^{-1}\right)$ \\
\hline FASHING et al., 2004 & Floresta montana & Kenya & 378 & - & - \\
\hline CONDIT et al., 1999 & Floresta de terras baixas - BCI & Panama & 429 & 27,8 & 405,0 \\
\hline LIEBERMAN; LIEBERMAN, 1987 & Floresta de terras baixas & Costa Rica & 446 & 27,8 & - \\
\hline AYYAPAN et al., 2004 & Floresta tropical sempre verde & Índia & 447 & - & - \\
\hline VIEIRA et al., 2004 & Terra firme - Amazônia / Santarém & Brasil & 460 & - & 281,0 \\
\hline CLARK; CLARK, 2000 & Floresta de terras baixas & Costa Rica & 462 & 25,8 & 182,9 \\
\hline VIEIRA et al., 2004 & Terra firme - Amazônia / Rio Branco & Brasil & 466 & - & 190,0 \\
\hline NEBEL et al., 2001 & Restinga alta - Amazônia & Peru & 467 & 26,0 & - \\
\hline RICE et al., 2004 & Terra firme - Amazônia / Santarém & Brasil & 469 & - & 293,3 \\
\hline MANOKARAN; KOCHUMEN, 1987 & Floresta de terras baixas - Dipterocarpaceae & Malasia & 492 & 32,4 & - \\
\hline JIRKA et al., 2007 & Terra firme (Ombrofila Aberta) - Amazônia & Brasil & 509 & - & 197,6 \\
\hline PHILLIPS et al., 1994 & "Oldfloodplain" - Amazônia & Peru & 546 & 26,9 & - \\
\hline NEBEL et al., 2001 & Restinga baixa - Amazônia & Peru & 556 & 22,6 & \\
\hline OKALI; OLA-ADAMS, 1987 & Floresta tropical "semi-evergreen" & Nigeria & 563 & 29,6 & 229,6 \\
\hline PHILLIPS et al., 1994 & Terra firme - Amazônia & Brasil & 572 & 27,7 & - \\
\hline PHILLIPS et al., 1994 & Terra firme - Amazônia & Peru & 575 & 29,1 & - \\
\hline JIRKA et al., 2007 & Campinarana - Amazônia & Brasil & 577 & - & 83,1 \\
\hline ESTE ESTUDO & Floresta Tropical Atlântica - Terras Baixas & Brasil & 600 & 26,5 & 204,7 \\
\hline VIEIRA et al., 2004 & Terra firme - Amazônia / Manaus & Brasil & 626 & - & 360,0 \\
\hline ESTE ESTUDO & Floresta Tropical Atlântica - Restinga & Brasil & 778 & 24,8 & 154,7 \\
\hline HOSHIZAKI et al., 2004 & Floresta de terras baixas - Dipterocarpaceae & Malasia & - & - & 431,2 \\
\hline MALHI et al., 2009 & Terra firme - Amazônia / Santarém (Km 67) & Brasil & - & - & 297,6 \\
\hline MALHI et al., 2009 & Terra firme - Amazônia / Caixuanã & Brasil & - & - & 426,5 \\
\hline
\end{tabular}


Tabela 22 - Taxa de incremento diamétrico médio $\left(\mathrm{mm} \mathrm{ano}^{-1}\right)$ das áreas utilizadas neste estudo e de diversas florestas tropicais no Brasil e no mundo. A coluna precipitação contém informação de pluviosidade quando disponível ou o tipo de classificação da floresta quanto a essa característica (quando a informação de pluviosidade não foi disponível) (DAP de inclusão igual a $10 \mathrm{~cm}$ )

\begin{tabular}{|c|c|c|c|c|}
\hline Referência & Floresta & País & $\begin{array}{l}\text { Precipitação } \\
(\mathbf{m m})^{*}\end{array}$ & $\begin{array}{l}\text { Taxa de incremento } \\
\left((\mathrm{mm} \mathrm{ano})^{-1}\right)\end{array}$ \\
\hline BELLINGHAM; TANNER, 2000 & Floresta tropical montana & Jamaica & 2500 & 0,9 \\
\hline ESTE ESTUDO & Floresta Tropical Atlântica - Restinga & Brasil & 2456 & 1,3 \\
\hline LIEBERMAN et al., 1985 & Floresta de terras baixas & Costa Rica & "moist" & 1,3 \\
\hline MANOKARAN; KOCHUMMEN, 1987 & Floresta de terras baixas - Dipterocarpaceae & Malasia & 2376 & 1,3 \\
\hline ESTE ESTUDO & Floresta Tropical Atlântica - Terras Baixas & Brasil & 2456 & 1,5 \\
\hline VIEIRA et al., 2004 & Floresta Amazônica - Manaus & Brasil & 2285 & 1,7 \\
\hline VEILLON, 1985 & Floresta tropical & Venezuela & "moist" & 2,3 \\
\hline VIEIRA et al., 2004 & Floresta Amazônica - Santarém & Brasil & 1909 & 3,1 \\
\hline VIEIRA et al., 2004 & Floresta Amazônica - Rio Branco & Brasil & 1940 & 3,9 \\
\hline NEBEL et al., 2001 & Restinga baixa - Amazônia & Peru & - & 4,4 \\
\hline NEBEL et al., 2001 & Restinga alta - Amazônia & Peru & - & 4,5 \\
\hline
\end{tabular}


Tabela 23 - Perdas devido a mortalidade, incremento devido ao recrutamento e crescimento dos indivíduos vivos e mudanças líquidas da BAS (Mg ha ${ }^{-1}$ ano ${ }^{-1}$ ) das áreas utilizadas neste estudo e de diversas florestas tropicais no Brasil e no mundo (DAP de inclusão igual a $10 \mathrm{~cm}$ )

\begin{tabular}{|c|c|c|c|c|c|c|}
\hline Referência & Floresta & País & $\begin{array}{c}\text { Mortalidade } \\
\left(\mathrm{Mg} \mathrm{ha}^{-1} \text { ano }^{-1}\right)\end{array}$ & $\begin{array}{l}\text { Recrutamento } \\
\left(\mathrm{Mg} \mathrm{ha}^{-1} \text { ano }^{-1}\right)\end{array}$ & $\begin{array}{l}\text { Crescimento } \\
\left(\mathrm{Mg} \mathrm{ha}^{-1} \text { ano }^{-1}\right)\end{array}$ & $\begin{array}{c}\text { Mudanças líquidas } \\
\left(\mathrm{Mg} \mathrm{ha}^{-1} \text { ano }^{-1}\right)\end{array}$ \\
\hline ROLIM et al., $2005^{*}$ & Floresta Tropical Atlântica Linhares & Brasil & - & - & - & -1.20 \\
\hline CHAVE et al., 2008 & "Wet Forest" - Sinharaja & Sri Lanka & 8.41 & 0.03 & 7.40 & -0.98 \\
\hline CHAVE et al., 2008 & "Moist Forest" - BCI & Panama & 5.29 & 0.03 & 5.01 & -0.25 \\
\hline CHAVE et al., 2008 & "Dry Forest" - HKK & Tailândia & 3.85 & 0.06 & 3.56 & -0.24 \\
\hline CHAVE et al., 2008 & "Wet Forest" - Palanan & Filipinas & 4.69 & 0.10 & 4.80 & 0.21 \\
\hline CHAVE et al., 2008 & "Moist Forest" - Edoro & DR Congo & 6.42 & 0.02 & 6.65 & 0.24 \\
\hline ESTE ESTUDO & Floresta Tropical Atlântica - Restinga & Brasil & 1.80 & 0.20 & 1.80 & 0.30 \\
\hline CHAVE et al., 2008 & "Moist Forest" - Yasuni & Equador & 6.22 & 0.05 & 6.76 & 0.38 \\
\hline ESTE ESTUDO & Floresta Tropical Atlântica - Terras Baixas & Brasil & 2.70 & 0.40 & 3.10 & 0.80 \\
\hline CHAVE et al., 2008 & "Moist Forest" - Lambir & Malasia & 6.14 & 0.04 & 7.13 & 1.03 \\
\hline CHAVE et al., 2008 & "Wet Forest " - La Planada & Colômbia & 3.57 & 0.09 & 4.75 & 1.27 \\
\hline CHAVE et al., 2008 & "Moist Forest - Lenda & DR Congo & 4.36 & 0.02 & 5.78 & 1.44 \\
\hline CHAVE et al., 2008 & "Moist Forest" - Pasoh & Malasia & 5.37 & 0.02 & 6.96 & 1.61 \\
\hline VIEIRA et al., 2004 & Terra Firme - Amazônia / Rio Branco & Brasil & - & - & 5.20 & 2.00 \\
\hline RICE et al., 2004 & Terra firme - Amazônia / Santarém (Km 67) & Brasil & 4.80 & 1.30 & 6.40 & 2.80 \\
\hline MALHI et al., 2009 & Terra firme - Amazônia / Manaus (BIONTE) & Brasil & 3.20 & - & 4.90 & - \\
\hline MALHI et al., 2009 & Terra firme - Amazônia / Caixuanã & Brasil & 4.10 & - & 5.00 & - \\
\hline MALHI et al., 2009 & Terra firme - Amazônia / Santarém (Km 67) & Brasil & 5.50 & - & 7.50 & - \\
\hline CHAVE et al., 2003 & "Moist Forest" - BCI & Panama & 5.34 a 5.60 & 0.21 a 0.58 & 5.04 a 6.47 & $(-1.19)$ a 0.82 \\
\hline
\end{tabular}

* Evento de "El-Niño" 
Tabela 24 - Taxas de mortalidade, recrutamento e "turnover" (\%) das áreas utilizadas neste estudo e de diversas florestas tropicais no Brasil e no mundo (DAP de inclusão igual a $10 \mathrm{~cm}$ )

\begin{tabular}{|c|c|c|c|c|c|}
\hline Referência & Floresta & País & $\begin{array}{c}\begin{array}{c}\text { Mortalidade } \\
(\%)\end{array} \\
\end{array}$ & $\begin{array}{c}\text { Recrutamento } \\
(\%)\end{array}$ & $\begin{array}{c}\text { "Turnover" } \\
(\%)\end{array}$ \\
\hline ESTE ESTUDO & Floresta Tropical Atlântica - Restinga & Brasil & 1,7 & $\mathbf{0 , 9}$ & 1,3 \\
\hline PHILLIPS et al., 2004 & Amazonia - sazonalmente inundada & Bolívia & 1,4 & 1,4 & 1,4 \\
\hline ESTE ESTUDO & Floresta Tropical Atlântica - Terras Baixas & Brasil & 1,8 & 1,2 & 1,5 \\
\hline PHILLIPS et al., 2004 & Terra Firme - Amazônia & Venezuela & 0,7 & 2,3 & 1,5 \\
\hline PHILLIPS et al., 2004 & Terra Firme - Amazônia & Brasil & 1,2 & 1,9 & 1,5 \\
\hline PHILLIPS et al., 2004 & Terra Firme - Amazônia & Bolívia & 2,0 & 1,3 & 1,7 \\
\hline SWAINE; HALL; ALEXANDER, 1987 & Floresta Semi-decídua & Ghana & 1,8 & - & 1,8 \\
\hline PHILLIPS et al., 2004 & Terra Firme - Amazônia & Brasil & 1,7 & 1,8 & 1,8 \\
\hline PHILLIPS et al., 2004 & Terra Firme - Amazônia & Brasil & 1,8 & 2,0 & 1,9 \\
\hline PHILLIPS et al., 2004 & Terra Firme - Amazônia & Peru & 2,5 & 1,3 & 1,9 \\
\hline MANOKARAN; KOCHUMMEN, 1987 & Floresta de terras baixas - Dipterocarpaceae & Malasia & 2,0 & - & 2,0 \\
\hline LIEBERMAN; LIEBERMAN, 1987 & Floresta de terras baixas & Costa Rica & 2,0 & - & 2,0 \\
\hline ROLIM et al., $2005 *$ & Floresta Tropical Atlântica Linhares & Brasil & 2,0 & 2,1 & 2,1 \\
\hline CONDIT et al., 1999 & Floresta de terras baixas - Dipterocarpaceae & Malasia & 1,5 & 2,8 & 2,1 \\
\hline PHILLIPS et al., 2004 & Terra Firme - Amazônia & Equador & 1,1 & 3,3 & 2,2 \\
\hline CONDIT et al., 1999 & Floresta de Terras Baixas - BCI & Panama & 2,0 & 2,7 & 2,3 \\
\hline PHILLIPS et al., 2004 & Amazonia - sazonalmente inundada & Bolívia & 3,3 & 1,8 & 2,5 \\
\hline OLIVEIRA-FILHO et al., 1997 & Floresta Tropical Atlântica - Montana (fragmento) & Brasil & 1,5 & 3,7 & 2,6 \\
\hline PHILLIPS et al., 2004 & Terra Firme - Amazônia & Peru & 3,3 & 3,9 & 3,6 \\
\hline
\end{tabular}

\footnotetext{
* Evento de "El-Niño"
} 


\section{CONCLUSÃO}

Variações em curto prazo na comunidade florestal de dois tipos distintos de floresta tropical Atlântica foram reportadas neste estudo. A floresta de restinga, fisionomia de características peculiares que a distingue das demais fisionomias da Floresta Atlântica, mostrou ser estruturalmente diferente da floresta de Terras Baixas do inicio da encosta da Serra do Mar.

Tais diferenças estruturais refletiram significativamente na quantidade de biomassa estocada em cada tipo de floresta. A floresta de terras baixas possui o maior estoque e as maiores árvores. Essas árvores maiores da floresta de terras baixas provavelmente são mais antigas que as árvores da restinga, evidenciado pelos valores de idade gerados pela taxa de incremento.

Apesar da diferença estrutural, as duas florestas mostraram ter dinamismo semelhante. É claro que diferenças relacionadas à composição florística, que refletem diferenças na história de vida das espécies, não abordado neste estudo, podem ter mascarado algum tipo de informação que possivelmente revelaria diferenças na dinâmica de algum grupo de espécie.

Por outro lado, as diferenças relacionadas com a forma de vida abordadas neste estudo revelaram padrões marcantes. A estrutura, crescimento e dinâmica das palmeiras da floresta tropical Atlântica foram expressivamente diferentes das árvores. Ainda, a dinâmica das palmeiras na floresta de Restinga foi diferente da floresta de Terras baixas.

$\mathrm{Na}$ floresta de restinga as palmeiras são mais dinâmicas que as árvores, principalmente devido as altas taxas de mortalidade que também proporcionam baixa meia vida. Esse comportamento é uma indicação clara de declínio de populações de espécies de palmeiras, principalmente da espécie predominante Euterpe edulis, nesse tipo de ambiente. Por outro lado, na floresta de terras baixas, as palmeiras da maior classe apresentaram baixa taxa de "turnover". Quando considera-se os indivíduos menores, as taxas de mortalidade são relativamente elevadas mas não tão expressivas quanto da floresta de restinga. 
Mesmo sem diferenças no crescimento e dinamismo, a floresta de terras baixas acumulou mais biomassa ( $60 \%$ a mais) do que a floresta de restinga. Novamente, as diferenças estruturais encontradas tiveram papel determinante nessa diferença.

A relação entre a dinâmica de uma floresta e as variações de biomassa acima do solo foi muito bem elucidada. As árvores grandes tiveram papel bastante pronunciado no estoque e variação de biomassa deste importante compartimento. Ainda, as variações dentro de um mesmo tipo de floresta podem ser ainda maiores do que entre outros tipos de floresta. A necessidade de ampla amostragem espacial foi vista nesse sentido. Além da ampla amostragem espacial, o papel dos estudos em longo prazo para descrever aspectos relacionados com a dinâmica de uma floresta e a inserção de uma abordagem diferenciada entre grupos de espécies de comportamento semelhante também se mostraram influentes.

É fato que existe extrema necessidade de utilizar variações na composição florística entre os diferentes tipos de floresta para estudar dinâmica de comunidade, principalmente em um prazo curto de tempo. Porém, resultados com a ausência desse tipo de informação mostraram-se eficientes para avaliar a dinâmica florestal.

A floresta tropical atlântica da Serra do Mar aparenta ser a floresta menos dinâmica dentre as florestas tropicais já estudadas, quando se considera o período deste estudo. A alta densidade de indivíduos e a distribuição da precipitação ao longo do ano podem ser fatores determinantes para esse fato, além de possíveis relações com o histórico de degradação dessa floresta.

Por fim, devido ao baixo crescimento e abundância natural de árvores grandes, a floresta tropical Atlântica possivelmente possui menor acúmulo bruto de biomassa viva quando comparado com outras florestas tropicais. Porém, as perdas devido a mortalidade são menores devido ao baixo dinamismo. A combinação desses fatores podem realmente colocar a floresta tropical Atlântica com papel significativo no ciclo do carbono, mesmo com área reduzida, em escala regional. 


\section{REFERÊNCIAS}

ACHARD, F.; EVA, H. D.; STIBIG, H. J.; MAYAUX, P.; GALLEGO J.; RICHARDS, T.; MALINGREAU J. P. Determination of deforestation rates of the world's humid tropical forests. Science, Washington, v. 297, n. 5583, p. 999-1002, 2002.

AGYEMAN, V. K.; SWAINE M. D.; THOMPSON, J. Responses of tropical forest tree seedlings to irradiance and the derivation of a light response index. Journal of Ecology, Oxford, v. 87, n. 5, p. 815-827, 1999.

AIBA, S.; TAKYU, M.; KYTAYAMA, K. Dynamics, productivity and species richness of tropical rainforests along elevational and edaphic gradients on Mount Kinabalu, Borneo. Ecological Research, Tokyo, v. 20, n. 3, p. 279-286, 2005.

ALVES, L. F. Estrutura, dinâmica e alometria de quatro espécies arbóreas tropicais. 2000. $146 \mathrm{f}$. Tese (Doutorado em Biologia Vegetal) - Universidade Estadual de Campinas, Campinas.

ALVES, L. F.; MARTINS, F. M.; SANTOS F. A. M. Allometry of a neotropical palm, Euterpe edulis Mart. Acta Botânica Brasilica, Porto alegre, v. 18, n. 2, p. 369-374, 2004.

ARAGAO, L. E. O. C.; MALHI, Y.; METCALFE, D. B. et al. Above- and below-ground net primary productivity across ten Amazonian forests on contrasting soils. Biogeociences, Göttingen, v. 6, p. 2441-2488, 2009.

ARRIAGA, L. Types and causes of tree mortality in a tropical montane cloud forest of Tamaulipas, Mexico. Journal of Tropical Ecology, Cambridge, v. 16, n. 5, p. 623636, 2000.

ASHTON, P. S.; HALL, P. Comparisons of structure among mixed dipterocarp forests of north-western Borneo. Journal of Ecology, Oxford, v. 80, n. 3, p. 459-481, 1992.

ASSIS, M. A. Florística e caracterização das comunidades vegetais da planície costeira de Picinguaba, Ubatuba - SP. 1999. 250 f. Tese (Doutorado em Biologia Vegetal) - Universidade Estadual de Campinas, Campinas.

AYYAPPAN, N.; PARTHASARATHY, N. Short-term changes in tree populations in a tropical evergreen forest at Varagalaiar, Western Ghats, India. Biodiversity and Conservation, London, v. 13, n. 10, p. 1843-1851, 2004.

BAKER, T. R.; SWAINE, M. D.; BURSLEM, D. F. R. P. Variation in tropical forest growth rates: combined effects of functional group composition and resource availability. Perspectives in Plant Ecology, Evolution and Systematics, Amsterdam, v. 6, n. 1-2, p. 21-36, 2003.

BAKER, T. R.; PHILLIPS, O. L.; MALHI, Y. et al. Increasing biomass in Amazonian forest plots. Philosophical Transactions of the Royal Society of London Series B - Biological Sciences, London, v. 359, n. 1443, p. 353-365, 2004a. 
BAKER, T. R.; PHILLIPS, O. L.; MALHI, Y. et al. Variation in wood density determines spatial patterns in Amazonian forest biomass. Global Change Biology, Oxford, v. 10, n. 5, p. 545-562, 2004b.

BEGON, M.; HARPER, J. L.; TOWNSEND, C. R. Ecology: individuals, populations and communities. 3. ed. Oxford: Blackwell Science, 1996. 1068 p.

BELLINGHAM, P. J.; TANNER E. V. J. The Influence of topography on tree growth, mortality, and recruitment in a tropical montane forest. Biotropica, Washington, v. 32, n. 3, p. 378-384, 2000.

BIGLER, C.; GRICAR, J.; BUGMANN, H.; CUFAR, K. Growth patterns as indicators of impending tree death in silver fir. Forest Ecology and Management, Amsterdam, v. 199, n. 2, p. 183-190, 2004.

BORMANN, F. H.; LIKENS, G. E. Pattern and process in a forested ecosystem. 2. ed. New York: Springer-Verlag, 1994. 272 p.

BRIENEN, R. J. W.; ZUIDEMA, P. A.; DURING, H. J. Auto correlated growth of tropical forest trees: Unraveling patterns and quantifying consequences. Forest Ecology and Management, Amsterdam, v. 237, n. 1-3, p. 179-190, 2006.

BROKAW, N. V. L.; WALKER, L. R. Summary of the effects of Caribbean hurricanes on vegetation. Biotropica, Washington, v. 23, n. 4, p. 442-447, 1991.

BROWN, S. Estimating biomass and biomass change of tropical forests: a primer. 1. ed. Rome: FAO, 1997. 55 p. (FAO Forestry Paper).

BROWN, I. F.; MARTINELLI, L. A.; THOMAS, W. W.; MOREIRA, M. Z.; CIDFERREIRA, C. A.; VICTORIA, R. L. Uncertainty in the biomass of Amazonian forests: an example from Rondonia, Brazil. Forest Ecology and Management, Amsterdam, v. 75, n. 1, p. 175-189, 1995.

BULLOCK, S. H. Effects of seasonal rainfall on radial growth in two tropical tree species. International Journal of Biometeorology, Leiden, v. 41, n. 1, p. 13-16, 1997.

CAREY, E. V.; BROWN, S.; GILLESPIE, A. J. R.; LUGO, A. E. Tree mortality in mature lowland tropical moist and tropical lower montane moist forests of Venezuela. Biotropica, Washington, v. 26, n. 3, p. 255-265, 1994.

CAVELIER, J.; TANNER, E.; SANTAMARIA, J. Effect of water, temperature and fertilizers on soil nitrogen net transformations and tree growth in an elfin cloud forest of Colombia. Journal of Tropical Ecology, Cambridge, v. 16, n. 1, p. 83-99, 2000.

CHAO, K. J.; PHILLIPS, O. L.; BAKER, T. R. Wood density and stocks of coarse woody debris in a northwestern Amazonian landscape. Canadian Journal of Forest Research, Ottawa, v. 34, n. 4, p. 795-805, 2008. 
CHAVE, J.; CONDIT, R.; LAO, S.; CASPERSEN, J. P.; FOSTER, R. B.; HUBBELL, S. P. Spatial and temporal variation of biomass in a tropical forest: results from a large census plot in Panama. Journal of Ecology, Oxford, v. 91, n. 2, p. 240-252, 2003.

CHAVE, J.; ANDALO, C.; BROWN, S.; CAIRNS, M.; CHAMBERS, J. C.; EAMUS, D.; FÖLSTER, H.; FROMARD, F.; HIGUCHI, N.; KIRA, T.; LESCURE, J.; NELSON, B. W.; OGAWA, H.; PUIG, H.; RIÉRA, B.; YAMAKURA, T. Tree allometry and improved estimation of carbon stocks and balance in tropical forests. Oecologia, Berlin, v. 145, n. 1, p. 87-99, 2005.

CHAVE, J.; CONDIT, R.; MULLER-LANDAU, H. C. et al. Assessing evidence for a pervasive alteration in tropical tree communities. PlosBiology, Karnataka, India, v. 6, n. 3, p. 455-462, 2008.

CHAZDON, R. L.; FETCHER, N. Light environments of tropical forests. In: MEDINA, E.; MOONEY, H. A.; VASQUES YANES, C. (Ed.). Physiological ecology of plants of the wet tropics. New York: Springer-Verlag, 1984. p. 27-36.

CIIAGRO. Série histórica de dados meteorológicos do município de Ubatuba, SP. <http://www.ciiagro.sp.gov.br/ciiagroonline/> Acesso em: 20 jul. 2009.

CLARK, D. A. Are tropical forests an important carbon sink? Reanalysis of the longterm plot data. Ecological Applications, Washington, v. 12, n. 1, p. 3-7, 2002.

CLARK, D. A.; CLARK, D. B. Life history diversity of canopy and emergent trees in a neotropical rainforest. Ecological Monographs, Durham, v. 62, n. 3, p. 315-344, 1992.

CLARK, D. A.; BROWN, S.; KICKLIGHTER, D. W.; CHAMBERS, J. Q.; THOMLINSON, J. R.; NI, J. Measuring net primary production in forests: Concepts and field methods. Ecological Applications, Washington, v. 11, n. 2, p. 356-370, 2001.

CLARK, D. A.; CLARK, D. B. Climate-induced annual variation in canopy tree growth in a Costa-Rica tropical rain-forest. Journal of Ecology, Oxford, v. 82, n. 4, p. 865872, 1994.

CLARK, D. B.; CLARK, D. A.; READ, J. M. Edaphic variation and the mesoscale distribution of tree species in a neotropical rain forest. Journal of Ecology, Oxford, v. 86, n. 1, p. 101-112, 1998.

CLARK, D. B.; CLARK, D. A. Landscape-scale variation in forest structure and biomass in a tropical rain forest. Forest Ecology and Management, Amsterdam, v. 137 , n. 1, p. 185-198, 2000.

CLARK, D. A.; PIPER, S. C.; KEELING, C. D.; CLARK, D. B. Tropical rain forest tree growth and atmospheric carbon dynamics linked to inter-annual temperature variation during 1984-2000. Proceedings of the National Academy of Sciences of the USA, Washington, v. 100, n. 10, p. 5852-5857, 2003. 
CLARK, J. S. Uncertainty and variability in demography and population growth: a hierarchical approach. Ecology, Brooklyn, v. 84, n. 6, p. 1370-1380, 2003.

COLLINS, M. The last rain forests: a world conservation atlas. 1. ed. London: Oxford University Press, 1990. 200 p.

CONDIT, R.; HUBBELL, S. P.; FOSTER, R. B. Mortality and growth of a commercial hardwood 'el-cativo', prioria-copaifera, in Panama. Forest Ecology and Management, Amsterdam, v. 62, n. 1-4, p. 107-122, 1993.

CONDIT, R.; ASHTON, P.; MANOKARAN, N.; LAFRANKIE, J. V.; HUBBELL, S. P.; FOSTER, R. B. Dynamics of the forest communities at Pasoh and Barro Colorado: comparing two 50-ha plots. Philosophical Transactions of the Royal Society of London Series B - Biological Sciences Journal, London, v. 354, n. 1391, p. 17391748, 1999.

CONDIT, R.; HUBBELL, S. P.; FOSTER, R. B. Mortality rates of 205 neotropical tree and shrub species and the impact of a severe drought. Ecological Monographs, Durham, v. 65, n. 4, p. 419-439, 1995.

CONNELL, J. H.; TRACEY, J. G.; WEBB, L. J. Compensatory recruitment, growth, and mortality as factors maintaining rain forest tree diversity. Ecological Monographs, Durham, v. 54, n. 2, p. 141-164, 1984.

CROWLEY, T. J. Causes of climate change over the past 1000 years. Science, Washington, v. 289, n. 5477, p. 270-277, 2000.

DEAN, W. With broadax and firebrand: the destruction of the Brazilian Atlantic forest. Berkeley: University of California Press, 1997. 482 p.

DEWALT, S. J.; MALIAKAL, S. K.; DENSLOW, J. S. Changes in vegetation structure and composition along a tropical forest chronosequence: implications for wildlife. Forest Ecology and Management, Amsterdam, v. 182, n. 1-3, p. 139-151, 2003.

DIXON, R. K.; BROWN, S.; HOUGHTON, R. A.; SOLOMON, A. M.; TREXLER, M. C.; WSNIEWSKI, J. Carbon pools and flux of global forest ecosystems. Science, Washington, v. 263, n. 5144, p. 185-190, 1994.

FASHING, P.; FORRESTEL, A.; SCULLY, C.; CORDS, M. Long-term tree population dynamics and their implications for the conservation of the Kakamega Forest, Kenya. Biodiversity and Conservation, London, v. 13, n. 4, p. 753-771, 2004.

FEELEY, K. J.; WRIGHT, S. J.; SUPARDI, M. N. N.; KASSIM, A. R.; DAVIES, S. J. Decelerating growth in tropical forest trees. Ecology Letters, Oxford, v. 10, n. 6, p. 461-469, 2007.

FERRI, M. G. Fisiologia vegetal. 2. ed. São Paulo: Editora Pedagógica, 1979. 401 p. 
FIELD, C. B.; BEHRENFELD, M. J.; RANDERSON, J. T.; FALKOWSKI, P. Primary production of the biosphere: integrating terrestrial and oceanic components. Science, Washington, v. 281, n. 5374 p. 237-240, 1998.

FRANKLIN, J. F.; SHUGART, H. H.; HARMON, M. Tree death as an ecological process. The causes, consequences and variability of tree mortality. Bioscience, Washington, v. 37, n. 8, p. 550-556, 1987.

FULTON, M. R.; HARCOMBE, P. A. Fine-scale predictability of forest community dynamics. Ecology, Brooklyn, v. 83, n. 5, p. 1204-1208, 2002.

GALE, N.; BARFORD, A. S. Canopy tree mode of death in a western Ecuadorian rainforest. Journal of Tropical Ecology, Cambridge, v. 15, n. 4, p. 415-436, 1999.

GIBBS, H. K.; BROWN, S.; NILES, J. O.; FOLEY, J. A. Monitoring and estimating tropical forest carbon stocks: making REDD a reality. Environmental Research Letters, Bristol, v. 2, n. 4, p. 1-13, 2007.

GOWER, S. T.; KUCHARIK, C. J.; NORMAN, J. M. Direct and indirect estimation of leaf area index, $f(A P A R)$, and net primary production of terrestrial ecosystems. Remote Sensing of Environment, New York, v. 70, n. 1, p. 29-51, 1999.

GUILHERME, F. A. G.; OLIVEIRA-FILHO, A. T.; APPOLINÁRIO, V.; BEARZOTI, E. Effects of flooding regime and woody bamboos on tree community dynamics in a section of tropical semideciduous forest in South-Eastern Brazil. Plant Ecology, Dordrecht, v. 174, n. 1, p. 19-36, 2004.

HARMON, M. E.; FRANKLIN, J. F.; SWANSON, F. J.; SOLLINS, P.; GREGORY, S. V.; LATTIN, J. D.; ANDERSON, N. H.; CLINE, S. P.; AUMEN, N. G.; SEDELL, J. R.; LIENKAEMPER, G. W.; CROMACK, K.; CUMMINS, K. W. Ecology of coarse woody debris in temperate ecosystems. Advances in Ecology Research, Amsterdam, v. 15, n. 1, p. 133-302, 1986.

HARMON, M. E. Guidelines for measurements of woody detritus in forest ecosystems. 1. ed. Seattle: U.S. LTER Network Office, 1996. 73 p.

HENRIQUES, R. P. B.; ARAUJO, D. S. D.; HAY, J. D. Descrição e classificação dos tipos de vegetação da restinga de Carapebus, Rio de Janeiro. Revista Brasileira de Botânica, São Paulo, v. 9, n. 2, p. 173-89, 1986.

HOUGHTON, R. A.; LAWRENCE, K. T.; HACKLER, J. L.; BROWN, S. The spatial distribution of forest biomass in the Brazilian Amazon: a comparison of estimates. Global Change Biology, Oxford, v. 7, n. 7, p. 731-746, 2001.

HOSHIZAKI, K.; NIIYAMA, K.; KIMURA, K.; YAMASHITA, T.; BEKKU, Y.; OKUDA, T.; QUAH, E. S.; SUPARDI Md. NOOR, N. Temporal and spatial variation of forest biomass in relation to stand dynamics in a mature, lowland tropical rainforest, Pasoh Forest Reserve, Malaysia. Ecological Research, Tokyo, v. 19, n. 3, p. 357-363, 2004. 
HUGHES, R. F.; KAUFFMAN, J. B.; JARAMILLO, V. J. Biomass, carbon, and nutrient dynamics of secondary forests in a humid tropical region of Mexico. Ecology, Brooklyn, v. 80, n. 6, p. 1892-1907, 1999.

IPCC. Climate Change 2007: impacts, adaptation and vulnerability. In: PARRY, M. L.; CANZIANI, O. F.; PALUTIKOF, J. P.; VAN DER LINDEN, P. J.; HANSON, C. E. (Ed.). Contribution of Working Group II to the Fourth Assessment Report of the Intergovernmental Panel on Climate Change. Cambridge: Cambridge University Press, 2007. p. 211-272.

JIRKA, S.; MCDONALD, A.; JOHNSON, M.; FELDPAUSCH, T.; COUTO, E. G.; RIHA, S. J. Relationships between soil hydrology and forest structure and composition in the southern Brazilian Amazon. Journal of Vegetation Science, Uppsala, v. 18, n. 2, p. 183-194, 2007.

JOLY, C. A.; MARTINELLI, L. A.; ALVES, L. F.; TAMASHIRO, J. Y.; AIDAR, M. P. M.; CAMARGO, P. B. de.; ASSIS, M. A.; BERNACCI, L. C.; DURIGAN, G. 2008. As parcelas permanentes do projeto temático biota gradiente funcional: composição florística, estrutura e funcionamento da floresta ombrófila densa dos núcleos Picinguaba e Santa Virgínia do Parque Estadual da Serra do Mar, estado de São Paulo, Brasil. In: SANQUETA, C. R. (Ed.). Experiências de monitoramento no bioma Mata Atlântica com uso de parcelas permanentes. Curitiba: RedeMAP; Funpar, 2008. p. 109-148.

KEELING, H. C.; BAKER, T.; MARTINEZ, R.; MONTEAGUDO, A.; PHILLIPS, O. Contrasting patterns of diameter and biomass increment across tree functional groups in Amazonian forests. Oecologia, Berlin, v. 158, n. 3, p. 521-534, 2008.

KELLER, M.; CLARK, D. A.; CLARK, D. B.; WEITZ, A. M.; VELDKAMP, E. If a tree falls in the forest. Science, Washington, v. 273, n. 1, p. 201-201, 1996.

KING, D. A.; DAVIES, S. J.; TAN, S.; NOOR, N. S. M. D. The role of wood density and stem support costs in the growth and mortality of tropical trees. Journal of Tropical Ecology, Cambridge, v. 94, n. 3, p. 670-680, 2006.

KORNING, J.; BALSLEV, H. Growth Rates and Mortality Patterns of Tropical Lowland Tree Species and the Relation to Forest Structure in Amazonian Ecuador. Journal of Tropical Ecology, Cambridge, v. 10, n. 2, p. 151-166, 1994.

KREBS, C.J. Ecological methodology. 2. ed. California: Benjamin Cummings, 1998. $624 \mathrm{p}$.

LANG, G. E.; KNIGHT, D. H. Tree growth, mortality, recruitment, and canopy gap formation during a 10-year period in a tropical moist forest. Ecology, Brooklyn, v. 64, n. 5 , p. $1075-1080,1983$.

LAURANCE, W. F.; NASCIMENTO, H. E. M.; LAURANCEA, S. G.; CONDIT, R.; D'ANGELO, S.; ANDRADE, A. Inferred longevity of Amazonian rainforest trees based on a long-term demographic study. Forest Ecology and Management, Amsterdam, v. 190, n. 2-3, p. 131-143, 2004. 
LAURANCE, W. F.; OLIVEIRA, A. A.; LAURANCE, S. G.; CONDIT, R.; NASCIMENTO, H. E. M.; SANCHEZ-THORIN, A. C.; LOVEJOY, T. E.; ANDRADE, A.; D'ANGELO, S.; RIBEIRO, J. E.; DICK, C. W. Pervasive alteration of tree communities in undisturbed Amazonian forests. Nature, London, v. 428, n. 6979, p. 171-175, 2004.

LEWIS, S. L.; PHILLIPS, O. L.; BAKER, T. R. et al. Concerted changes in tropical forest structure and dynamics: evidence from 50 South American long-term plots. Philosophical Transactions of the Royal Society of London Series B Biological Sciences, London, v. 359, n. 1443, p. 421-436, 2004.

LEWIS, S. L.; LOPEZ-GONZALEZ, G.; SONKE, B. et al. Increasing carbon storage in intact African tropical forests. Nature, London, v. 457, n. 1, p. 1003-1006, 2009.

LEWIS, S. L. Tropical forests and the changing earth system. Philosophical Transactions of the Royal Society of London Series B - Biological Sciences, London, v. 361, n. 1465, p. 439-450, 2006.

LEWIS, S. L.; MALHI, Y.; PHILLIPS, O. L. Fingerprinting the impacts of global change on tropical forests. Philosophical Transactions of the Royal Society of London Series B - Biological Sciences, London, v. 359, n. 1443, p. 437-462, 2004.

LIEBERMAN, D.; LIEBERMAN, M.; PERALTA, R.; HARTSHORN, G. S. Mortality patterns and stand turnover rates in a wet tropical forest in Costa Rica. Journal of Ecology, Oxford, v. 73, n. 3, p. 915-924, 1985.

LIEBERMAN, D.; LIEBERMAN, M. Forest tree growth and dynamics at La Selva, Costa Rica. Journal of Tropical Ecology, Cambridge, v. 3, n. 4, p.347-358, 1987.

MALHI, Y.; ARAGAO, L. E. O. C.; METCALFE, D. B. et al. Comprehensive assessment of carbon productivity, allocation and storage in three Amazonian forests. Global Change Biology, Oxford, v. 15, n. 5, p. 1255-1274, 2009.

MALHI, Y.; GRACE, J. Tropical forests and atmospheric carbon dioxide. Trends in Ecology and Evolution, Cambridge, v. 15, n. 8, p. 332-337, 2000.

MALHI, Y.; NOBRE, A. D.; GRACE, J.; KRUIJT, B.; PEREIRA, M. G. P.; CULF, A.; SCOTT, S. Carbon dioxide transfer over a Central Amazonian rain forest. Journal of Geophysical Research, Washington, v. 103, n. 24, p. 31593-31612, 1998.

MANOKARAN, N.; KOCHUMMEN, K. M. Recruitment, growth and mortality of tree species in a lowland dipterocarp forest in peninsular Malaysia. Journal of Tropical Ecology, Cambridge, v. 3, n. 4, p. 315-330, 1987.

MARTINS, S. C.; PICCOLO, M. C.; CAMARGO, P. B.; MARTINELLI, L. A.; ALMEIDA, D. Q. A. Nutrients, carbon and clay contents of soils along an altitudinal gradient in the coastal Atlantic Forest of Southeast Brazil (Ubatuba, SP). Geoderma, Amsterdan, 2010, Submetido. 
MELILLO, J. M.; MCGUIRE, A. D.; KICKLIGHTER D. W.; MOORE B.; VOROSMARTY C. J.; SCHLOSS A. L. Global climate change and terrestrial net primary production. Nature, London, v. 363, n. 6426, p. 234-240, 1993.

MORELLATO P. L. C.; HADDAD C. F. B. Introduction: The Brazilian Atlantic Forest. Biotropica, Washington, v. 32, n. 4, p. 786-792, 2000.

MYERS, N.; MITTERMIER, R. A.; MITTERMEIER, C. G.; FONSECA, G. A. B.; KENT, J. Biodiversity hotspots for conservation priorities. Nature, London, v. 403, n. 6772, p. 853-858, 2000.

NASCIMENTO, H. E. M.; LAURANCE, W. F. Total aboveground biomass in central Amazonian rainforests: a landscape-scale study. Forest Ecology and Management, Amsterdam, v. 168, n. 1-3, p. 311-321, 2002.

NASCIMENTO, H. E. M.; LAURANCE, W. F.; CONDIT, R.; LAURANCE, S. G. J.; D'ANGELO, S.; ANDRADE, A. C. Demographic and life-history correlates for Amazonian trees. Journal of Vegetation Science, Uppsala, v. 16, n. 6, p. 625-634, 2005.

NEBEL, G.; KVIST, L. P.; VANCLAY, J. K.; VIDAURRE, H. Forest dynamics in flood plain forests in the Peruvian Amazon: effects of disturbance and implications for management. Forest Ecology and Management, Amsterdam, v. 150, n. 1, p. 79-92, 2001.

NELSON, B. W.; KAPOS, V.; ADAMS, J. B.; OLIVEIRA, W. J.; BRAUN, O. P.; DOAMARAL, L. Forest disturbance by large blowdowns in the Brazilian Amazon. Ecology, Brooklyn, v. 75, n. 3, p. 853-858, 1994.

NEWTON, A. C. Forest ecology and conservation: a handbook of techniques. 1. ed. Oxford: University Press, 2007. 454 p.

NOGUEIRA, E. M.; FEARNSIDE, P. M.; NELSON, B. W.; BARBOSA, R. I.; KEIZER, E. W. H. Estimates of forest biomass in the Brazilian Amazon: new allometric equations and adjustments to biomass from wood-volume inventories. Forest Ecology and Management, Amsterdam, v. 256, n. 11, p. 1853-1867, 2008.

NOGUEIRA, E. M.; FEARNSIDE, P. M.; NELSON, B. W.; BARBOSA R.I.; KEIZER, E. W. H. Tree height in Brazil's 'arc of deforestation': shorter trees in south and southwest Amazonia imply lower biomass. Forest Ecology and Management, Amsterdam, v. 255, n. 7, p. 2963-2972, 2008.

OKALI, D. U.; OLA ADAMS, B. A. Tree Population Changes in treated Rainforest at Omo Forest Reserve, South Western Nigeria. Journal of Tropical Ecology, Cambridge, v. 3, n. 1, p. 291-312, 1987.

OLIVEIRA-FILHO, A.; MELLO, J. M.; SCOLFORO, J. R. Effects of past disturbance and edges on tree community structure and dynamics within a fragment of tropical semideciduous forest in south-eastern Brazil over a five-year period (1987-1992). Plant Ecology, Dordrecht, v. 131, n. 1, p. 45-66, 1997. 
PAROLIN, P. Submergence tolerance vs. escape from submergence: two strategies of seedling establishment in Amazonian floodplains. Environmental and Experimental Botany, Oxford, v. 48, n. 2, p. 177-186, 2002

PEDRONI, F. Aspectos da estrutura e dinâmica da comunidade arbórea na Mata Atlântica de planície e encosta em Picinguaba, Ubatuba, SP. 2001. 196 f. Tese (Doutorado em Biologia Vegetal) - Universidade Estadual de Campinas, Campinas, 2001.

PHILLIPS, O. L. Long-term environmental change in tropical forests: increasing tree turnover. Environmental Conservation, Lausanne, v. 23, n. 1, p. 235-248, 1996.

PHILLIPS, O. L.; GENTRY, A. H. Increasing turnover through time in tropical forests. Science, Washington, v. 263, n. 5149, p. 954-958, 1994.

PHILLIPS, O. L.; BAKER, T. R.; ARROYO, L. et al. Pattern and process in Amazon tree turnover, 1976-2001. Philosophical Transactions of the Royal Society of London Series B - Biological Science, London, v. 359, n. 1443, p. 381-407, 2004.

PHILLIPS, O. L.; ARAGÃO, L. E. O. C.; LEWIS, S. L. et al. Drought sensitivity of the Amazon Rainforest. Science, Washington, v. 323, n. 5919, p. 1344-1344, 2009.

PHILLIPS, O. L.; HALL, P.; GENTRY, A. H.; SAWYER, S. A.; VASQUEZ, R. Dynamics and species richness of tropical rain forests. Proceedings of the National Academy of Sciences of the USA, Washington, v. 91, n. 7, p. 2805-2809, 1994.

PHILLIPS, O. L.; MALHI, Y.; HIGUCHI, N.; LAURANCE, W.F.; NUNEZ, P. V.; VASQUEZ, R. M.; LAURANCE, S. G.; FERREIRA, L. V.; STERN, M.; BROWN, S.; GRACE, J. Changes in the carbon balance of tropical forests: Evidence from longterm plots. Science, Washington, v. 282, n. 5388, p. 439-442, 1998.

PIVELLO, V. R.; PETENON, D.; JESUS, F. M.; MEIRELLES, S. T.; VIDAL, M. M.; ALONSO, R. A. S. Chuva de sementes em fragmentos de Floresta Atlântica (São Paulo, SP, Brasil), sob diferentes situações de conectividade, estrutura florestal e proximidade da borda. Acta Botanica Brasilica, Porto Alegre, v. 20, n. 4, p. 845859, 2006.

PUTZ, F. E.; COLEY, P. D.; LU, K.; MONTALVO, A.; AIELLO, A. Uprooting and snapping of trees: structural determinants and ecological consequences. Canadian Journal of Forest Research, Ottawa, v. 13, n. 3, p. 1011-1020, 1983.

RICE, A. H.; PYLE, E. H.; SALESKA, S. R.; HUTYRA, L.; PALACE, M.; KELLER, M.; CAMARGO, P. B.; PORTILHO, K.; MARQUES, D. F.; WOFSY, S. C. Carbon balance and vegetation dynamics in an old-growth Amazonian forest. Ecological Applications, Washington, v. 14, n. 4, p. 55-71, 2004.

$\mathrm{RICH}$, P. M. Mechanical architecture of arborescent rain forest palms. Principes, Austin, v. 30, p. 117-131, 1986. 
RIZZINI, C. T. Tratado de fitogeografia do Brasil: aspectos sociológicos e florísticos. Sao Paulo: Edusp, 1979.

ROLIM, S.; JESUS, R. M.; NASCIMENTO, H. E. M.; COUTO, H. T. Z.; CHAMBERS, J. Q. Biomass change in an Atlantic tropical moist forest: the ENSO effect in permanent sample plots over a 22-year period. Oecologia, Berlin, v. 142, n. 2, p. 238-246, 2005.

LEWIS, S. L.; PHILLIPS, O. L.; BAKER, T. R. et al. Concerted changes in tropical forest structure and dynamics: evidence from 50 South American long-term plots. Philosophical Transactions of the Royal Society of London Series B Biological Sciences, London, v. 359, n. 1443, p. 421-436, 2004.

SALESKA, S. R.; MILLER, S. D.; MATROSS, D. M. et al. Carbon in Amazon forests: Unexpected seasonal fluxes and disturbance induced losses. Science, Washington, v. 302, n. 5650, p. 1554-1557, 2003.

SANCHEZ, M. Florística e Fitossociologia da vegetação arbórea nas margens do Rio da Fazenda (Parque Estadual da Serra do Mar - Núcleo Picinguaba Ubatuba S.P.). 1994. 90 f. Dissertação (Mestrado em Biologia Vegetal), Universidade Estadual Paulista, Rio Claro, SP.

SANCHEZ, M.; PEDRONI, F.; LEITÃO-FILHO, H. F.; CESAR, O. Composição florística de um trecho de floresta ripária na Mata Atlântica em Picinguaba, Ubatuba, SP. Revista Brasileira de Botânica, São Paulo, v. 22, n. 1, p. 31-42, 1999.

SÃO PAULO. Secretaria do Meio Ambiente do Estado de São Paulo. Planos de Manejo das Unidades de Conservação: Parque Estadual da Serra do Mar - Núcleo Picinguaba - Plano de Gestão Ambiental - fase 1. São Paulo, 1998.

SCARANO, F. R. Structure, function and floristic relantioships of plants communities in stressful habitats marginal to Brazilian Atlantic rainforest. Annals of Botany, Oxford, v. 90, n. 1, p. 517-524, 2002.

SHEIL, D. Growth assessment in tropical trees: large daily diameter fluctuations and their concealment by dendrometer bands. Canadian Journal of Forest Research, Ottawa, v. 33, n. 10, p. 2027-2035, 2003.

SHEIL, D.; JENNINGS, S.; SAVILL, P. Long-term permanent plot observations of vegetation dynamics in Budongo, a Ugandan rain Forest. Journal of Tropical Ecology, Cambridge, v. 16, n. 6, p. 765-800, 2000.

SHEIL, D.; BURSLEM, D. F. R. P.; ALDER D. The Interpretation and Misinterpretation of Mortality Rate Measures. Journal of Ecology, Oxford, v. 83, n. 2, p. 331-333, 1995.

SHEIL, D.; MAY, R. M. Mortality and recruitment rate evaluations in heterogeneous tropical forests. Journal of Ecology, Oxford, v. 84, n. 1, p. 91-100, 1996. 
SHEIL, D. Evaluating turnover in tropical forests. Science, Washington, v. 268, n. 5212, p. 894, 1995.

SILVA, R. P.; SANTOS, J.; TRIBUZY, E. S.; CHAMBERS, J. Q.; NAKAMURA, S.; HIGUCHI, N. Diameter increment and growth patterns for individual tree growing in Central Amazon, Brazil. Forest Ecology and Management, Amsterdam, v. 166, n. 1, p. 295-301, 2002.

SOS MATA ATLÂNTICA. Atlas dos remanescentes florestais da Mata Atlântica, período 1995-2000. São Paulo: Fundação SOS Mata Atlântica \& INPE, 2002.

SOS MATA ATLÂNTICA. Boletim Informativo, São Paulo, v. 1, n. 8, jun./jul., 1999.

SPIES, T. A.; FRANKLIN, J. F.; THOMAS, T. B. Coarse woody debris in Douglas-fir forests of Western Oregon and Washington. Ecology, Brooklyn, v. 69, n. 6, p. 1689$1702,1988$.

SWAINE, M. D.; HALL, J. B.; ALEXANDER, I. J. Tree Population Dynamics at Kade, Ghana (1968-1982). Journal of Tropical Ecology, Cambridge, v. 3, n. 4, p. 331345, 1987.

SWAINE, M. D.; LIEBERMAN, D.; PUTZ, F. E. The Dynamics of Tree Populations in Tropical Forest: A Review. Journal of Tropical Ecology, Cambridge, v. 3, n. 4, p. 359-366, 1987.

SWAINE, M. D.; LIEBERMAN, D. Note on the calculation of mortality rates. Journal of Tropical Ecology, Cambridge, v. 3, p. 2-3, 1987.

SWAINE, M. D.; HALL, J. B. Early succession on cleared forest land in Ghana. Journal of Ecology, Oxford, v. 71, n. 2, p. 601-627, 1983.

TALORA, D. C.; MAGRO, T. C.; SCHILLING, A. C. Impacts associated with trampling on tropical sand dune vegetation. Forest Snow and Landscape Research, Zurich, v. 81, n. 1-2, p. 151-162, 2007.

VAN-DER-MEER, P. J.; BONGERS, F. Patterns of tree-fall and branch-fall in a tropical rain forest in French Guiana. Journal of Ecology, Oxford, v. 84, n. 1, 1996.

VAN-GELDER, H. A.; POORTER, L.; STERCK, F. J. Wood mechanics, allometry, and life-history variation in a tropical rain forest tree community. New Phytologist, London, v. 171, n. 2, p. 171, 367-378, 2006.

VAN MANTGEM, P. J.; STEPHENSON, N. L.; MUTCH, L. S.; JOHNSON, V. G.; ESPERANZA, A. M.; PARSONS, D. J. Growth rate predicts mortality of Abies concolor in both burned and unburned stands. Canadian Journal of Forest Research, Ottawa, v. 33, n. 6, p. 1029-1038, 2003.

VANCLAY, J. K. Sustainable timber harvesting - Simulation studies in the tropical rain-forests of North Queensland. Forest Ecology and Management, Amsterdam, v. 69, n. 1-3, p. 299-320, 1994. 
VANCLAY, J. Modelling forest growth and yield: applications to mixed tropical forests. 1 ed. Oxford: CAB International, 1994. $336 \mathrm{p}$.

VÁSQUEZ, M. R.; PHILLIPS, O. L. Allpahuayo: floristics, structure, and dynamics of a high-diversity forest in Amazonian Peru. Annals of the Missouri Botanical Garden, St. Louis, v. 87, n. 1, p. 499-527, 2000.

VEILLON, J. P. El crecimiento de algunos bosques naturales de Venezuela en relación con los para'metros Del medio ambiente. Revista Forestal Venezolana, Mérida, v. 29, n. 1, p. 5-121, 1985.

VELOSO, H. P.; RANGEL, A. L. R. F.; LIMA J. C. A. Classificação da vegetação brasileira adaptada a um sistema universal. Rio de Janeiro: IBGE, Departamento de Recursos Naturais e Estudos Ambientais, 1991.

VELOZO, H. P.; KLEIN, R. M. As comunidades e associações da mata pluvial do sul do Brasil. III. As associações das planícies costeiras do quaternário, situadas entre o Rio Itapocu (estado de Santa Catarina) e a Baía de Paranaguá (estado do Paraná). Sellowia, Florianópolis, v. 13, p. 205-260, 1961.

VIDAL, M. M.; PIVELLO, V. R.; MEIRELLES, S. T.; METZGER J. P. Produção de serapilheira em floresta Atlântica secundária numa paisagem fragmentada (Ibiúna, SP): importância da borda e tamanho dos fragmentos. Revista Brasileira de Botânica, São Paulo, v. 30, n. 3, p. 521-532, 2007.

VIEIRA, S. A.; ALVES, L. F.; AIDAR, M. et al. Estimation of biomass and carbon stocks: the case of the Atlantic Forest. Biota Neotropica, São Paulo, v.8, n. 2, p. 2129, 2008.

VIEIRA, S.; CAMARGO, P. B.; SELHORST, D.; DA SILVA, R.; HUTYRA, L.; CHAMBERS, J. Q.; BROWN, I. F.; HIGUCHI, N.; DOS SANTOS, J.; WOFSY, S. C.; TRUMBORE, S. E.; MARTINELLI, L. A. Forest structure and carbon dynamics in Amazonian tropical rain forests. Oecologia, Berlin, v. 140, n. 3, p. 468-479, 2004.

VIEIRA, S. A. Mudanças globais e taxa de crescimento arbóreo na Amazônia. 2003. 115 f. Tese (Doutorado em Ciências) - Centro de Energia Nuclear na Agricultura, Universidade de São Paulo, Piracicaba, 2003.

VITOUSEK, P. M.; WALKER, L. R.; WHITEAKER, L. D.; MATSON, P. A. Nutrient limitations to plant growth during primary succession in Hawaii Volcanoes National Park. Biogeochemistry, Cidade, v. 23, n. 3, p. 197-215, 1993.

WHITMORE, T. C. Canopy gaps and the two major groups of forest trees. Ecology, Brooklyn, v. 70, n. 3, p. 536-538, 1989.

WHITMORE, T. C.; BROWN, N. D. Dipterocarp seedling growth in rain forest canopy gaps during six and a half years. Philosophical Transactions of the Royal Society of London Series B - Biological Sciences, London, v. 351, n. 1344, p. 1195-1203, 1996. 
WIEGAND, T.; MARTÍNEZ, I.; HUTH, A. Recruitment in tropical tree species: revealing complex spatial patterns. American Naturalist, Chicago, v. 174, n. 4, 2009. DOI: 10.1086/605368. Disponível em: http://www.thorstenwiegand.de/pdf/WiegandEtAll2009AmNat_small.pdf. Acesso em: 12/11/2009

WILLIS, K. J.; MCELWAIN, J. C. The evolution of plants. 1. ed. Oxford: Oxford University Press, 2002. 378 p.

YAO, X. H.; TITUS, S. J.; MACDONALD, S. E. A generalized logistic model of individual tree mortality for aspen, white spruce, and lodgepole pine in Alberta mixedwood forests. Canadian Journal of Forest Research, Ottawa, v. 31, n. 2, p. 283-291, 2001.

YODA, K. Three-dimensional distribution of light intensity in a tropical rain forest of West Malaysia. Malaysian Nature Journal, Kuala Lumpur, v. 30, n. 2, p. 161-177, 1978.

ZAR, J. H. Biostatistical analysis. 3. ed. New Jersey: Prentice-Hall International, 1996. $929 \mathrm{p}$.

ZAVALAA, M. A.; ANGULO, O.; PARRAC, R. B.; LOPEZ-MARCOS, J. C. An analytical model of stand dynamics as a function of tree growth, mortality and recruitment: The shade tolerance-stand structure hypothesis revisited. Journal of Theoretical Biology, London, v. 244, n. 3, p. 440-450, 2007. 


\section{APÊNDICES}




\section{APÊNDICE 1}

Tabela 1 - Densidade de árvores e palmeiras em 2006 e 2008, número de mortos e recrutas, resumo do DAP e altura total de cada parcela permanente desse estudo

\begin{tabular}{|c|c|c|c|c|c|c|c|c|c|c|c|c|c|c|c|}
\hline & & \multicolumn{4}{|c|}{ Densidade (individuos ha ${ }^{-1}$ ) } & \multicolumn{2}{|c|}{ M (individuos $\mathrm{ha}^{-1}$ ) } & \multicolumn{2}{|c|}{$\mathbf{R}$ (individuos $\mathrm{ha}^{-1}$ ) } & \multicolumn{3}{|c|}{$\operatorname{DAP}(\mathbf{c m})$} & \multicolumn{3}{|c|}{ Altura total (m) } \\
\hline & & \multicolumn{2}{|c|}{2006} & \multicolumn{2}{|c|}{2008} & & & & & & & & & & \\
\hline \multicolumn{2}{|c|}{ Floresta de Restinga } & $>4,8 \mathrm{~cm}$ & $>10 \mathrm{~cm}$ & $>4,8 \mathrm{~cm}$ & $>10 \mathrm{~cm}$ & $>4,8 \mathrm{~cm}$ & $>10 \mathrm{~cm}$ & $>4,8 \mathrm{~cm}$ & $>10 \mathrm{~cm}$ & $\max$ & media & mediana & $\max$ & $\min$ & mediana \\
\hline \multirow[t]{3}{*}{ Parcela A } & árvore & 1467 & 766 & 1450 & 753 & 62 & 28 & 49 & 15 & 76,4 & $12,9(8,4)$ & 10,3 & 18,4 & 5,8 & 10,2 \\
\hline & palmeira & 168 & 12 & 146 & 10 & 24 & 2 & 3 & 0 & 33,8 & $7,7(2,5)$ & 7,6 & n.s.* & 5,9 & 8,6 \\
\hline & total & 1635 & 778 & 1596 & 763 & 86 & 30 & 52 & 15 & & & & & & \\
\hline \multicolumn{16}{|c|}{ FOD de Terras Baixas } \\
\hline \multirow[t]{3}{*}{ Parcela B } & árvore & 1013 & 550 & 986 & 542 & 55 & 29 & 34 & 21 & 115,6 & $14,8(11,7)$ & 10,9 & 29,7 & 6,1 & 10,2 \\
\hline & palmeira & 139 & 35 & 126 & 46 & 13 & 1 & 7 & 12 & 18,9 & $9,1(3,3)$ & 8,4 & 21,9 & 6,2 & 9,8 \\
\hline & total & 1152 & 585 & 1112 & 588 & 68 & 30 & 41 & 33 & & & & & & \\
\hline \multirow[t]{3}{*}{ Parcela $C$} & árvore & 1015 & 522 & 1003 & 523 & 34 & 16 & 25 & 17 & 78,4 & $14,0(11,3)$ & 10,2 & 26,4 & 6,1 & 9,8 \\
\hline & palmeira & 149 & 44 & 147 & 54 & 3 & 1 & 4 & 11 & 23,2 & $9,2(3,9)$ & 8,4 & n.s. ${ }^{*}$ & 6,2 & 9,7 \\
\hline & total & 1164 & 566 & 1150 & 577 & 37 & 17 & 29 & 28 & & & & & & \\
\hline \multirow[t]{3}{*}{ Parcela D } & árvore & 1075 & 551 & 1053 & 542 & 43 & 19 & 24 & 10 & 88,3 & $14,4(11,2)$ & 10,2 & 27,5 & 6,1 & 9,8 \\
\hline & palmeira & 250 & 79 & 250 & 86 & 13 & 1 & 19 & 8 & 29,5 & $9,2(3,4)$ & 8,6 & n.s. ${ }^{*}$ & 6,2 & 10,1 \\
\hline & total & 1325 & 630 & 1303 & 628 & 56 & 20 & 43 & 18 & & & & & & \\
\hline \multirow[t]{3}{*}{ Parcela E } & árvore & 1054 & 548 & 1045 & 542 & 30 & 15 & 23 & 8 & 92,8 & $14,6(11,4)$ & 10,5 & 27,9 & 6,1 & 10,0 \\
\hline & palmeira & 189 & 69 & 183 & 69 & 10 & 0 & 6 & 0 & 25,9 & $9,4(3,7)$ & 8,4 & n.s. ${ }^{*}$ & 6,2 & 9,8 \\
\hline & total & 1243 & 617 & 1228 & 611 & 40 & 15 & 29 & 8 & & & & & & \\
\hline
\end{tabular}


Tabela 2 - Área basal, estoque de BAS (2-var) de árvores e palmeiras em 2006 e 2008, em cada parcela permanente desse estudo

\begin{tabular}{|c|c|c|c|c|c|c|c|c|c|}
\hline & & \multicolumn{4}{|c|}{2006} & \multicolumn{4}{|c|}{2008} \\
\hline & & \multicolumn{2}{|c|}{ Area basal $\left(m^{2} h a^{-1}\right)$} & \multicolumn{2}{|c|}{ Estoque de BAS (Mg ha $\left.{ }^{-1}\right)$} & \multicolumn{2}{|c|}{ Area basal } & \multicolumn{2}{|c|}{ Estoque de BAS (Mg ha ${ }^{-1}$} \\
\hline \multicolumn{2}{|c|}{ Floresta de Restinga } & $>4,8 \mathrm{~cm}$ & $>10 \mathrm{~cm}$ & $>4,8 \mathrm{~cm}$ & $>10 \mathrm{~cm}$ & $>4,8 \mathrm{~cm}$ & $>10 \mathrm{~cm}$ & $>4,8 \mathrm{~cm}$ & $>10 \mathrm{~cm}$ \\
\hline \multirow{3}{*}{ Parcela A } & árvore & 27,3 & 24,5 & 259,3 & 246,7 & 27,5 & 24,7 & 260,8 & 248,1 \\
\hline & palmeira & 0,99 & 0,33 & 2,6 & 0,5 & 0,8 & 0,18 & 2,4 & 0,5 \\
\hline & total & 28,3 & 24,8 & 261,9 & 247,2 & 28,3 & 24,9 & 263,1 & 248,5 \\
\hline \multicolumn{10}{|c|}{ FOD de Terras Baixas } \\
\hline \multirow[t]{3}{*}{ Parcela B } & árvore & 28,7 & 25,9 & 314,9 & 306,9 & 26,3 & 24,6 & 309,8 & 302,3 \\
\hline & palmeira & 1,0 & 0,5 & 3,0 & 1,5 & 1,0 & 0,7 & 3,0 & 1,8 \\
\hline & total & 29,7 & 26,4 & 317,8 & 308,3 & 27,4 & 25,3 & 312,9 & 304,1 \\
\hline \multirow[t]{3}{*}{ Parcela C } & árvore & 25,3 & 23,4 & 287,4 & 278,9 & 25,9 & 24,0 & 290,0 & 281,5 \\
\hline & palmeira & 1,1 & 0,7 & 3,3 & 2,0 & 1,3 & 0,8 & 3,6 & 2,3 \\
\hline & total & 26,5 & 24,1 & 290,7 & 280,8 & 27,1 & 24,8 & 293,6 & 283,8 \\
\hline \multirow[t]{3}{*}{ Parcela D } & árvore & 27,2 & 25,2 & 304,9 & 296,0 & 27,9 & 25,9 & 307,6 & 298,8 \\
\hline & palmeira & 1,8 & 1,1 & 5,4 & 3,2 & 1,9 & 1,1 & 5,6 & 3,3 \\
\hline & total & 29,0 & 26,2 & 310,3 & 299,2 & 29,7 & 27,0 & 313,2 & 302,1 \\
\hline \multirow[t]{3}{*}{ Parcela E } & árvore & 29,8 & 27,8 & 331,9 & 323,0 & 29,6 & 27,6 & 337,5 & 328,8 \\
\hline & palmeira & 1,8 & 1,3 & 4,5 & 3,0 & 1,6 & 1,1 & 4,5 & 3,0 \\
\hline & total & 31,6 & 29,1 & 336,4 & 326,0 & 31,1 & 28,7 & 341,9 & 331,8 \\
\hline
\end{tabular}


Tabela 3 - Densidade, Área basal, estoque de BAS (2-var) por classe de DAP em 2006 e 2008, em cada parcela permanente desse estudo

\begin{tabular}{|c|c|c|c|c|c|c|c|}
\hline & & \multicolumn{3}{|c|}{2006} & \multicolumn{3}{|c|}{2008} \\
\hline & & $\begin{array}{l}\text { Densidade } \\
\text { (ind. ha-1) }\end{array}$ & $\begin{array}{c}\text { Area basal } \\
\left(m^{2} h a^{-1}\right)\end{array}$ & $\begin{array}{c}\text { Estoque de } \\
\text { BAS }\left(\mathrm{Mg} \mathrm{ha}^{-1}\right)\end{array}$ & $\begin{array}{l}\text { Densidade } \\
\text { (ind. ha-1) }\end{array}$ & $\begin{array}{l}\text { Area basal } \\
\qquad\left(m^{2} h a^{-1}\right)\end{array}$ & $\begin{array}{c}\text { Estoque de } \\
B A S\left(M g h a^{-1}\right)\end{array}$ \\
\hline \multicolumn{8}{|c|}{ Floresta de Restinga } \\
\hline \multirow[t]{4}{*}{ Parcela $A$} & $<10 \mathrm{~cm}$ & 857 & 3,5 & 14,6 & 833 & 3,4 & 14,6 \\
\hline & $10-30 \mathrm{~cm}$ & 696 & 15,9 & 132,3 & 680 & 15,7 & 132,2 \\
\hline & $30-50 \mathrm{~cm}$ & 77 & 7,5 & 92,3 & 78 & 7,8 & 94,2 \\
\hline & $\geq 50 \mathrm{~cm}$ & 5 & 1,4 & 22,7 & 5 & 1,4 & 22,2 \\
\hline \multicolumn{8}{|c|}{ FOD de Terras Baixas } \\
\hline \multirow[t]{4}{*}{ Parcela B } & $<10 \mathrm{~cm}$ & 567 & 3,3 & 9,4 & 524 & 2,1 & 8,8 \\
\hline & $10-30 \mathrm{~cm}$ & 493 & 11,8 & 98,0 & 496 & 11,8 & 95,6 \\
\hline & $30-50 \mathrm{~cm}$ & 68 & 7,4 & 91,7 & 69 & 7,4 & 91,3 \\
\hline & $\geq 50 \mathrm{~cm}$ & 24 & 7,2 & 118,7 & 23 & 6,1 & 117,2 \\
\hline \multirow[t]{4}{*}{ Parcela $C$} & $<10 \mathrm{~cm}$ & 598 & 2,4 & 9,8 & 573 & 2,3 & 9,7 \\
\hline & $10-30 \mathrm{~cm}$ & 482 & 10,6 & 82,7 & 496 & 10,9 & 85,1 \\
\hline & $30-50 \mathrm{~cm}$ & 65 & 7,5 & 96,3 & 60 & 7,0 & 87,4 \\
\hline & $\geq 50 \mathrm{~cm}$ & 19 & 6,0 & 101,8 & 21 & 6,9 & 111,4 \\
\hline \multirow[t]{4}{*}{ Parcela D } & $<10 \mathrm{~cm}$ & 695 & 2,8 & 11,4 & 675 & 2,7 & 11,2 \\
\hline & $10-30 \mathrm{~cm}$ & 534 & 12,7 & 103,0 & 529 & 12,5 & 98,4 \\
\hline & $30-50 \mathrm{~cm}$ & 78 & 8,8 & 111,7 & 80 & 9,1 & 113,3 \\
\hline & $\geq 50 \mathrm{~cm}$ & 18 & 4,7 & 84,3 & 19 & 5,4 & 90,4 \\
\hline \multirow[t]{4}{*}{ Parcela E } & $<10 \mathrm{~cm}$ & 626 & 2,5 & 10,4 & 617 & 2,4 & 10,2 \\
\hline & $10-30 \mathrm{~cm}$ & 510 & 12,4 & 88,5 & 504 & 11,3 & 86,6 \\
\hline & $30-50 \mathrm{~cm}$ & 79 & 8,5 & 105,6 & 76 & 8,2 & 100,1 \\
\hline & $\geq 50 \mathrm{~cm}$ & 28 & 8,2 & 131,8 & 31 & 9,3 & 145,1 \\
\hline
\end{tabular}


Tabela 4 - Densidade, número de mortos e recrutas e resumo do DAP e altura total por classe de IC em 2006 e 2008 , em cada parcela permanente desse estudo

\begin{tabular}{|c|c|c|c|c|c|c|c|c|c|c|c|}
\hline & & \multicolumn{2}{|c|}{ Densidade (individuos ha ${ }^{-1}$ ) } & \multirow[t]{2}{*}{$\mathrm{M}$ (ind. ha $\mathrm{h}^{-1}$ ) } & \multirow[t]{2}{*}{$\mathrm{R}$ (ind. ha $\mathrm{h}^{-1}$ ) } & \multicolumn{3}{|c|}{$\mathrm{DAP}(\mathrm{cm})$} & \multicolumn{3}{|c|}{ Altura total (m) } \\
\hline & & 2006 & 2008 & & & $\max$ & media & mediana & $\max$ & $\min$ & mediana \\
\hline \multicolumn{12}{|c|}{ Floresta de Restinga } \\
\hline \multirow[t]{3}{*}{ Parcela $A$} & IC 3 & 1062 & 1142 & 60 & 52 & 76,4 & $9,9(6,1)$ & 8,1 & 18,4 & 5,8 & 8,7 \\
\hline & IC 4 & 353 & 248 & 13 & 0 & 43,1 & $15,8(7,7)$ & 14,3 & 17,6 & 6,1 & 12,2 \\
\hline & IC 5 & 220 & 206 & 13 & 0 & 56,8 & $22,3(10,1)$ & 21,5 & 18,1 & 6,3 & 14,7 \\
\hline \multicolumn{12}{|c|}{ FOD de Terras Baixas } \\
\hline \multirow[t]{3}{*}{ Parcela B } & IC 3 & 728 & 841 & 45 & 37 & 42,0 & $10,3(5,7)$ & 8,7 & 20,6 & 6,1 & 8,9 \\
\hline & IC 4 & 258 & 170 & 12 & 2 & 76,3 & $18,1(11,2)$ & 16,5 & 26,2 & 6,1 & 12,9 \\
\hline & IC 5 & 166 & 101 & 11 & 2 & 115,6 & $29,6(16,8)$ & 27,4 & 29,7 & 6,3 & 16,9 \\
\hline \multirow[t]{3}{*}{ Parcela C } & IC 3 & 850 & 880 & 29 & 27 & 49,2 & $10,6(6,2)$ & 8,7 & 22,1 & 6,1 & 8,9 \\
\hline & IC 4 & 236 & 200 & 8 & 2 & 69,1 & $18,1(10,9)$ & 15,8 & 25,3 & 6,2 & 12,6 \\
\hline & IC 5 & 78 & 70 & 0 & 0 & 78,4 & $39,3(18,3)$ & 38,0 & 26,4 & 7,6 & 19,7 \\
\hline \multirow[t]{3}{*}{ Parcela D } & IC 3 & 1019 & 1060 & 48 & 43 & 50,3 & $11,1(7,0)$ & 8,7 & 22,3 & 6,2 & 8,9 \\
\hline & IC 4 & 175 & 140 & 7 & 0 & 69,4 & $20,5(11,4)$ & 18,9 & 25,3 & 6,2 & 13,9 \\
\hline & IC 5 & 122 & 112 & 1 & 0 & 88,3 & $34,8(15,0)$ & 33,2 & 27,5 & 10,9 & 18,5 \\
\hline \multirow[t]{3}{*}{ Parcela $E$} & IC 3 & 873 & 865 & 31 & 29 & 50,9 & $10,0(5,5)$ & 8,4 & 22,4 & 6,2 & 8,7 \\
\hline & IC 4 & 247 & 243 & 6 & 0 & 63,0 & $21,5(10,8)$ & 18,8 & 24,4 & 6,4 & 13,9 \\
\hline & IC 5 & 121 & 122 & 3 & 0 & 92,8 & $36,7(18,3)$ & 34,5 & 27,9 & 6,3 & 18,9 \\
\hline
\end{tabular}


Tabela 5 - Densidade, número de mortos e recrutas e taxa de mortalidade e recrutamento das árvores na parcela B (floresta de terras baixas) por classe de DAP, IC e total

\begin{tabular}{|c|c|c|c|c|c|c|c|c|c|c|}
\hline \multirow[b]{2}{*}{ C.DAP } & \multicolumn{2}{|c|}{ Densidade (ind.ha) } & \multirow{2}{*}{$\begin{array}{c}\begin{array}{c}\text { № } \\
\text { mortos }\end{array} \\
M\end{array}$} & \multirow{2}{*}{$\begin{array}{c}\text { № } \\
\text { recrutas } \\
R\end{array}$} & \multicolumn{3}{|c|}{ Mortalidade } & \multicolumn{3}{|c|}{ Recrutamento } \\
\hline & 2006 & 2008 & & & $\lambda(\%)$ & $L I(\%)$ & $L S(\%)$ & $i(\%)$ & $L I(\%)$ & $L S(\%)$ \\
\hline$<10 \mathrm{~cm}$ & 463 & 444 & 26 & 34 & 2,63 & 1,95 & 3,46 & - & - & - \\
\hline $10-30 \mathrm{~cm}$ & 458 & 450 & 25 & 0 & 2,55 & 1,36 & 2,41 & - & - & - \\
\hline $30-50 \mathrm{~cm}$ & 68 & 69 & 2 & 0 & 1,36 & 0,36 & 3,62 & - & - & - \\
\hline $\begin{array}{c}\geq 50 \mathrm{~cm} \\
\text { IC }\end{array}$ & 24 & 23 & 2 & 0 & 3,96 & 1,03 & 10,60 & - & - & - \\
\hline 3 & 644 & 745 & 34 & 30 & 2,47 & 1,88 & 3,22 & - & - & - \\
\hline 4 & 222 & 149 & 10 & 2 & 2,10 & 1,29 & 3,30 & - & - & - \\
\hline$\frac{5}{\text { total }}$ & $\begin{array}{c}147 \\
1013\end{array}$ & $\begin{array}{c}92 \\
986\end{array}$ & $\begin{array}{l}11 \\
55\end{array}$ & $\begin{array}{c}2 \\
34\end{array}$ & $\begin{array}{l}3,54 \\
2,54\end{array}$ & $\begin{array}{l}2,19 \\
2,07\end{array}$ & $\begin{array}{l}5,48 \\
\mathbf{3 , 1 3}\end{array}$ & $\frac{-}{1,50}$ & $\frac{-}{1,15}$ & $\frac{-}{1,95}$ \\
\hline
\end{tabular}

Tabela 6 - Densidade, número de mortos e recrutas e taxa de mortalidade e recrutamento das árvores na parcela $\mathrm{C}$ (floresta de terras baixas) por classe de DAP, IC e total

\begin{tabular}{|c|c|c|c|c|c|c|c|c|c|c|}
\hline & \multicolumn{2}{|c|}{ Densidade (ind.ha) } & \multirow{2}{*}{$\begin{array}{c}\begin{array}{c}\text { № } \\
\text { mortos }\end{array} \\
M\end{array}$} & \multirow{2}{*}{$\begin{array}{c}\text { № } \\
\text { recrutas } \\
R\end{array}$} & \multicolumn{3}{|c|}{ Mortalidade } & \multicolumn{3}{|c|}{ Recrutamento } \\
\hline & 2006 & 2008 & & & $\lambda(\%)$ & $L I(\%)$ & $L S(\%)$ & $i(\%)$ & $L I(\%)$ & $L S(\%)$ \\
\hline \multicolumn{11}{|l|}{ C.DAP } \\
\hline$<10 \mathrm{~cm}$ & 493 & 480 & 18 & 25 & 1,77 & 1,27 & 2,47 & - & - & - \\
\hline $10-30 \mathrm{~cm}$ & 438 & 442 & 12 & 0 & 1,32 & 0,85 & 2,06 & - & - & - \\
\hline $30-50 \mathrm{~cm}$ & 65 & 60 & 4 & 0 & 3,02 & 1,31 & 6,05 & - & - & - \\
\hline$\geq 50 \mathrm{~cm}$ & 19 & 21 & 0 & 0 & 0,00 & 0,00 & 0,00 & - & - & - \\
\hline \multicolumn{11}{|l|}{ IC } \\
\hline 3 & 738 & 770 & 26 & 24 & 1,71 & 1,27 & 2,26 & - & - & - \\
\hline 4 & 210 & 172 & 8 & 1 & 1,85 & 1,07 & 2,98 & - & - & - \\
\hline 5 & 67 & 61 & 0 & 0 & 0,00 & 0,00 & 0,00 & - & - & - \\
\hline total & 1015 & 1003 & 34 & 25 & 1,62 & 1,23 & 2,13 & 1,16 & 0,86 & 1,53 \\
\hline
\end{tabular}


Tabela 7 - Densidade, número de mortos e recrutas e taxa de mortalidade e recrutamento das árvores na parcela D (floresta de terras baixas) por classe de DAP, IC e total

\begin{tabular}{|c|c|c|c|c|c|c|c|c|c|c|}
\hline & \multicolumn{2}{|c|}{ Densidade (ind.ha) } & \multirow{2}{*}{$\begin{array}{c}\begin{array}{c}\text { № } \\
\text { mortos }\end{array} \\
M\end{array}$} & \multirow{2}{*}{$\begin{array}{c}\text { № } \\
\text { recrutas } \\
\quad R\end{array}$} & \multicolumn{3}{|c|}{ Mortalidade } & \multicolumn{3}{|c|}{ Recrutamento } \\
\hline & 2006 & 2008 & & & $\lambda(\%)$ & $L I(\%)$ & $L S(\%)$ & $i(\%)$ & $L I(\%)$ & $L S(\%)$ \\
\hline \multicolumn{11}{|l|}{ C.DAP } \\
\hline$<10 \mathrm{~cm}$ & 524 & 511 & 24 & 24 & 2,34 & 1,74 & 3,10 & - & - & - \\
\hline $10-30 \mathrm{~cm}$ & 455 & 443 & 18 & 0 & 2,02 & 1,44 & 2,81 & - & - & - \\
\hline $30-50 \mathrm{~cm}$ & 78 & 80 & 1 & 0 & 0,65 & 0,07 & 2,52 & - & - & - \\
\hline$\geq 50 \mathrm{~cm}$ & 18 & 19 & 0 & 0 & 0,00 & 0,00 & 0,00 & - & - & - \\
\hline \multicolumn{11}{|l|}{ IC } \\
\hline 3 & 837 & 852 & 37 & 24 & 2,26 & 1,78 & 2,95 & - & - & - \\
\hline 4 & 139 & 112 & 6 & 0 & 2,21 & 1,15 & 3,88 & - & - & - \\
\hline 5 & 96 & 92 & 0 & 0 & 0,00 & 0,00 & 0,00 & - & - & - \\
\hline total & 1075 & 1053 & 43 & 24 & 2,04 & 1,60 & 2,66 & 1,10 & 0,82 & 1,46 \\
\hline
\end{tabular}

Tabela 8 - Densidade, número de mortos e recrutas e taxa de mortalidade e recrutamento das árvores na parcela $\mathrm{E}$ (floresta de terras baixas) por classe de DAP, IC e total

\begin{tabular}{|c|c|c|c|c|c|c|c|c|c|c|}
\hline & \multicolumn{2}{|c|}{ Densidade (ind.ha) } & \multirow{2}{*}{$\begin{array}{c}\begin{array}{c}\text { № } \\
\text { mortos }\end{array} \\
M\end{array}$} & \multirow{2}{*}{$\begin{array}{c}\text { № } \\
\text { recrutas } \\
R\end{array}$} & \multicolumn{3}{|c|}{ Mortalidade } & \multicolumn{3}{|c|}{ Recrutamento } \\
\hline & 2006 & 2008 & & & $\lambda(\%)$ & $L I(\%)$ & $L S(\%)$ & $i(\%)$ & $L I(\%)$ & $L S(\%)$ \\
\hline \multicolumn{11}{|l|}{ C.DAP } \\
\hline$<10 \mathrm{~cm}$ & 506 & 503 & 15 & 23 & 1.50 & 1.02 & 2.12 & - & - & - \\
\hline $10-30 \mathrm{~cm}$ & 441 & 435 & 14 & 0 & 1.61 & 1.08 & 2.29 & - & - & - \\
\hline $30-50 \mathrm{~cm}$ & 79 & 76 & 1 & 0 & 0.64 & 0.07 & 2.49 & - & - & - \\
\hline$\geq 50 \mathrm{~cm}$ & 28 & 31 & 0 & 0 & 0.00 & 0.00 & 0.00 & - & - & - \\
\hline \multicolumn{11}{|l|}{ IC } \\
\hline 3 & 749 & 742 & 21 & 23 & 1.42 & 1.02 & 1.97 & - & - & - \\
\hline 4 & 214 & 208 & 6 & 0 & 1.42 & 0.74 & 2.52 & - & - & - \\
\hline 5 & 91 & 95 & 3 & 0 & 1.68 & 0.61 & 3.77 & - & - & - \\
\hline total & 1054 & 1045 & 30 & 23 & 1.44 & 1.10 & 1.90 & 1.08 & 0.80 & 1.48 \\
\hline
\end{tabular}


Tabela 9 - Taxa de mortalidade ( $\lambda$ ), limite inferior (LI) e superior (LS), população inicial (NO) e número de mortos $(\mathrm{M})$ na floresta de restinga e de terras baixas, das palmeiras por classe de DAP

\begin{tabular}{|c|c|c|c|c|c|c|}
\hline & & \multicolumn{5}{|c|}{ Taxa de mortalidade } \\
\hline & & $\lambda(\%)$ & $L I(\%)$ & $L S(\%)$ & NO & $M$ \\
\hline \multirow[t]{4}{*}{ Floresta de restinga } & $<10 \mathrm{~cm}$ & 6,91 & 5,00 & 9,36 & 156 & 22 \\
\hline & $10-30 \mathrm{~cm}$ & 9,12 & 2,31 & 24,39 & 11 & 2 \\
\hline & $30-50 \mathrm{~cm}$ & 0,00 & 0,00 & 0,00 & 1 & 0 \\
\hline & $\geq 50 \mathrm{~cm}$ & 0,00 & 0,00 & 0,00 & 0 & 0 \\
\hline \multirow[t]{4}{*}{ Floresta de terras baixas } & $<10 \mathrm{~cm}$ & 3,56 & 2,80 & 4,63 & 500 & 36 \\
\hline & $10-30 \mathrm{~cm}$ & 0,63 & 0,23 & 1,42 & 227 & 3 \\
\hline & $30-50 \mathrm{~cm}$ & 0,00 & 0,00 & 0,00 & 0 & 0 \\
\hline & $\geq 50 \mathrm{~cm}$ & 0,00 & 0,00 & 0,00 & 0 & 0 \\
\hline
\end{tabular}

Tabela 10 - Taxa de mortalidade ( $\lambda$ ), limite inferior (LI) e superior (LS), população inicial (NO) e número de mortos $(\mathrm{M})$ das palmeiras na floresta de restinga e de terras baixas por classe de IC

\begin{tabular}{|c|c|c|c|c|c|c|}
\hline & \multirow[b]{2}{*}{ IC } & \multicolumn{5}{|c|}{ Taxa de mortalidade } \\
\hline & & $\lambda(\%)$ & LI (\%) & LS (\%) & NO & $M$ \\
\hline \multirow[t]{3}{*}{ Floresta de restinga } & 3 & 6,37 & 4,37 & 8,75 & 130 & 17 \\
\hline & 4 & 5,06 & 1,31 & 13,62 & 19 & 2 \\
\hline & 5 & 13,88 & 6,60 & 25,88 & 19 & 5 \\
\hline \multirow[t]{3}{*}{ Floresta de terras baixas } & 3 & 3,44 & 2,71 & 4,48 & 502 & 35 \\
\hline & 4 & 1,10 & 0,40 & 2,46 & 131 & 3 \\
\hline & 5 & 0,56 & 0,06 & 2,22 & 86 & 1 \\
\hline
\end{tabular}




\section{APÊNDICE 2}

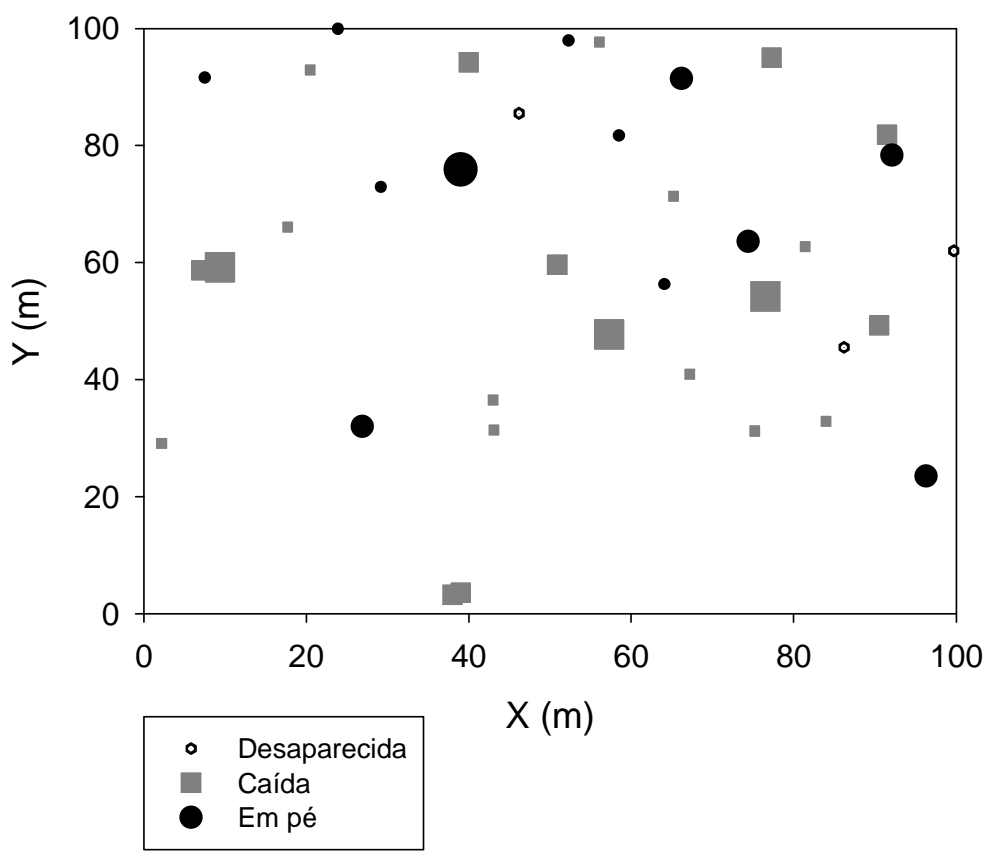

Figura 1 - Distribuição espacial dos indivíduos mortos na parcela $C$, nas diferentes classes de mortalidade. Os símbolos se apresentam em 3 tamanhos: menor representa a classe de DAP $<10 \mathrm{~cm}$, o intermediário $10-30 \mathrm{~cm}$ e o maior representa a classe e $30-50 \mathrm{~cm}$

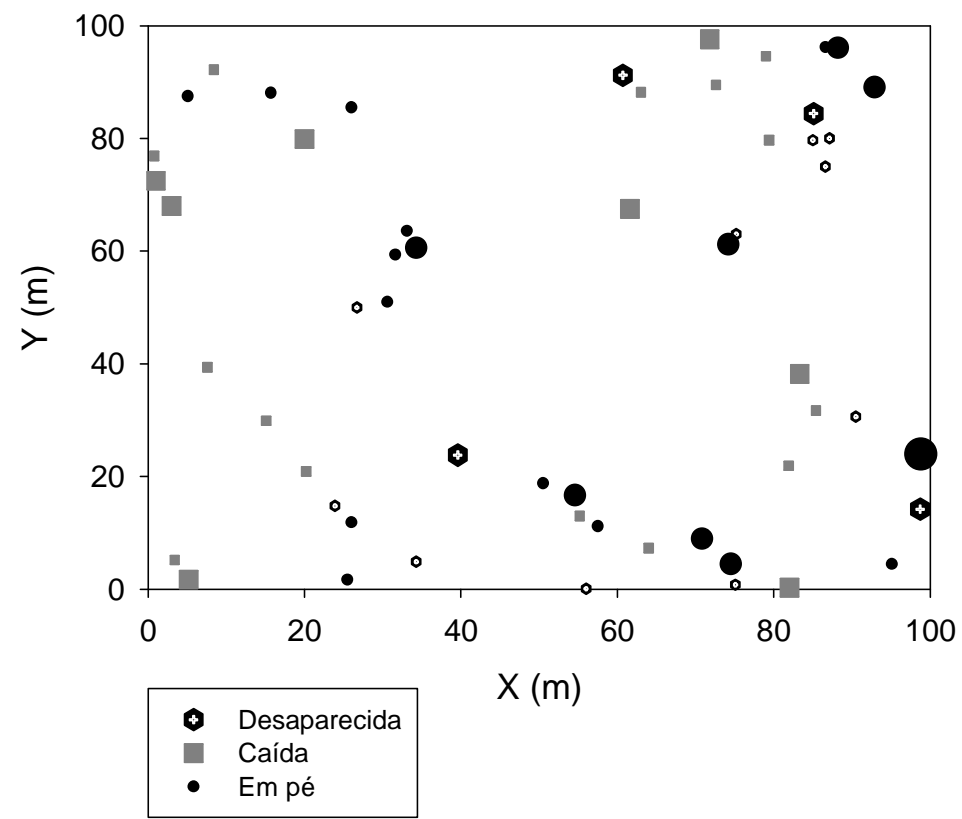

Figura 2 - Distribuição espacial dos indivíduos mortos na parcela D, nas diferentes classes de mortalidade. Os símbolos se apresentam em 3 tamanhos: menor representa a classe de DAP $<10 \mathrm{~cm}$, o intermediário $10-30 \mathrm{~cm}$ e o maior representa a classe e $30-50 \mathrm{~cm}$ 


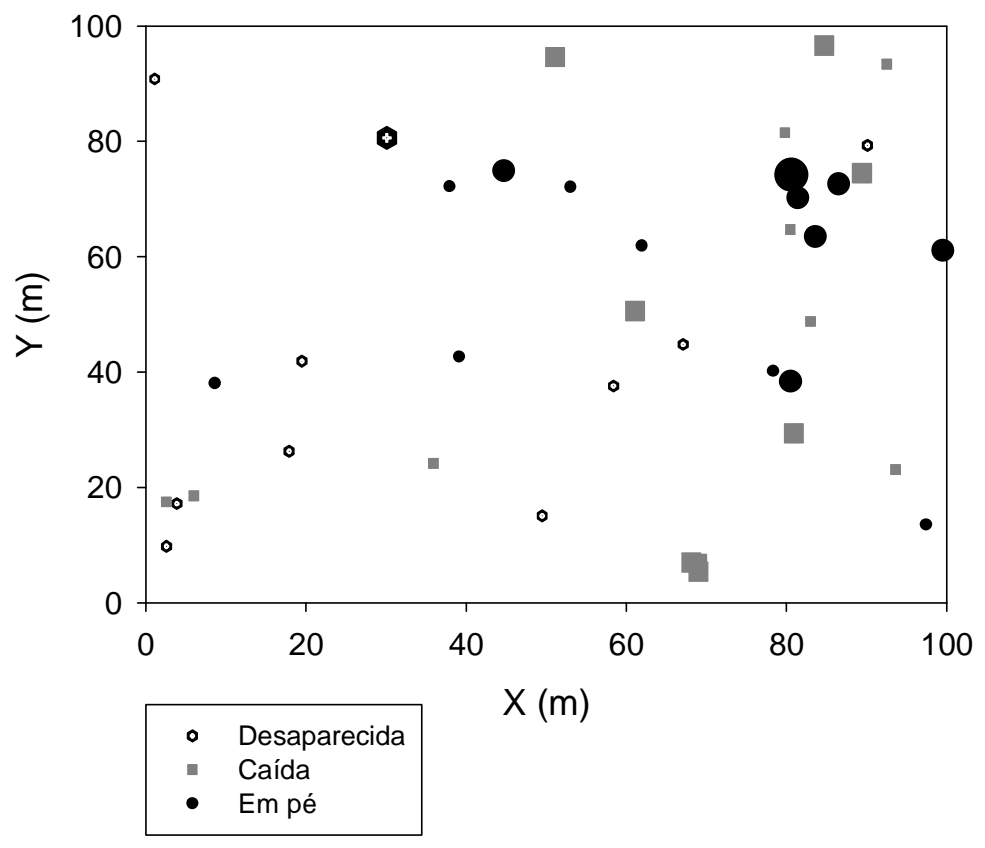

Figura 3 - Distribuição espacial dos indivíduos mortos na parcela E, nas diferentes classes de mortalidade. Os símbolos se apresentam em 3 tamanhos: menor representa a classe de DAP $<10 \mathrm{~cm}$, o intermediário $10-30 \mathrm{~cm}$ e o maior representa a classe e $30-50 \mathrm{~cm}$ 


\section{APÊNDICE 3}

Estimativa da variação líquida da BAS utilizando equação 4 (Chave et al. 2005, 2var)

Tabela 1 - Incremento em BASi (sobreviventes), ganho de BASr devido ao recrutamento, perdas de BASm devido a mortalidade e mudanças líquidas na BAS dos indivíduos com o DAP $\geq 4,8$ $\mathrm{cm}$ de cada parcela permanente deste estudo.A "média" representa a média da floresta de terras baixas

\begin{tabular}{lcccccc}
\hline & & BASi & BASr & BASm & $\begin{array}{c}\text { Mudanças } \\
\text { líquidas }\end{array}$ \\
\hline & & \multicolumn{5}{c}{$M g$ ha $^{-1}$ ano $^{-1}$} \\
\cline { 3 - 6 } Floresta de restinga & Parcela A & $\mathbf{3 , 5 9}$ & $\mathbf{0 , 1 8}$ & $\mathbf{3 , 1 6}$ & $\mathbf{0 , 6 1}$ \\
Floresta de terras baixas & & & & & \\
& Parcela B & 4,80 & 0,15 & 7,44 & $-2,50$ \\
& Parcela C & 5,67 & 0,10 & 4,34 & 1,44 \\
& Parcela D & 4,74 & 0,15 & 2,64 & 2,25 \\
& Parcela E & 5,12 & 0,11 & 2,32 & 2,91 \\
& média & $\mathbf{5 , 0 8}$ & $\mathbf{0 , 1 3}$ & $\mathbf{4 , 1 8}$ & $\mathbf{1 , 0 2}$ \\
\hline \hline
\end{tabular}

